\title{
Guías de referencia: Para instituciones y establecimientos de salud que buscan acreditar la calidad y enfoque de género de sus servicios
}

\author{
Patricia Riveros Hamel \\ Erica Palenque \\ Ricardo Vernon \\ Ignacio Carreno
}

Follow this and additional works at: https://knowledgecommons.popcouncil.org/departments_sbsr-rh

Part of the Community Health and Preventive Medicine Commons, Demography, Population, and Ecology Commons, Family, Life Course, and Society Commons, Health Communication Commons, International and Intercultural Communication Commons, and the Medicine and Health Commons How does access to this work benefit you? Let us know!

\section{Recommended Citation}

Riveros Hamel, Patricia, Erica Palenque, Ricardo Vernon, and Ignacio Carreno. 2007. "Guías de referencia: Para instituciones y establecimientos de salud que buscan acreditar la calidad y enfoque de género de sus servicios." Mexico, DF: Population Council. 
Patricia Riveros Hamel, Erica Palenque, Ricardo Vernon, Ignacio Carreño. Guía de procedimientos para instituciones y establecimientos de salud que buscan acreditar la calidad y enfoque de género de sus servicios. México, D. F.: Population Council.

\title{
Instituciones y Coordinadores(as) participantes en la estrategia:
}

\author{
APROSAR - Marco Antonio Herbas \\ APSAR - Adela Asbún \\ Care - Irma Carrazana \\ CEMSE - Marleni Narváez \\ CEPAC - Oswaldo Chávez \\ CIES - Rosario Cortéz \\ CSRA - Silvia Ajhuacho \\ Crecer - Isabel Rueda \\ Esperanza Bolivia - Evelin Villagrán \\ FHI - Zulema Tórrez \\ IPTK - Gonzalo Soruco \\ Pro Mujer - María Elena Gutierrez, Rosario Rojas \\ PCI - Alejandra Villafuerte
}

(C) Population Council, Inc .

El Population Council es una organización internacional, no lucrativa y no gubernamental, que busca mejorar el bienestar y la salud reproductiva de las generaciones presentes y futuras del mundo y ayudar a alcanzar un equilibrio humano, equitativo y sostenible entre la población y los recursos. El Council realiza investigación biomédica, en ciencias sociales y salud pública, y ayuda a fortalecer la capacidad de investigación en países en desarrollo. El Council fue fundado en 1952 y está dirigido por un consejo directivo internacional. Su oficina matriz en Nueva York apoya a una red mundial de oficinas regionales y nacionales.
Population Council/FRONTERAS
4301 Connecticut Ave., N.W. Suite 280
Washington, D.C. 20008
E.U.A.
Tel. (212) 339-0500
www.popcouncil.org/frontiers

\author{
Population Council \\ Escondida 110, Col. Villa Coyoacán \\ 04000 México, D.F. \\ MÉXICO \\ Tel (52-55) 5999-8630
}

El Programa Fronteras de la Salud Reproductiva (FRONTERAS) aplica técnicas sistemáticas de investigación para mejorar la prestación de servicios de planificación familiar y salud reproductiva y para incidir en las políticas relativas a estos servicios. El Programa FRONTERAS es financiado por la Agencia para el Desarrollo Internacional de Estados Unidos (USAID) y es dirigido por el Population Council en colaboración con Family Health International

Cualquier parte de esta publicación podrá reproducirse sin autorización de los editores, siempre y cuando se cite la fuente y se utilice sin fines de lucro.

Este estudio se realizó con el generoso apoyo del pueblo estadounidense a través de la Agencia de los Estados Unidos para el Desarrollo Internacional (USAID), bajo los términos del Acuerdo de Cooperación No. HRNA-00-98-00012-00 y el Subcontrato No. A103.04A. Los contenidos son responsabilidad del Programa FRONTERAS y no necesariamente reflejan los puntos de vista de USAID o del Gobierno de los Estados Unidos.

Primera edición, 2007 / Impreso en México / Printed in Mexico

Diseño y tipografía: Mercedes del Valle
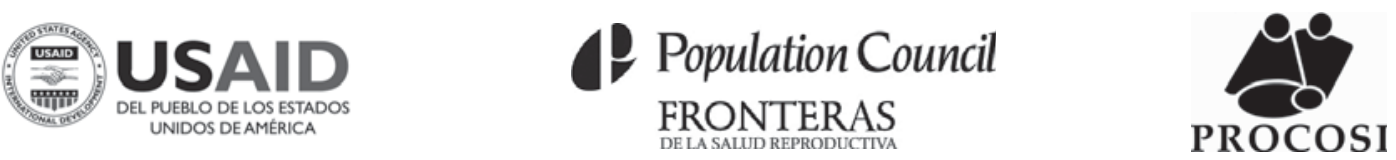


\section{Guías de referencia}

1. Guía de procedimientos

2. Guía de autocapacitación

3. Guía de evaluación

4. Guía de costos

5. Anexos 



\section{Guía de procedimientos}

Para instituciones y establecimientos

de salud que buscan acreditar la calidad y enfoque de género de sus servicios

La Paz • Bolivia • septiembre 2007 



\section{Contenido}

I. Introducción

II. Estrategia de acreditación 13

$\begin{array}{lll}\text { II.1 Estándares de calidad y género } & 14\end{array}$

$\begin{array}{lll}\text { II.2 Formación del equipo de trabajo } & 19\end{array}$

$\begin{array}{lll}\text { II.3 Evaluación interna } & 19\end{array}$

$\begin{array}{lll}\text { II.4 Plan de acción } & 20\end{array}$

II.5 Implementación de acciones y fortalecimiento 23

$\begin{array}{lll}\text { II.6 Nueva evaluación interna } & 23\end{array}$

$\begin{array}{lll}\text { II.7 Evaluación externa } & 23\end{array}$

III. Acreditación 27

IV. Re-acreditación 29 



\section{Introducción}

E sta guía busca presentar todos los elementos para que las organizaciones de - salud reproductiva puedan implantar un sistema para mejorar la calidad de los servicios y su sensibilidad a asuntos de género a través de una estrategia de acreditación.

En esta guía utilizamos indistintamente las palabras "acreditación” y "certificación" para denotar el reconocimiento público que hace una institución de que su propia clínica o aparato administrativo cumple con estándares de calidad pre-establecidos y evaluados. En muchos países, estas palabras están asociadas a un reconocimiento oficial de la autoridad sanitaria gubernamental. A falta de alternativas, nosotros las utilizamos en el sentido de la garantía de la calidad que ofrece la institución a sus clientes ${ }^{1}$.

La estrategia de acreditación comienza con una evaluación de las condiciones y servicios que ofrece la clínica, lo que permite identificar los estándares de calidad que no son cumplidos. Posteriormente, el personal de la clínica toma como insumo esta información y elabora un plan de trabajo para resolver los problemas identificados. Cuando el personal de la clínica cree que los problemas han sido superados, pide que evaluadores externos al equipo de trabajo de la clínica o área administrativa haga una nueva evaluación. Si la clínica demuestra cumplir cuando menos el 80 por ciento de los estándares mínimos de calidad, recibe el reconocimiento de ofrecer servicios de calidad con enfoque de género; en caso contrario, la clínica toma los resultados de la nueva evaluación, vuelve a preparar un plan de trabajo para solucionar los problemas identificados y vuelve a solicitar una evaluación externa para optar por el reconocimiento cuando crea que está lista para ello. El

1 El diccionario Larousse define certificar como "dar una cosa por segura", "hacer cierta una cosa por medio de documento público" y acreditar como "afamar", "dar seguridad de que una cosa es lo que representa o parece”. Este reconocimiento puede ser dado por un comité en las oficinas centrales de una institución o en la matriz de una red de prestadores de servicios independientes. 
reconocimiento, acreditación o certificación tiene una duración temporal definida, como, por ejemplo, dos o tres años, al cabo de los cuáles la unidad de salud debe realizar una nueva evaluación.

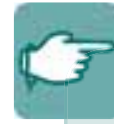

Esta metodología también puede ser usada por una clínica determinada para evaluar y mejorar la calidad de sus servicios aún en ausencia de una estrategia institucional de certificación o acreditación.

Los estándares de calidad y género que se usan están basados en los propuestos por la IPPF/ $\mathrm{RHO}^{2}$ en su Manual para Evaluar la Calidad de Atención desde una Perspectiva de Género. Estos estándares exigen que las políticas institucionales toman en cuenta la necesidad de empoderar a la mujer y de eliminar la discriminación y el abuso de poder; que los prestadores den a los clientes un trato digno y caluroso y la información que necesitan para resolver sus problemas; que el personal de salud tenga los conocimientos básicos sobre salud reproductiva y género; que los clientes estén satisfechos con los servicios que reciben; que se tengan y usen materiales de información, educación, comunicación y capacitación (IEC) para facilitar el aprendizaje de los clientes; y que se use el lenguaje incluyente con una perspectiva de género.

La estrategia de certificación que depende del cumplimiento de un conjunto de indicadores está basada en la metodología usada en la iniciativa Hospital Amigo del Niño promovida por UNICEF y los gobiernos de muchos países.

La estrategia propuesta no considera los aspectos de la capacidad técnica de los proveedores, un campo que requiere de la participación de especialistas y en el que se han enfocado la mayoría de las instituciones en sus procesos de mejoramiento de la calidad. La estrategia tampoco recomienda la manera como debe capacitarse al personal ni establece los recursos necesarios para llevar a cabo las actividades de mejoramiento de la calidad. Baste decir que las experiencias observadas han demostrado que casi todos los equipos de salud pueden llevar a cabo estas actividades con sus propios conocimientos, estrategias y recursos, sin apoyos adicionales a los incluidos en los manuales de la estrategia y el proporcionado por un supervisor institucional del proceso.

El manual de la IPPF fue elaborado por un equipo multidisciplinario de especialistas en salud sexual y reproductiva, salud de la mujer, derechos de la mujer y género y fue validado en varios países. El sistema de acreditación basado en los indicadores propuestos por la IPPF fue probado en dos diferentes proyectos emprendidos por la

2 Federación Internacional de Planificación Familiar/Región del Hemisferio Occidental. 
Red PROCOSI en Bolivia (institución que cuenta con una red de 33 organizaciones no gubernamentales afiliadas que tienen objetivos comunes de prestar servicios de calidad en salud reproductiva) con la asistencia técnica y financiera del Programa Fronteras de la Salud Reproductiva, del Population Council ${ }^{3}$.

Esta guía se complementa con otras tres: una guía de auto-capacitación, una guía de evaluación, y una guía de costos que explican detalladamente aspectos particulares de la estrategia. Todas estas guías se pueden encontrar en este mismo volumen.

La Guía de auto-capacitación incluye definiciones y conceptos que todo el personal debe conocer para cumplir con cada uno de los estándares de calidad y género propuestos. El personal de los establecimientos o instituciones de salud puede adoptar cualquier metodología, ya sea individual o grupal, para aprender sus contenidos.

La Guía de evaluación detalla cada una de las actividades del proceso de evaluación: conformación de los equipos de evaluación, cálculo de muestras, los instrumentos que se usan para recolectar los datos, la captura y análisis de datos, y la elaboración de informes de retroalimentación.

La Guía de costos presenta la metodología de recolección y análisis de toda la información pertinente para conocer los costos incurridos en la incorporación de un enfoque de género en cada establecimiento o institución de salud. Esta información es útil para comparar los beneficios contra los costos incurridos para mejorar la calidad de atención e introducir un enfoque de género.

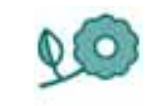

3 E. Palenque, L. Montaño, R. Vernon, F. Gonzales, P. Riveros y J. Bratt. 2004. Efectos y Costos de Incorporar el Enfoque de Género en los Programas de Salud Reproductiva. Informe final de investigación operativa, Programa Fronteras de la Salud Reproductiva, PROCOSI y Population Council, La Paz, Bolivia y Washington, D.C. y Erica Palenque, Patricia Riveros y Ricardo Vernon. 2007. Consolidando una Perspectiva de Género en la Red PROCOSI. Informe final de investigación operativa. PROCOSI y Population Council. La Paz, Bolivia y Washington D.C. 



\section{Estrategia de acreditación}

Dara certificar la calidad de los servicios con enfoque de género, las instituciones y establecimientos de salud deben completar cinco pasos:

(1) Comprender a cabalidad cada uno de los estándares a ser evaluados. Cada uno de los estándares mide el cumplimiento de aspectos relacionados con la calidad de atención y el enfoque de género.

(2) Realizar una auto-evaluación o evaluación interna que les permita conocer el grado en que la clínica o institución cumple con los estándares propuestos.

(3) Elaborar un plan de trabajo para lograr el cumplimiento de los estándares de calidad y perspectiva de género que todavía no se hayan alcanzado.

(4) Implementar las acciones de mejoramiento propuestas, que pueden incluir el reforzamiento de los conocimientos de los prestadores de servicio y cambios en las prácticas con clientes o colegas de trabajo, así como cambios en la organización de los servicios y aún en la infraestructura con que se cuenta.

(5) Realizar una evaluación con la participación de evaluadores externos al equipo de trabajo de la clínica u oficinas administrativas para determinar si las acciones de mejoramiento llevaron al cumplimiento mínimo de estándares para recibir el reconocimiento. Estos evaluadores externos pueden ser supervisores o prestadores de servicios de otros centros de salud de la misma red de salud o de otras redes de salud. 


\section{1 Estándares de calidad y género}

El Manual para Evaluar la Calidad de Atención desde una Perspectiva de Género de la IPPF/ RHO, cuenta originalmente 68 estándares en seis áreas relacionadas con las políticas y prácticas institucionales, las prácticas de proveedores(as), la comodidad del(la) cliente, la satisfacción del(la) cliente, el uso del lenguaje de género, y finalmente, la información, educación, comunicación (IEC) y capacitación. El anexo 12 contiene la lista original de estándares propuesta por la IPPF en Bolivia.

Sin embargo, cada institución puede adaptar estos indicadores de acuerdo a la realidad en que se encuentra inserta. Por ejemplo, en Bolivia, PROCOSI revisó la funcionalidad y pertinencia de los estándares y determinó que algunos difícilmente podrían ser cumplidos a cabalidad y que otros no se adaptaban a la realidad de las instituciones o establecimientos de salud de la red. Debido a que la estrategia de acreditación pretende mejorar los servicios sin incurrir en muchos gastos ni generar conflictos en la organización, se seleccionaron aquellos estándares que cubren los requisitos mínimos para incorporar la perspectiva de calidad y género. Como resultado de este análisis, se seleccionaron 59 estándares de calidad con enfoque de género para clínicas y 17 estándares relacionados con las políticas y prácticas de la organización, el uso del lenguaje de género, y en IEC y capacitación.

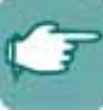

\section{Estándares para instituciones}

Los 17 estándares de calidad con una perspectiva de género que deben cumplir las organizaciones para ser acreditadas son los siguientes:

\section{Políticas y prácticas institucionales}

I.1 Existe una declaración que promueve el empoderamiento de la mujer

I.2 Existe una declaración que prohíbe la discriminación con base en el género

I.3 Existe una declaración que prohíbe la discriminación con base en el género en términos de promoción del personal

I.4 Existe una declaración que prohíbe el abuso del poder en la institución

I.5 Al menos 80 por ciento del personal siente que la dirección o gerencia de la institución es receptiva a sus opiniones y sugerencias

I.6 Al menos 80 por ciento del personal siente que se ponen en práctica sus recomendaciones o sugerencias

I.7 Al menos 80 por ciento del personal se siente motivado(a) para dar opiniones y sugerencias

I.8 Al menos 80 por ciento del personal siente que la institución tiene un ambiente de trabajo colectivo y de equipo 
I.9 Al menos 80 por ciento del personal siente que la institución es receptiva a explicaciones para dejar el trabajo cuando se requiere por razones familiares

I.10 Menos del 20 por ciento del personal siente que en su institución se le da un trato preferencial a un sexo en particular

\section{Conocimiento del personal}

III. 1 Al menos 80 por ciento del personal conoce la definición de salud sexual y reproductiva

III.3 Al menos 80 por ciento del personal conoce la definición de género

V Satisfacción del personal

V.2 Las condiciones de limpieza y comodidad son satisfactorias

VI Uso de lenguaje de género

VI.1 Se usa lenguaje no discriminatorio

VI.2 Se usa lenguaje inclusivo

VII Información, educación, comunicación y capacitación

VII.1 Existen materiales de IEC y capacitación con información sobre derechos sexuales y reproductivos, derechos de los(as) clientes, derechos de la mujer

VII.2 Existen materiales de IEC y capacitación con información sobre aspectos de salud sexual y reproductiva

\section{Estándares para establecimientos de salud}

Los 65 estándares de calidad que la estrategia de acreditación propone que cumplan las clínicas o establecimientos donde se prestan servicios de salud son los siguientes:

\section{Políticas y prácticas institucionales}

I.1 Existe una declaración que promueve el empoderamiento de la mujer

I.2 Existe una declaración que prohíbe la discriminación con base en el género

I.3 Existe una declaración que prohíbe la discriminación con base en el género en términos de promoción del personal

I.4 Existe una declaración que prohíbe el abuso del poder en el establecimiento de salud

I.5 Al menos 80 por ciento del personal siente que la dirección o gerencia del establecimiento de salud es receptiva a sus opiniones y sugerencias

I.6 Al menos 80 por ciento del personal siente que se ponen en práctica sus recomendaciones o sugerencias

I.7 Al menos 80 por ciento del personal se siente motivado(a) para dar opiniones y sugerencias 
I.8 Al menos 80 por ciento del personal siente que el establecimiento de salud tiene un ambiente de trabajo colectivo y de equipo

I.9 Al menos 80 por ciento del personal siente que el establecimiento de salud es receptivo a explicaciones para dejar el trabajo cuando se requiere por razones familiares

I.10 Menos del 20 por ciento del personal siente que en el establecimiento de salud se le da un trato preferencial a un sexo en particular

I.11 Al menos 50 por ciento de las consultas de salud sexual y reproductiva se ofrecen a parejas

I.12 Existe una declaración que establece como procedimiento rutinario ofrecer servicios de orientación

I.13 No existen servicios para los que se requiera el consentimiento de la pareja

I.14 Existe una gama de métodos de anticoncepción disponibles de acuerdo a las normas establecidas por el establecimiento de salud

\section{Prácticas de los(as) proveedores(as)}

II. 1 Al menos 80 por ciento de proveedores(as) saludan a los(as) clientes

II.2 Al menos 80 por ciento de proveedores(as) portan una insignia de identificación visible

II.3 Al menos 80 por ciento de proveedores(as) se refieren a los(as) clientes respetuosamente

II.4 Al menos 80 por ciento de proveedores(as) exploran temas de salud sexual y reproductiva en las consultas/sesiones de orientación

II.5 Al menos 80 por ciento de proveedores(as) exploran aspectos relacionados con la salud sexual del(la) cliente en las consultas/sesiones de orientación

II.6 Menos del 20 por ciento de proveedores(as) sienten que por barreras no se exploran temas de SSR

II.7 Al menos 80 por ciento de proveedores(as) usan material didáctico (dibujos, trípticos, rotafolios u otro material) para reforzar sus explicaciones en las consultas/sesiones de orientación

II.8 Al menos 80 por ciento de proveedores(as) se comunican con el(la) cliente utilizando un lenguaje sencillo en las consultas/sesiones de orientación

II.9 Al menos 80 por ciento de proveedores(as) explican al(la) cliente los detalles del diagnóstico en las consultas/sesiones de orientación

II.10 Al menos 80 por ciento de proveedores(as) explican al(la) cliente los detalles del tratamiento en las consultas/sesiones de orientación

II.11 Al menos 80 por ciento de proveedores(as) miran directamente al(la) cliente mientras explican el diagnóstico o el tratamiento en las consultas/sesiones de orientación

II.12 Al menos 80 por ciento de proveedores(as) preguntan al(la) cliente si tiene preguntas o dudas en las consultas/sesiones de orientación 
II.13 Al menos 80 por ciento de proveedores(as) responden a las preguntas o aclaran dudas del(la) cliente en las consultas/sesiones de orientación

II.14 Al menos 80 por ciento de proveedores(as) explican qué es lo que hacen durante la auscultación o el examen pélvico

II.15 Al menos 80 por ciento de proveedores(as) proporcionan al(la) cliente materiales educativos de refuerzo

II.16 Menos del 20 por ciento de proveedores(as) dicen que existe un tiempo de espera de más de media hora entre el tiempo de llegada del personal de salud al establecimiento de salud y el momento en que inicia la atención a clientes

II.17 Menos del 20 por ciento de clientes dicen haber esperado más de media hora para ser atendidos

II.18 Al menos 80 por ciento del personal identifica los servicios de salud sexual y reproductiva que ofrece el establecimiento de salud

II.19 Al menos 80 por ciento de proveedores(as) dedican todo su tiempo al(la) cliente sin interrupciones durante las consultas/servicios de orientación

II.20 Al menos 80 por ciento del personal conoce y promueve el uso del método de doble protección

II.21 Al menos 80 por ciento del personal conoce y promueve el examen de Papanicolaou

II.22 Al menos 80 por ciento del personal conoce y promueve el auto-examen de senos

\section{Conocimiento de los(as) proveedores(as)}

III. 1 Al menos 80 por ciento del personal conoce la definición de salud sexual y reproductiva

III.2 Al menos 80 por ciento del personal conoce los métodos anticonceptivos disponibles en el establecimiento de salud

III.3 Al menos 80 por ciento del personal conoce la definición de género

\section{Comodidad del[la) cliente}

IV.1 Menos del 20 por ciento de clientes manifiestan dificultades relacionadas al género para acudir al servicio

IV.2 Existen recursos para atender y entretener a los(as) menores que acompañan a los(as) clientes en el servicio de salud

\section{Satisfacción del(la) cliente}

V.1 Existen mecanismos para conocer las opiniones de los(as) clientes sobre el horario y satisfacción del(la) cliente

V.2 Las condiciones de limpieza y comodidad son satisfactorias

V.3 El equipamiento se encuentra disponible y en buen estado 
V.4 Existen condiciones para asegurar la confidencialidad y la privacidad del(la) cliente

V.5 Existen asientos suficientes disponibles para los(as) clientes en el área de espera

V.6 Al menos 80 por ciento de clientes se sienten cómodos(as) hablando con la persona que los(as) atendió en consulta

V.7 Al menos 80 por ciento de clientes se sienten cómodos(as) para hacer preguntas y aclarar sus dudas con los(as) proveedores(as)

V.8 Al menos 80 por ciento de clientes consideran que el tiempo en consulta es suficiente

V.9 Al menos 80 por ciento de clientes dicen haber recibido un buen trato del personal del establecimiento de salud

V.10 Al menos 80 por ciento de clientes fueron atendidos(as) por una persona del sexo de su preferencia

V.11 Al menos 80 por ciento de clientes consideran que el horario de atención se adapta a sus necesidades (relacionadas con género)

VI. Uso de lenguaje de género

VI.1 Se usa lenguaje no discriminatorio

VI.2 Se usa lenguaje inclusivo

\section{Información, educación, comunicación y capacitación}

VII.1 Existen materiales de IEC y capacitación con información sobre derechos sexuales y reproductivos, derechos de los(as) clientes, derechos de la mujer

VII.2 Existen materiales de IEC y capacitación con información sobre aspectos de salud sexual y reproductiva

VII.3 Existen información visual y accesible sobre el establecimiento de salud (servicios que se ofrecen, horarios y lista de precios)

VII.4 Se desarrollan actividades educativas para los(as) clientes en el área de espera

VIII. Monitoreo y evaluación

VIII.1 Existe un mecanismo para establecer cambios programáticos con base en sugerencias de clientes

La Guía de auto-capacitación contiene la descripción de cada uno de los estándares, con sugerencias de actividades a realizar para cumplirlos. 


\section{II.2 Formación del equipo de trabajo}

La primera actividad que se tiene que llevar a cabo para iniciar el proceso de acreditación es la conformación de un equipo básico de trabajo.

En aquellas instituciones donde varias clínicas participen en el proceso de acreditación, se deberá nombrar un coordinador o coordinadora institucional del proceso de acreditación. El o la coordinadora puede pertenecer al área de supervisión, de fortalecimiento institucional, de evaluación o de cualquier otra cuya responsabilidad implique visitar rutinariamente las diferentes clínicas y revisar diferentes aspectos del establecimiento.

También en cada clínica participante deberá nombrarse un coordinador o coordinadora del proceso de acreditación que se encargue de dar seguimiento a las actividades.

En ambos casos el o la coordinadora debe contar con todo el apoyo del director o jefe de la unidad, tener la capacidad para poder comprender los diferentes aspectos involucrados en el proceso de acreditación y tener el poder de convocatoria para asegurar la participación de todos los miembros de la organización para diferentes actividades.

La existencia de un(a) coordinador(a) no implica que él o ella vaya a hacer todas las actividades del proceso de acreditación.

A lo largo del proceso se deberán ir haciendo equipos para cumplir con diferentes etapas del proceso: algunos participarán en la evaluación interna, casi todas las personas tendrán que estar involucradas en la formulación de planes de acción para alcanzar los estándares no cumplidos y en la implementación de estas acciones, otros más participarán en las evaluaciones finales internas. Sin embargo, el coordinador servirá como eje para organizar el trabajo, documentar los avances y trabajar en coordinación con el o la coordinadora nacional.

\section{II.3 Evaluación interna}

Para determinar la situación inicial de las instituciones o establecimientos de salud, la clínica o área administrativa realiza una auto-evaluación o evaluación interna. Esta actividad consiste en revisar cada uno de los estándares y determinar con cuáles cumple la unidad de salud y cuáles es necesario mejorar. 
Para realizar esta revisión, el equipo de trabajo de la clínica o de la institución usa los formularios de evaluación incluidos en el Anexo IV. Estos formularios son también usados en la evaluación externa que se hace para verificar el cumplimiento con los estándares de calidad. En términos generales, la información se obtiene mediante entrevistas directas a clientes y a prestadores de servicios, por observación directa de las interacciones de clientes y proveedores y de las condiciones existentes en la clínica, o revisando los documentos institucionales.

Es recomendable que el personal de un área determinada ayude a evaluar los estándares relacionados con esa misma área.

Así, es importante la participación del(la) administrador(a) para revisar las políticas y prácticas institucionales, de médicos y enfermeras para revisar las prácticas de los(as) proveedores(as) y la comodidad y satisfacción del(la) cliente, de los gerentes de capacitación y supervisión para revisar estos aspectos, etc.

La Guía de evaluación contiene los detalles de todo el proceso de evaluación: conformación de los equipos de evaluación, cálculo de muestras, llenado de formularios, y la captura y análisis de datos para conocer los resultados del ejercicio de la autoevaluación.

Cabe agregar que la experiencia ha demostrado que es necesario usar los instrumentos para evaluar el grado en que una organización cumple con los estándares de calidad. A menudo, el personal siente que la evaluación inicial puede basarse en sus propias percepciones sin ser necesario hacer observaciones y entrevistas. Sin embargo, diferentes experiencias han demostrado que invariablemente el personal califica a sus servicios de mejor manera de lo que ameritan las circunstancias.

Después de conocer los aspectos débiles de la unidad de salud en temas de calidad con enfoque de género, el mismo grupo de personas elabora un plan de acción para alcanzar los estándares no cumplidos.

\section{II.4 Plan de acción}

Los resultados de la evaluación interna deberán socializarse entre todos los miembros de la institución o clínica, mostrando claramente cuáles son los estándares cumplidos y los no cumplidos y convocando a que el personal piense en las acciones necesarias para poder cumplir en el futuro cercano con los estándares no cumplidos.

La coordinadora del proceso y el equipo de trabajo de la unidad deberán preparar un plan de acción en el que se identifiquen las actividades que tienen que hacerse 
para alcanzar los estándares no cumplidos. El plan también debe identificar a las personas responsables de ejecutar las acciones, las fechas en que las acciones deben llevarse a cabo y terminarse y los recursos con lo que debe contar el personal para finalizar la acción. En términos generales, las personas rutinariamente responsables de un área específica deberán hacerse cargo de las actividades de mejoramiento de su propia área. Por ejemplo; si se trata de una institución que presta asistencia técnica a establecimientos de salud, para trabajar los estándares establecidos de IEC, se deberá comprometer la participación del(la) experto(a) en comunicación.

Como complemento a esta guía se encuentra la Guía de auto-capacitación. Esta última contiene definiciones y sugerencias de actividades a realizarse para lograr el cumplimiento para cada estándar. Este instrumento también permite conocer los recursos necesarios para cumplir con los estándares de calidad y género, y por lo tanto, se convierte en un insumo para la elaboración de los planes de acción.

En el Cuadro 1 en la siguiente página presentamos un ejemplo de un plan de acción. En este ejemplo se listan los estándares I.1 al I.5, pero el plan de acción completo deberá incluir los 59 estándares de calidad y género (o los 17 estándares para las áreas administrativas, dependiendo del caso).

Si la institución o establecimiento de salud cumple inicialmente con los requisitos del estándar, entonces se anotará en la columna actividades la palabra "CUMPLE" y en las otras tres columnas (responsables, fecha, recursos) la abreviatura "N/A" (no aplica). En el caso de los estándares no cumplidos, se anota en la columna actividades aquellas que se llevarán a cabo para resolver la carencia institucional y en las otras tres columnas la información respectiva sobre los responsables que llevarán a cabo la acción, la fecha en que tendrá que haber sido terminada y los recursos que la institución deberá hacer disponibles para llevar a cabo la acción. El uso de estos recursos deberá ser autorizado por el director de la clínica o de la institución para que la meta sea válida.

El Anexo 2 incluye las plantillas de plan de acción para ser usadas en instituciones o establecimientos de salud.

El(la) coordinador(a) del proceso de acreditación del establecimiento o institución de salud, deberá realizar el seguimiento semanal de las actividades planteadas en el plan de acción hasta la finalización satisfactoria de todas las actividades. Además, el(la) coordinador(a) recolectará semanalmente una copia de las actualizaciones del plan de acción para anotar los avances y obstáculos encontrados. Esto le permitirá, ofrecer asistencia técnica oportuna y eficiente. Al cabo del cumplimiento de los requisitos de todos los estándares, la última copia del plan de acción debe contener en todas las casillas de la columna actividades la palabra "CUMPLE". 


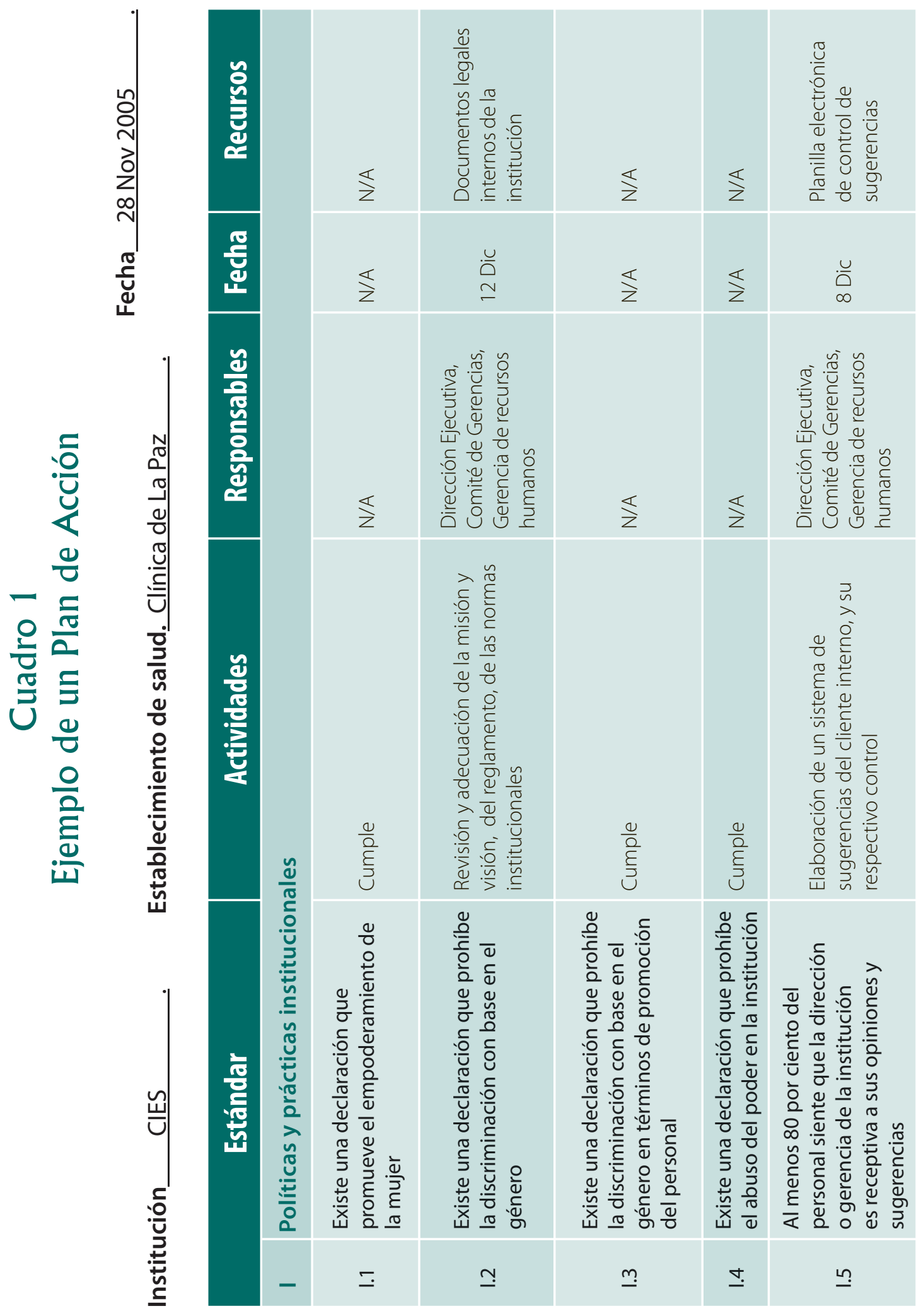




\section{II.5 Implementación de acciones y fortalecimiento}

Para solucionar los problemas, los equipos deberán hacer uso de los recursos que tiene su propia institución y otros recursos externos. Esto incluye las publicaciones y documentos que explican los diferentes conceptos, la asesoría de las áreas de capacitación y supervisión, la información disponible a través de agencias de cooperación técnica, instituciones hermanas prestadoras de servicios de salud o el Internet.

Para completar esta guía de procedimientos también se cuenta con una Guía de auto-capacitación que incluye ejemplos a seguir para capacitar al personal de las instituciones o establecimientos de salud. También contiene sugerencias de actividades que se deben ejecutar para cumplir con los estándares.

El Anexo 3 contiene un ejemplo de una lista de verificación que puede ser usada para mejorar la calidad de atención de los establecimientos de salud. La lista de verificación es un instrumento de apoyo al personal de salud que permite ofrecer a los(as) clientes una atención integral en una sola visita. Este instrumento puede ser modificado de acuerdo a las necesidades de la institución o establecimiento de salud.

\section{II.6 Nueva evaluación interna}

Al término del proceso de implementación de acciones incluidas en el plan para alcanzar el cumplimiento de los estándares, la institución o establecimiento de salud realiza nuevamente una evaluación interna aplicando todos los instrumentos y metodologías que fueron utilizados en la evaluación para hacer el diagnóstico inicial. Si los resultados de esta auto-evaluación comprueban el cumplimiento de por lo menos 80 por ciento de los estándares (siguiendo los procedimientos de análisis incluidos en la Guía de evaluación), el(la) directora(a) y el(la) coordinador(a) de evaluación de la institución o establecimiento de salud, solicitan por medio de carta formal a la institución que se realice una evaluación externa. El requerimiento debe incluir una copia de los planes de acción semanales, y una copia de los resultados de la evaluación interna.

\section{II.7 Evaluación externa}

Una vez requerida la evaluación formal, comité evaluador analizará los planes de acción semanales para verificar el cumplimiento de las acciones planteadas, y su concordancia con los resultados de la evaluación interna. 
Si el comité no encuentra incongruencias entre los documentos analizados, organizará un grupo multidisciplinario de tres evaluadores (por ejemplo: un(a) médico, un(a) enfermera(o) y un(a) trabajador(a) social) que realizarán la evaluación externa.

Los(as) evaluadores(as) para la evaluación externa pueden ser miembros de la misma red de salud, pero no de la misma institución o establecimiento de salud que busca la acreditación. También pueden ser evaluadores(as) los miembros del personal de las gerencias de la organización matriz.

Este grupo evaluador realizará, en uno o máximo dos días, las siguientes actividades:

a. Revisión de documentos. Mide el nivel de integración de un enfoque de género en las políticas y en la estructura del establecimiento de salud. Esta revisión consiste en trabajar sobre documentos institucionales, protocolos y procedimientos, para determinar el estado actual de su institución en el tema de género.

b. Observación de aspectos generales. Mide el nivel de las condiciones de infraestructura y materiales expuestos en la institución o establecimiento de salud. Esta observación consiste en un recorrido por los diferentes ambientes de la institución o establecimiento, sin necesidad de ingresar a consultorios o salas privadas.

c. Observación de la consulta. Sólo para establecimientos de salud. A través de la observación de dos o tres consultas, se mide la calidad de atención que el personal del establecimiento brinda a las(os) clientes. Parte de este estudio es la observación de las consultas médicas y las sesiones de orientación en salud sexual y reproductiva.

d. Entrevista de salida a clientes. Sólo para establecimientos de salud. A través de un sondeo de opinión, se mide la calidad de atención que el establecimiento de salud brinda a los(as) clientes. Se mide también el comportamiento y el trato del(la) proveedor(a) de salud en la atención brindada.

e. Entrevista al personal. A través de entrevistas al personal, se mide la calidad de atención que se brinda en los servicios, desde una perspectiva de género, y se evalúan las políticas y prácticas de la institución, también desde el punto de vista del enfoque de género. 
El Anexo 4 incluye los cinco instrumentos de evaluación, y el Anexo 5 incluye una tabla que muestra la relación entre los estándares y los instrumentos de evaluación. La Guía de evaluación ofrece información más detallada sobre la aplicación de estos instrumentos.

Al igual que en la auto-evaluación, esta evaluación externa tendrá una calificación. Si se cumple un mínimo del 80 por ciento de los estándares, la institución o establecimiento de salud es candidato a recibir un reconocimiento por ofrecer servicios de calidad con enfoque de género.

Si en los resultados de la evaluación externa se encuentra un cumplimiento de estándares menor al 80 por ciento, el comité evaluador entregará a la institución o establecimiento de salud un informe completo de los resultados de la evaluación con recomendaciones para repetir el proceso de cumplimiento de los estándares.

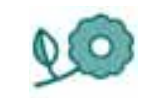





\section{Acreditación}

C i los resultados de la evaluación externa son satisfactorios (se cumple con un mínimo del 80 por ciento de los estándares), el comité entregará a la institución o establecimiento de salud, un informe completo de la evaluación con un certificado de certificado de cumplimiento de los estándares de calidad con enfoque de género.

En los siguientes días, si el comité evaluador lo dispone, se puede instalar una placa meritoria en el muro principal del establecimiento o institución de salud en un acto de reconocimiento al personal por la labor realizada. Esta placa simbolizará el esfuerzo del personal de incorporar el enfoque de género a fin de mejorar la calidad de atención tanto al cliente interno (empleados[as]) como al cliente externo (usuarios[as] de servicios de salud).

También se realizará un acto público con presencia de las autoridades de salud del país y de la prensa nacional. En este acto es importante difundir la importancia del logro para las instituciones o establecimientos de salud y los beneficios para la población en general. Todos estos gastos correrán por cuenta del comité evaluador.

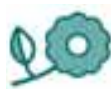





\section{Re-acreditación}

a acreditación o reconocimiento público es un instrumento que utiliza la institución — para dar a sus clientes una garantía de la calidad de los servicios y de su sensibilidad a asuntos de género. Esta garantía no puede ser indefinida. Se recomienda que la acreditación tenga una vigencia máxima de dos años. Acabado este plazo, las instituciones o establecimientos de salud deberán repetir el proceso: realizar una auto-evaluación, alcanzar los estándares no cumplidos y cuando se tenga certeza del cumplimiento, solicitar una evaluación externa para certificar la calidad del servicio. Si la solicitud de una nueva evaluación no se realiza, el comité evaluador puede remover la placa de mérito y rectificar el reconocimiento previamente otorgado.

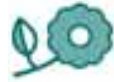





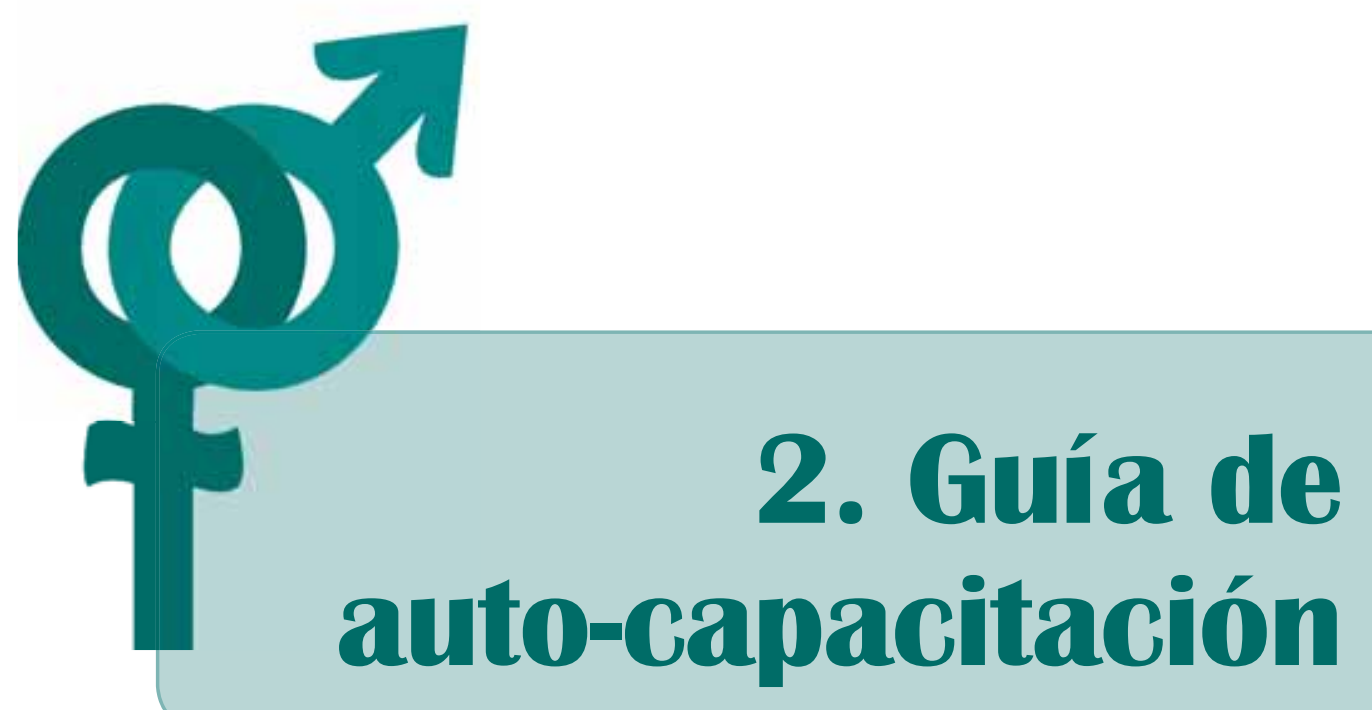

Para instituciones y establecimientos

de salud que buscan acreditar la calidad y enfoque de género de sus servicios

La Paz • Bolivia • septiembre 2007 



\section{Contenido}

Introducción

I. Políticas y prácticas institucionales

Estándar I.1: Existe una declaración que promueve el empoderamiento de la mujer

Estándar I.2: Existe una declaración que prohíbe la discriminación con base en el género

Estándar I.3: Existe una declaración que prohíbe la discriminación con base en el género en términos de promoción del personal

Estándar I.4: Existe una declaración que prohíbe el abuso de poder en la

institución/establecimiento de salud

Estándar I.5: $\quad$ Al menos 80 por ciento del personal siente que la dirección o gerencia de la institución/establecimiento de salud es receptiva a sus opiniones y sugerencias

Estándar I.6: $\quad \mathrm{Al}$ menos 80 por ciento del personal siente que se ponen en práctica sus recomendaciones o sugerencias

Estándar I.7: $\quad$ Al menos 80 por ciento del personal se siente motivado(a) para dar opiniones y sugerencias

Estándar I.8: Al menos 80 por ciento del personal siente que la institución/ establecimiento de salud tiene un ambiente de trabajo colectivo y de equipo

Estándar I.9: Al menos 80 por ciento del personal siente que la institución/ establecimiento de salud es receptiva a explicaciones para dejar el trabajo cuando se requiere por razones familiares

Estándar I.10: Menos de 20 por ciento del personal siente que en la institución/establecimiento de salud se le da un trato preferencial a un sexo en particular 
Estándar I.11: Al menos 50 por ciento de las consultas de salud sexual y reproductiva se ofrecen a parejas

Estándar I.12: Existe una declaración que establece como procedimiento rutinario ofrecer servicios de orientación

Estándar I.13: No existen servicios para los que se requiera el consentimiento de la pareja

Estándar I.14: Existe una gama de métodos de anticoncepción de acuerdo a las normas establecidas por el establecimiento de salud

\section{Practicas de los(as) provedores(as)}

Estándar II.1: Al menos 80 por ciento de proveedores(as) saludan a los(as) clientes

Estándar II.2: $\quad$ Al menos 80 por ciento de proveedores(as) portan una insignia de identificación visible

Estándar II.3: Al menos 80 por ciento de proveedores(as) se refieren a $\operatorname{los}$ (as) clientes respetuosamente

Estándar II.4: Al menos 80 por ciento de proveedores(as) exploran temas de salud sexual y reproductiva en las consultas/sesiones de orientación

Estándar II.5: Al menos 80 por ciento de proveedores(as) exploran aspectos relacionados con la salud sexual del(la) cliente en las consultas/sesiones de orientación

Estándar II.6: Menos del 20 por ciento de proveedores(as) sienten que por barreras no se exploran temas de salud sexual y reproductiva

Estándar II.7: $\quad$ Al menos 80 por ciento de proveedores(as) usan material didáctico para reforzar sus explicaciones en las consultas/ sesiones de orientación

Estándar II.8: Al menos 80 por ciento de proveedores(as) se comunican con el(la) cliente utilizando un lenguaje sencillo en consultas/ sesiones de orientación

Estándar II.9: $\quad \mathrm{Al}$ menos 80 por ciento de proveedores(as) explican al(la) cliente los detalles del diagnóstico en las consultas/sesiones de orientación

Estándar II.10: Al menos 80 por ciento de proveedores(as) explican al(la) cliente los detalles del tratamiento en las consultas/sesiones de orientación 
Estándar II.11: Al menos 80 por ciento de proveedores(as) miran directamente al(la) cliente mientras explican el diagnóstico o el tratamiento en las consultas/sesiones de orientación

Estándar II.12: Al menos 80 por ciento de proveedores(as) preguntan al(la) cliente si tiene preguntas o dudas en las consultas/sesiones de orientación

Estándar II.13: Al menos 80 por ciento de proveedores(as) responden a las preguntas o aclaran dudas del(la) cliente en las consultas/ sesiones de orientación

Estándar II.14: Al menos 80 por ciento de proveedores(as) explican qué es lo que hacen durante la auscultación o el examen pélvico

Estándar II.15: Al menos 80 por ciento de proveedores(as) proporcionan al(la) cliente materiales educativos de refuerzo

Estándar II. 16: Menos del 20 por ciento de proveedores(as) dicen que existe un tiempo de espera de más de media hora entre el tiempo de llegada del personal de salud al establecimiento de salud y el momento en que inicia la atención a clientes

Estándar II.17: Menos del 20 por ciento de clientes dicen haber esperado más de media hora para ser atendidos

Estándar II.18: Al menos 80 por ciento del personal identifica los servicios de salud sexual y reproductiva que ofrece el establecimiento de salud

Estándar II.19: Al menos 80 por ciento de proveedores(as) dedican todo su tiempo al(la) cliente sin interrupciones durante las consultas/servicios de orientación

Estándar II.20: Al menos 80 por ciento del personal conoce y promueve el uso del método de doble protección

Estándar II.21: Al menos 80 por ciento del personal conoce y promueve el examen de Papanicolaou

Estándar II.22: Al menos 80 por ciento del personal conoce y promueve el auto-examen de senos

\section{Conocimiento de los(as) proveedores(as)/personal}

Estándar III.1: Al menos 80 por ciento del personal conoce la definición de la salud sexual y reproductiva

Estándar III.2: Al menos 80 por ciento del personal conoce los métodos anticonceptivos disponibles en el establecimiento de salud 
Estándar III.3: Al menos 80 por ciento del personal conoce la definición de género

\section{Comodidad del(la) cliente}

Estándar IV.1: $\quad$ Menos del 20 por ciento de los(as) clientes manifiestan

dificultades relacionadas al género para acudir al servicio

Estándar IV.2: $\quad$ Existen recursos para atender y entretener a los(as) menores que acompañan a los(as) clientes en el servicio de salud

\section{Satisfacción del(la) cliente}

Estándar V.1: $\quad$ Existen mecanismos para conocer las opiniones de 95 las(los) clientes sobre el horario y satisfacción del (la) cliente

Estándar V.2: $\quad$ Las condiciones de limpieza y comodidad son satisfactorias

Estándar V.3: $\quad$ El equipamiento se encuentra disponible y en buen estado

Estándar V.4: $\quad$ Existen condiciones para asegurar la confidencialidad y la privacidad del(la) cliente

Estándar V.5: $\quad$ Existen asientos suficientes disponibles para los(as) clientes en el área de espera

Estándar V.6: $\quad$ Al menos 80 por ciento de los(as) clientes se sienten cómodos(as) hablando con la persona que los(as) atendió en consulta

Estándar V.7: $\quad$ Al menos 80 por ciento de los(as) clientes se sienten cómodos(as) para hacer preguntas y aclarar sus dudas con los(as) proveedores(as)

Estándar V.8: $\quad$ Al menos 80 por ciento de los(as) clientes consideran que el tiempo en consulta es suficiente

Estándar V.9: $\quad \mathrm{Al}$ menos 80 por ciento de los(as) clientes dicen haber recibido un buen trato del personal del establecimiento de salud

Estándar V.10: Al menos 80 por ciento de los(as) clientes fueron atendidos(as) por una persona del sexo de su preferencia

Estándar V.11: Al menos 80 por ciento de clientes consideran que el horario de atención se adapta a sus necesidades (relacionadas con género) 


\section{Uso del lenguaje de género}

Estándar VI.1: $\quad$ Se usa lenguaje no discriminatorio

Estándar VI.2: Se usa lenguaje inclusivo

\section{Información, educación, comunicación y capacitación}

Estándar VII.1: Existen materiales de IEC y capacitación con información sobre derechos sexuales y reproductivos, derechos de los(as) clientes y derechos de la mujer

Estándar VII.2: Existen materiales de IEC y capacitación con información sobre aspectos de salud sexual y reproductiva

Estándar VII.3: Existe información visual y accesible sobre el establecimiento de salud (servicios que se ofrecen, horarios y lista de precios)

Estándar VII.4: Se desarrollan actividades educativas para los(las) clientes en el área de espera

\section{Monitoreo y evaluación}

Estándar VIII.1: Existe un mecanismo para establecer cambios programáticos con base en sugerencias de clientes

\section{Bibliografía}





\section{Introducción}

El propósito de esta Guía de auto-capacitación es proporcionar los contenidos y Conceptos que el personal institucional, incluidos los prestadores de servicios, deben conocer para poder cumplir con los estándares exigidos para acreditar instituciones como prestadoras de servicios de calidad con un enfoque de género. La guía también sugiere estrategias y procedimientos para realizar cambios en la estructura, procedimientos y prácticas organizacionales e individuales para alcanzar este mismo fin.

La guía está diseñada para que el personal institucional pueda estudiarla por si mismo en un proceso de auto-capacitación. Sin embargo, las instituciones y equipos de salud buscando la acreditación pueden reforzar el proceso autodidacta con talleres, conferencias, clases, orientaciones individuales, sesiones grupales para responder a dudas o cualquiera de las otras muchas estrategias existentes para transmitir los conocimientos. Estamos conscientes de que existen dificultades especiales para llevar a cabo procesos autodidactas, pero esta recomendación está basada en un punto determinante para las instituciones: el costo de la capacitación. Creemos que en la práctica, la alternativa más viable para mantener los costos de capacitación bajos es el auto-aprendizaje.

Sin embargo, aún en las mejores circunstancias, el desafío del estudio requiere motivación, planificación y la habilidad para analizar y aplicar la información puesta a disposición. En una auto-capacitación, el proceso de aprendizaje es aún más complejo debido a que la persona se encuentra sola. Los factores de motivación que surgen del contacto o de la competencia con otras personas están ausentes. El que aprende -el aprendiz- tampoco cuenta con el apoyo inmediato de un facilitador que pueda motivarlo $y$, en caso necesario, atender las dificultades que se presenten durante el estudio.

Los aprendices pueden tener dificultades para determinar cuáles son las demandas y necesidades reales de un programa de estudio, ya que no cuentan con el apoyo de un grupo de estudio ni acceso inmediato a un facilitador. Pueden surgir dudas sobre el proceso de aprendizaje y recurrirse a la simple memorización de conceptos y detalles, lo cual conduce a una mala comprensión del material de estudio. 
Lo que NO se debe hacer durante el proceso de aprendizaje es:

- Concentrarse en elementos específicos.

- Memorizar información y procedimientos.

- Asociar conceptos y hechos sin reflexionar sobre el significado del texto.

Los aprendices en una auto-capacitación deben centrar su atención en lo siguiente:

- Distinguir las ideas nuevas del conocimiento previo y relacionarlas.

- Relacionar los conceptos con la experiencia diaria.

- Organizar y estructurar los contenidos.

- Hacer énfasis en la relación entre el material de estudio y la realidad.

No es fácil concentrarse en los puntos arriba mencionados. Los aprendices deben vencer varios desafíos como: mantenerse motivados; 'apropiarse' de sus propias fortalezas, deseos, habilidades y necesidades; mantener y aumentar su autoestima; relacionarse con otras personas; clarificar lo que han aprendido; redefinir lo que es conocimiento legítimo y saber asimilar los contenidos del material.

\section{- Mantenerse motivados}

Es muy importante conservar una alta motivación debido a la falta de contacto con un facilitador y otros aprendices. Los supervisores pueden ayudar a motivar a los aprendices ofreciendo retroalimentación consistente y oportuna, propiciando momentos de discusión entre el personal y reforzando hábitos de estudio entre los aprendices.

\section{- Apropiarse de sus propias fortalezas, deseos, habilidades y necesidades}

Los aprendices necesitan reconocer sus fortalezas y limitaciones. También necesitan comprender cuáles son las metas y objetivos de aprendizaje. El supervisor puede ayudarles a explorar sus fortalezas y limitaciones y sus metas y objetivos de aprendizaje al asumir un rol de facilitador en el proceso de aprendizaje. El supervisor puede ofrecer a los aprendices oportunidades para compartir sus metas y objetivos personales de aprendizaje y de esta forma aumentar la motivación.

\section{- Mantener y aumentar la autoestima}

El supervisor puede ayudar a mantener la autoestima del aprendiz ofreciéndole retroalimentación oportuna. Es muy importante que el supervisor responda a preguntas y preocupaciones de una manera personalizada y cálida. 


\section{- Relacionarse con otras personas}

Las personas aprenden más efectivamente cuando tienen la oportunidad de interactuar con otras personas. La interacción entre aprendices generalmente lleva al análisis grupal. Cuando las personas no se pueden reunir, es importante mantener mecanismos de comunicación informales.

\section{- Clarificar lo aprendido}

Los aprendices en un proceso de auto-capacitación deben reflexionar sobre lo aprendido; necesitan examinar los marcos de conocimiento existentes y cómo estos marcos se están modificando con la nueva información. Existen métodos informales para evaluar los conocimientos adquiridos. Por ejemplo, el supervisor puede requerir periódicamente que los aprendices escriban una breve reflexión sobre lo aprendido y ofrecerles la oportunidad de compartir sus puntos de vista con el resto del personal.

\section{- Redefinir lo que es conocimiento legítimo}

Es a veces difícil para los aprendices adultos reconocer su propia experiencia y reflexiones como un conocimiento legítimo. El supervisor puede apoyar a los aprendices a ver que su propia experiencia es valiosa e importante para un mayor aprendizaje. Se sugiere que los aprendices usen el lenguaje en primera persona ('yo') para adoptar una apropiación de valores personales, experiencias $\mathrm{y}$ puntos de vista.

\section{- Asimilar los contenidos del material}

El aprendizaje mejora cuando los contenidos se relacionan con ejemplos. Los supervisores deben encontrar ejemplos que sean relevantes al diario vivir del personal. 



\section{Políticas y prácticas institucionales}

\section{Estándar I.1: \\ Existe una declaración que promueve el empoderamiento de la mujer}

\section{?)}

¿A qué nos referimos?

$\mathrm{P}$

ara entender el término empoderamiento de la mujer, se deben concebir primero los cuatro elementos que conforman este proceso:

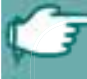

(1) las mujeres deben tomar conciencia de las dinámicas de poder que operan en su contexto vital;

2 deben desarrollar las habilidades y capacidades necesarias para lograr un control razonable sobre sus vidas;

3 deben ejercitar ese control sin infringir los derechos de otros, $y$

4 deben apoyar el empoderamiento de otras mujeres en su ámbito de acción.

Esto quiere decir que las mujeres deben comprender primero su situación, para entonces tener más posibilidades de actuar para intervenir sobre ellas mismas. El empoderamiento supone trabajar para eliminar los efectos y el propio hecho de que existan situaciones injustas de desigualdad. Todas las definiciones de empoderamiento se centran en las mujeres como sujetos que se convierten en 'sujetos' de sus propias vidas y desarrollan una conciencia crítica, es decir, la comprensión de sus circunstancias y del entorno social que las conduce a la acción.

Es necesario diseñar procesos y estructuras dirigidas a ofrecer a las mujeres la oportunidad de ser capaces de conocer de su propia autonomía y hacer valer sus 
derechos. Para lograrlo, se requiere diseñar actividades que combinen el acceso a la información, el desarrollo de confianza, autoestima y habilidades analíticas, la capacidad para identificar y aprovechar los recursos disponibles y de tener influencia política y social, entre otros elementos. Los campos laborales que parten de las demandas y deseos de las mujeres que participan en ellos son un paso hacia el empoderamiento.

El empoderamiento puede darse a pequeña escala, uniendo a personas que viven situaciones similares, o a una escala mayor, a través de la organización de la sociedad trabajadora, realizando reuniones sobre las políticas institucionales, la planificación del trabajo y el desarrollo del mismo.

El empoderamiento debe ser un proceso interno, propio de la institución. Éste es un proceso que no puede imponerse por actores externos.

Por último, el empoderamiento tiene mucho en común con otros conceptos utilizados en las organizaciones laborales, como 'participación', 'fortalecimiento de capacidades', 'sostenibilidad' y 'desarrollo institucional'. Existe, sin embargo, la preocupante tentación de emplearlos dejando fuera de escena los problemáticos conceptos del poder y de la distribución del poder. A pesar de su atractivo, estos términos pueden convertirse fácilmente en una forma más de ignorar o de ocultar las realidades del poder, de la desigualdad y de la opresión.

El concepto de empoderamiento, si se emplea de forma precisa y deliberada, puede contribuir a centrar el pensamiento, la planificación y la acción en el ámbito laboral. No obstante, cuando se emplea de forma descuidada, deliberadamente imprecisa o como una mera consigna, se corre el riesgo de degradarlo y devaluarlo.

\section{¿Qué hacemos para cumplir con este estándar?}

(1) Todo documento institucional (reglamento de trabajo, reglamento interno, normas y manuales institucionales, protocolos, etc.) debe ajustarse al formato que indique o recomiende la instancia rectora del trabajo del Estado (e.g. Ministerio del Trabajo), para que sea aprobado y tenga vigencia legal y debe identificarse por capítulos, artículos, códigos, etc. (e.g. Capítulo I, Artículo XXII, Código IV).

(2) En algún documento institucional debe establecerse, a través de un capítulo, artículo o código, una instrucción claramente definida que reglamente que toda mujer miembro de la institución (empleada) debe tener acceso a capacitarse dentro o fuera de la institución, a informarse, a ejercer cargos de alta responsabilidad y a tener espacios de opinión. 


\section{Estándar I.2: \\ Existe una declaración que prohíbe la discriminación con base en el género}

\section{8) \\ ¿A qué nos referimos?}

a definición de discriminación en el empleo y la ocupación implica cualquier distinción, exclusión o preferencia que tenga el efecto de anular o desequilibrar la equidad de oportunidades o de trato en un empleo u ocupación. La discriminación puede producirse condicionada por factores de tipo racial, de género, de religión, opinión política o clase social. Por supuesto, las distinciones basadas estrictamente en los requerimientos inherentes a un trabajo, no están consideradas como discriminación.

El no discriminar significa que las y los empleados sean seleccionados con base en su capacidad de realizar el trabajo y que no exista ninguna distinción, exclusión o preferencia basada en otras cuestiones, principalmente por el sexo de las o los postulantes. Las y los empleados que se ven afectados por la discriminación en el trabajo no reciben las mismas oportunidades y sus derechos humanos son violados.

La discriminación puede ser directa, cuando las leyes, reglamentos o prácticas citan explícitamente algún motivo como el género o la raza para ser privado de alguna oportunidad. Pero, en general, la discriminación suele ser indirecta y se ejerce donde los reglamentos y las prácticas aparentan ser neutrales pero en realidad promueven las exclusiones.

Con frecuencia la discriminación en una organización no tiene sentido, ya que esta práctica restringe el flujo de empleadas o empleados y de sus habilidades y desacelera el crecimiento o fortalecimiento de la institución y de la sociedad en general.

Las instituciones u organizaciones pueden realizar actividades específicas para solucionar el problema de la discriminación por género, por ejemplo:

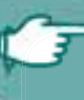

- Crear políticas y procedimientos para que el número de empleados sea igual al número de empleadas, de acuerdo a las exigencias del cargo.

- Crear políticas y procedimientos para que las aptitudes y la experiencia sean las bases de las contrataciones, la capacitación, etc.

- Eliminar los requerimientos sistemáticos que pongan en desventaja a determinados grupos basados en el género.

- Cuando se identifiquen prácticas discriminatorias, desarrollar procedimientos de reclamación para atender las quejas. 
Para finalizar, el concepto de discriminación con base en el género se debe entender como el tratamiento inequitativo, injusto o desigual, de una persona o grupo de personas basado en el sexo. Ésta es una violación de los derechos humanos, que incluye el derecho al trato justo e igual por parte de los gobiernos mediante programas, políticas y leyes.

\section{¿Qué hacemos para cumplir con este estándar?}

(1) Todo documento institucional (reglamento de trabajo, reglamento interno, normas y manuales institucionales, protocolos, etc.) debe ajustarse al formato que indique o recomiende la instancia rectora del trabajo del Estado (e.g. Ministerio del Trabajo), para que sea aprobado y tenga vigencia legal y debe identificarse por capítulos, artículos, códigos, etc. (e.g. Capítulo I, Artículo XXII, Código IV).

(2) En algún documento institucional debe establecerse, a través de un capítulo, artículo o código, una instrucción claramente definida que reglamente que las aptitudes y la experiencia sean las bases de las contrataciones, la capacitación, etc. y que de ninguna manera sea cuestión de género.

\section{Estándar I.3: \\ Existe una declaración que prohíbe la discriminación con base en el género en términos de promoción del personal}

\section{¿A qué nos referimos?}

a promoción del personal dentro una institución laboral se refiere a la valoración de - las aptitudes de un(a) empleado(a) para mejorarle su puesto de trabajo y su salario. En la mayoría de los casos, este procedimiento se realiza como reconocimiento a la buena labor desempeñada por el o la empleada dentro una institución.

Para que un empleado o empleada sea promovido, la institución debe valorar su gestión y aprovechar todo el potencial que tiene como ser humano. También se debe valorar el puesto de promoción, evitando todo tipo de discriminación, sea de género, raza, minusvalía, etc. 
En organizaciones donde la política de promoción busca brindar igual oportunidad a su personal (tomando en cuenta el género) se debe proceder de la siguiente manera:

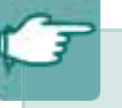

- Potenciar la capacitación de las personas para poder acceder a determinados puestos de trabajo sin discriminación.

- Potenciar la formación, estableciendo medidas de compensación/ incentivo del tiempo destinado a la formación (dentro el horario laboral, con compensación de horas en caso de que se realice fuera del horario establecido, etc.).

- La formación de las mujeres debe darse, como mínimo, en igual porcentaje que los hombres.

- Analizar el número de personas que han recibido formación, según sexo.

- Realizar un análisis cualitativo por sexos de la formación recibida.

- Comunicar a todo el personal los perfiles de competencia de los puestos de trabajo.

- Diseñar planes de formación para trabajadores(as) con tipologías diferenciadas y comunicarlos a todo el personal.

- Tener en cuenta, a la hora de planear la formación, las condiciones en las que se desarrollará, en función del género: horarios, jornadas, lugares, desplazamientos.

\section{¿Qué hacemos para cumplir con este estándar?}

(1) Todo documento institucional (reglamento de trabajo, reglamento interno, normas y manuales institucionales, protocolos, etc.) debe ajustarse al formato que indique o recomiende la instancia rectora del trabajo del Estado (e.g. Ministerio del Trabajo), para que sea aprobado y tenga vigencia legal y debe identificarse por capítulos, artículos, códigos, etc. (e.g. Capítulo I, Artículo XXII, Código IV).

(2) En algún documento institucional debe establecerse, a través de un capítulo, artículo o código, una o varias instrucciones claramente definidas que reglamenten que toda promoción de personal estará exenta de la condición de género. 


\section{Estándar I.4: \\ Existe una declaración que prohíbe el abuso de poder en la institución/establecimiento de salud}

\section{(8)}

\section{¿A qué nos referimos?}

E

término abuso de poder dentro una institución de trabajo se refiere al exceso del ejercicio de atribuciones que un personal con cargo de dirección, "personal superior", ejerce sobre otro personal que se encuentra bajo su responsabilidad o supervisión, en perjuicio de éste último.

Generalmente, las estructuras jurídicas de una institución tienen como base la neutralidad de la política institucional y la imparcialidad para juzgar casos "raros" ocasionados por el personal. Sin embargo, bajo el lente de esta neutralidad e imparcialidad se desconoce una realidad: la violencia contra empleadas y empleados. Es decir, se está frente a una estructura de control insensible a la forma de funcionar de la violencia contra el personal y, por lo tanto, incapaz de reconocer los actos punibles y sancionarlos. El abuso de poder es una forma de ejercer violencia.

El abuso de poder se ejerce tanto con hombres como con mujeres. Dentro el marco de éste ejercicio se encuentran el irrespeto al horario de trabajo del personal de base, el desconocimiento de los términos de referencias de los cargos y la exigencia de tareas que no se encuentran en los mismos.

Dentro de este concepto de abuso de poder también se encuentran el acoso sexual y el hostigamiento al personal. En el primer caso, el personal de poder (directores, gerentes, etc.), solicita a una persona favores o respuestas sexuales para sí o para un tercero o procura cualquier tipo de acercamiento sexual no deseado, prevaliéndose de su situación de superioridad laboral y con la amenaza expresa o tácita de causarle un mal en el campo laboral, en caso de negativa. El segundo caso, el de hostigamiento sexual, se presenta cuando el personal dependiente escucha cualquier tipo de comentario sexual no solicitado, miradas, sugerencias o contacto físico que cree un ambiente de trabajo incómodo para cualquier persona. 
¿Qué hacemos para cumplir con este estándar?

(1) Todo documento institucional (reglamento de trabajo, reglamento interno, normas y manuales institucionales, protocolos, etc.) debe ajustarse al formato que indique o recomiende la instancia rectora del trabajo del Estado (e.g. Ministerio del Trabajo), para que sea aprobado y tenga vigencia legal y debe identificarse por capítulos, artículos, códigos, etc. (e.g. Capítulo I, Artículo XXII, Código IV).

(2) En algún documento institucional debe establecerse, a través de un capítulo, artículo o código, una instrucción claramente definida que reglamente la prohibición del abuso de poder, es decir, el ejercicio exagerado de las atribuciones que tiene el personal que ejerce directrices en el campo de trabajo. En este espacio se debe hacer hincapié en casos de hostigamiento o acoso sexual. Todo tipo de abuso de poder debe ser penalizado por ley.

3 Se deberá crear y normar la existencia de instancias para realizar denuncias sobre casos de abuso de poder. Una buena opción son las organizaciones laborales.

\section{Estándar I.5: $\mathrm{Al}$ menos 80 por ciento del personal siente que la dirección o gerencia de la institución/establecimiento de salud es receptiva a sus opiniones y sugerencias}

\section{?)}

¿A qué nos referimos?

E ste estándar debe entenderse como la proporción del personal en una institución

que declara sentir que sus opiniones o sugerencias son escuchadas por el personal de "dirección o gerencia" y son tomadas en cuenta para la toma de decisiones.

El significado de la participación en una organización se encuentra determinado por el contexto en el que se origina y con el que es congruente, es decir, la coherencia de la participación del personal con las políticas y normas institucionales de bienestar, las 
cuales se inspiran en la planificación y garantizan su eficacia mediante alguna forma de participación del personal.

Las instituciones $\mathrm{u}$ organizaciones que trabajan a la luz de este modelo, es decir, que se "inspiran" en las opiniones y sugerencias del personal, mejoran sus prácticas organizacionales. En este sentido, su trabajo se encuentra enmarcado en la cultura de calidad total, ya que se tiene el convencimiento de que toda institución debe modernizar su gestión incrementando su capacidad para transformarse en un organismo receptivo a las demandas de su personal, particularmente para mejorar la calidad de su relación con ellos.

La dirección o gerencia debe mantener canales de comunicación abiertos para informar, promover, estimular y dar a conocer sus planes, objetivos y acciones a su personal. Asimismo, debe utilizar esos canales de comunicación para conocer, informarse y ponderar las opiniones y sugerencias de su personal.

\section{¿Qué hacemos para cumplir con este estándar?}

(1) Cada determinado tiempo la institución debe realizar sondeos de opinión al personal para conocer sus percepciones sobre diversos temas inherentes al desempeño laboral.

2 En reuniones mensuales o semanales de personal, se debe permitir un tiempo para conocer las sugerencias y opiniones de los(as) empleados(as).

(3) En reuniones mensuales o semanales de personal, se debe informar cuáles sugerencias fueron adoptadas y cuáles no, explicando las razones. organización. 


\section{Estándar I.6: \\ $\mathrm{Al}$ menos 80 por ciento del personal siente que se ponen en práctica sus recomendaciones o sugerencias}

L ¿A qué nos referimos?

a contribución del personal en términos de opiniones y sugerencias para superar crisis de derechos humanos, políticas o prácticas es fundamental para el éxito en la conducción de una organización o institución que incluya la satisfacción del personal.

Investigaciones recientes sobre la práctica de los derechos humanos en organizaciones no gubernamentales han demostrado que el éxito en el desempeño de varias de ellas se basa en la puesta en práctica de las recomendaciones que el personal de base sugiere a la dirección o gerencia. Las conclusiones de estos estudios señalan que para seguir avanzando en esa dirección es necesario que se mantenga una relación estrecha con el sentir y el pensar del personal, principalmente del de base.

\section{¿Qué hacemos para cumplir con este estándar?}

(1) Debe crearse un comité con personal de dirección, gerencia y de base que asuma con decisión y prontitud el cumplimiento de las recomendaciones realizadas por el personal y adopte mecanismos adicionales para asegurar que las decisiones produzcan frutos.

(2) Este comité deberá hacer sondeos específicos sobre opiniones respecto a lo que no esté funcionando en la organización, utilizando un formulario para registrar las condiciones que deban mejorarse y, especialmente, las recomendaciones correspondientes.

(3) Por otra parte, el comité deberá verificar que las recomendaciones del personal hayan sido puestas en práctica e insistir en aquellas que aún no hayan sido cumplidas o estén pendientes.

(4) El punto de partida para el éxito de un comité es el trabajo en armonía, caracterizado por una participación activa, responsable y constructiva, que busque las mejores soluciones preventivas para la realidad de la organización. 


\section{Estándar I.7: \\ $\mathrm{Al}$ menos 80 por ciento del personal se siente motivado(a) para dar opiniones y sugerencias}

?

¿A qué nos referimos?

a motivación es un impulso que permite mantener una cierta continuidad en aquellas acciones que nos acerquen al logro de un objetivo que, una vez logrado, saciará una necesidad o una carencia. La intensidad y duración de dicho impulso están condicionadas por diversos factores, entre ellos, los sentimientos que genere el proceso, es decir, si además de satisfacer la necesidad se obtiene un resultado positivo (éxito, reconocimiento, etc.), ello reforzará aún más la conducta de repetir dicha práctica.

Un personal motivado dentro una organización es aquel que siente una serie de procesos que lo estimulan a tener una conducta manifiesta para beneficio propio y de la institución.

El personal motivado a comunicar sus intereses es aquel que ha combinado deseos y energías para alcanzar algo. Esta motivación se mantendrá en la institución fundamentalmente si el nivel gerencial ha sido eficiente en poner en práctica un buen porcentaje de las opiniones y sugerencias emanadas desde el personal de los diferentes niveles, especialmente del personal de base.

El(la) supervisor(a) puede ser una fuerza motivacional para el personal; puede ayudar a realizar las tareas de manera responsable y eficiente y puede inspirar al personal a buscar objetivos más ambiciosos, aunque no tenga el poder de motivarlos mediante incentivos financieros. Es posible utilizar cierto número de incentivos no financieros tales como:

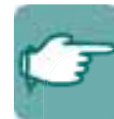

- hacer que la dirección apoye y apruebe el buen desempeño;

- reconocer públicamente a los empleados que tengan un buen desempeño;

- inculcar en los trabajadores la creencia sobre el valor de su trabajo;

- proporcionar a los empleados oportunidades de usar su inteligencia para resolver problemas;

- ofrecer oportunidades al trabajador para asumir más responsabilidades y liderazgo, $\mathrm{y}$

- otorgar medios para el desarrollo y mejoramiento individual. 


\section{¿Qué hacemos para cumplir con este estándar?}

(1) La dirección de la organización debe contemplar dentro sus funciones crear un ambiente propicio para motivar al personal a manifestar sus inquietudes (e.g. realizar reuniones mensuales con todo el personal, donde se expongan los éxitos, avances y dificultades que atraviesa la organización como tal y solicitar opiniones al respecto y sugerencias para avanzar).

(2) En reuniones mensuales o semanales del personal se debe informar sobre cuáles sugerencias fueron adoptadas y cuáles no, explicando las razones.

(3) Dar apoyo y reconocimiento regularmente y, en lo posible, en público.

(4) Dar explicaciones y exaltar el valor del trabajo de las y los empleados.

(5) Suministrar al personal símbolos de la importancia y naturaleza oficial de sus trabajos por medio de uniformes, sombreros, prendedores, bolsas con el logo del programa, anuncios para sus casas, diplomas de cursos de entrenamiento, premios, etc.

6 Prestar atención inmediata a los obstáculos que enfrenta el personal en su trabajo y que están fuera de su control.

(7) Durante las reuniones de supervisión o visita, centrarse en lo detalles del trabajo de la persona (comunicar estos detalles es importante).

8 Buscar la opinión del personal en todos los asuntos que se relacionen con su trabajo. Esto incluye preguntarles sus puntos de vista sobre los problemas que enfrentan y sus sugerencias para posibles soluciones.

(9) Sugerir oportunidades para el desarrollo.

(10) Proporcionar medios para la capacitación y la actualización de habilidades, particularmente si esto incluye viajes. 


\section{Estándar I.8: $\mathrm{Al}$ menos 80 por ciento del personal siente que la institución/establecimiento de salud tiene un ambiente de trabajo colectivo y de equipo}

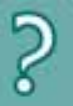

¿A qué nos referimos?

E ste estándar debe entenderse como la proporción del personal que declara sentir, que la institución le proporciona un conjunto de condiciones favorables para su desempeño laboral. Estas condiciones tienen que ver con el ambiente físico, económico y principalmente con la interacción que se tiene con el personal de dirección o gerencia y el resto del personal con quienes esté vinculado para el desarrollo de sus funciones.

El tema de trabajo colectivo y en equipo se refiere al desempeño de funciones armónico, democrático y justo dentro del ambiente laboral. Este tema en las organizaciones debe trabajarse de forma estratégica cuando se trata del personal.

El trabajo en equipo y colectivo es como una actividad lúdica, que tiene la propiedad de proporcionar satisfacciones emocionales, espirituales y económicas.

El trabajo colectivo y en equipo en una institución con carácter publico debe considerarse relevante, ya que permite rescatar valores que han sido motor del humanismo (solidaridad, justicia social, participación, democracia, etc.) Por lo tanto, en una organización debe tratarse con empeño el tema de los valores y principios institucionales, que repercuten en el surgimiento de soluciones a los problemas personales de los trabajadores que, en muchos casos, entorpecen el espíritu de cooperación en la realización del desempeño laboral.

El éxito o fracaso de un equipo de trabajo, no sólo depende de sus integrantes. La cultura organizacional, el estilo de liderazgo y los sistemas retributivos -renumeración y reconocimiento-, también influyen en la construcción de un equipo de alto desempeño para un trabajo colectivo exitoso. 
¿Qué hacemos para cumplir con este estándar?

(1) Para que exista un sentimiento de trabajo colectivo y de equipo en el personal de la organización, sus documentos institucionales deben contemplar ciertas normas que establezcan que:

- Periódicamente, el personal directivo, en reuniones con el resto del personal, debe explicar metas, tareas, responsabilidades y acuerdos con el equipo de trabajo, en directa concordancia con los principios y valores de la institución.

- El personal directivo debe crear un clima adecuado para que el resto del personal se sienta bien y asuma confianza. El personal directivo debe fomentar el dialogo.

2 Periódicamente, el personal directivo debe revisar la forma de trabajo y los sistemas de trabajo, fomentar la iniciativa del personal y revisar que todos trabajan con la misma visión.

\section{Estándar 1.9:}

\section{Al menos 80 por ciento del personal siente que la institución/ establecimiento de salud es receptiva a explicaciones para dejar el trabajo cuando se requiere por razones familiares}

?

¿A qué nos referimos?

El permiso por motivos personales graves es parte de las políticas institucionales de personal y es importante, desde el punto de vista del enfoque de género, porque ayuda a las mujeres y a los hombres a compaginar su vida familiar y laboral.

En el marco de los derechos humanos, en muchos países, la legislación laboral ha dejado establecido que el personal que trabaja en instituciones privadas o estatales tiene derecho a disfrutar de permiso por asuntos personales, cuando una enfermedad o un accidente de un miembro de su familia exigen su presencia inmediata. La legislación de estos países establece qué requisitos deben cumplirse para ejercer este derecho, así 
como el número de horas autorizadas al año y las circunstancias en las que puede obtenerse este permiso.

A la luz de esta legislación, el personal de dirección o gerencial debe responder de forma inmediata a la solicitud de las personas que necesiten salir del ámbito laboral para resolver problemas, sin recibir amonestación, retención económica o alguna otra compensación a cambio.

\section{¿Qué hacemos para cumplir con este estándar?}

(1) En el marco de las políticas de tratamiento al personal de la institución, el personal de dirección o gerencial debe comprender todo conflicto que atraviese el personal a su cargo y apoyar en la resolución de los mismos, en concordancia con políticas institucionales que compaginen la vida familiar y laboral de su personal.

\section{Estándar I.10: Menos de 20 por ciento del personal siente que en la institución/establecimiento de salud se le da un trato preferencial a un sexo en particular}

\section{()}

¿A qué nos referimos?

E n una organización o institución laboral, los tratos preferenciales a hombres o mujeres

L se practican cuando se denominan de manera diferente trabajos que son fundamentalmente iguales y cuya retribución debe ser la misma. Por ejemplo, una coordinadora de proyecto y un jefe de operaciones de un proyecto, que efectúan tareas idénticas para la misma institución u organización y que disponen de las mismas calificaciones y experiencia, deben recibir la misma retribución. Si existen diferencias salariales, no se respeta el derecho a una retribución igual y entonces se observa que el personal de dirección o gerencial está dando un trato preferencial a un determinado sexo.

Cualquier trabajador(a) tiene derecho a beneficiarse del principio de igualdad de trato en el lugar de trabajo, lo que significa que no puede discriminársele por razones de sexo. 
Discriminar significa diferenciar, distinguir, separar una cosa de otra. La discriminación es una situación en la que una persona, hombre o mujer, es tratada de forma desfavorable a causa de prejuicios, en este caso, por pertenecer a un sexo en particular, recibe un trato diferenciado.

\section{¿Qué hacemos para cumplir con este estándar?}

(1) Cualquier miembro del personal tiene derecho a beneficiarse del principio de igualdad de trato en el lugar de trabajo, lo que significa que no puede discriminársele por razones de sexo.

(2) Crear un ambiente de trabajo de confianza que permita al personal comunicar a la dirección o gerencia sus inquietudes con relación a sus percepciones de tratos preferenciales.

\section{Estándar I.11: Al menos 50 por ciento de las consultas de salud sexual y reproductiva se ofrecen a parejas}

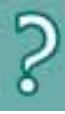

¿A qué nos referimos?

E ste estándar debe entenderse como la proporción de parejas (hombre-mujer) que consultan sobre su salud sexual y reproductiva en forma conjunta, no en forma separada.

En los establecimientos de salud se fomenta la prestación de servicios de salud sexual y reproductiva a parejas (hombre-mujer), ya que hombres y mujeres tienen patrones distintos de comportamiento y reproducción sexual y cada patrón se particulariza en cada persona de manera única, por lo que, al interior de la sociedad en la que se desenvuelven estas parejas, su comportamiento tiene una repercusión social importante.

Por lo tanto, llevar el control a nivel de registro, de toda consulta en pareja es importante para las entidades que dirigen y coadyuvan a los cambios sociales. 


\section{¿Qué hacemos para cumplir con este estándar?}

(1) Todo servicio referido a salud sexual y reproductiva (orientación, anticoncepción, atención prenatal, parto, posparto y cuidados inmediatos y durante el primer mes del recién nacido) deben tener un registro especial, independientemente de los registros de prestación de servicios a hombres o mujeres.

(2) El registro especial debe permitir realizar un conteo de visitas realizadas por mujeres solas, hombres solos, y parejas.

\section{Estándar I.12: \\ Existe una declaración que establece como procedimiento rutinario ofrecer servicios de orientación}

\section{(2)}

¿A qué nos referimos?

a orientación es una parte vital de los servicios de salud reproductiva y planificación - familiar, la cual permite a las personas hacer una elección libre e informada a partir de las opciones anticonceptivas, usar el método en forma segura y eficaz y reducir las tasas de abandono del método elegido.

Una buena orientación se concentra en las necesidades y la situación de la persona y los buenos orientadores están dispuestos a escuchar y resolver preguntas e inquietudes. Al informar de las alternativas anticonceptivas, se debe referir a todos los métodos disponibles. Los(as) proveedores(as) de servicios deben ser conscientes de una serie de factores relacionados con los usuarios que podrían ser importantes, dependiendo del método en cuestión. Ellos incluyen:

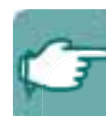

- las metas de la mujer, el hombre o la pareja respecto a la reproducción (el espaciamiento o limitación para los nacimientos);

- las características del método: reversibilidad, efectos secundarios a corto y largo plazo, accesibilidad, costos, beneficios y limitaciones;

- la necesidad de protección contra candidiasis, vaginosis e infecciones de transmisión sexual (ITS) y VIH/SIDA;

- las creencias y costumbres y la calidad de las relaciones de pareja, y

- el efecto del método con relación al placer o satisfacción sexual. 


\section{¿Qué hacemos para cumplir con este estándar?}

(1) Todo documento institucional (reglamento de trabajo, reglamento interno, normas y manuales institucionales, protocolos, etc.) debe ajustarse al formato que indique o recomiende la instancia rectora del trabajo del Estado (e.g. Ministerio del Trabajo), para que sea aprobado y tenga vigencia legal y debe identificarse por capítulos, artículos, códigos, etc. (e.g. Capítulo I, Artículo XXII, Código IV).

(2) En algún documento institucional debe establecerse, a través de un capítulo, artículo o código, una instrucción claramente definida que reglamente que se deben brindar servicios de orientación como un procedimiento rutinario a todos los clientes del establecimiento de salud.

(3) La información y la orientación deben provenir de diferentes fuentes, para lo cual todo el personal debe tener los conocimientos básicos necesarios sobre los métodos anticonceptivos disponibles, siendo su responsabilidad mantener dichos conocimientos actualizados y homogéneos.

\section{Estándar I.13: \\ No existen servicios para los que se requiera el consentimiento de la pareja}

\section{?)} ¿A qué nos referimos?

C uando se habla de la existencia de servicios que requieren el consentimiento de la pareja, se refiere generalmente a aquellos servicios que implican una cirugía. Tomando en cuenta que toda cirugía tiene un margen de riesgo, en algunos casos los servicios de salud requieren que tanto el hombre como la mujer corran el riesgo y autoricen oficialmente la realización de la intervención quirúrgica.

En otros casos, especialmente en el campo de la salud sexual y reproductiva, algunos servicios de salud requieren el consentimiento de la pareja de la mujer para realizar la esterilización femenina u otros procedimientos relacionados con la fertilidad de la 
mujer. Estos requerimientos representan barreras para que la mujer tome decisiones libremente sobre sus deseos de tener más hijos o de no tenerlos.

Ningún establecimiento de salud debe requerir el consentimiento de la pareja, sea hombre o mujer, para ofrecer servicios de salud sexual y reproductiva. Las decisiones las debe tomar la persona que requirió el servicio, previo ofrecimiento de toda la información necesaria para realizar esta decisión.

\section{¿Qué hacemos para cumplir con este estándar?}

(1) Informar a todos y todas las clientes que requieran algún servicio de salud sobre las alternativas de procedimientos que se ofrecen en el establecimiento de salud, para que puedan tomar una decisión informada y libre de presiones.

(2) No requerir ningún consentimiento, ni escrito ni verbal, de la pareja de la persona que solicita el servicio o procedimiento, cualquiera que éste sea.

No se debe confundir la autorización que todo establecimiento de salud requiere para realizar procedimientos quirúrgicos, con el permiso de la pareja que algunos establecimientos de salud requieren particularmente para servicios de salud sexual y reproductiva.

\section{Estándar I.14: \\ Existe una gama de métodos de anticoncepción de acuerdo a las normas establecidas por el establecimiento de salud}

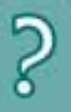

\section{¿A qué nos referimos?}

Esto significa que la institución cuenta con varios tipos de métodos anticonceptivos

- para ofrecer, de acuerdo a sus normas establecidas. Por ejemplo, en algunas instituciones de salud está normada sólo la oferta de métodos naturales; en otras, sólo los de uso externo y no los que incluyen cirugía. 
En la actualidad existen varios métodos anticonceptivos. Para determinar cuál necesita el(la) cliente, debe tomarse en cuenta el desarrollo físico y emocional de la persona, si tiene una pareja estable o no, lo que piensa acerca del uso de los mismos y por qué decidió usar el método que eligió.

Los métodos anticonceptivos más conocidos son condón masculino, condón femenino, diafragma, espermicidas, DIU (dispositivo intrauterino), inyectables como la Depoprovera, píldora anticonceptiva, esterilización femenina, esterilización masculina, método del ritmo y método de la amenorrea de la lactancia (MELA).

\section{¿Qué hacemos para cumplir con este estándar?}

(1) No deben faltar, en ningún momento y por ninguna circunstancia, los métodos anticonceptivos establecidos por la institución para ser ofrecidos a las y los usuarios de los establecimientos de salud.

(2) Asegurarse que las normas del establecimiento de salud respondan a la demanda de métodos de anticoncepción de la población. 



\section{Prácticas de los(as) proveedores(as)}

\section{Estándar II.1: \\ Al menos 80 por ciento de proveedores(as) saludan a los(as) clientes}

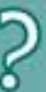

¿A qué nos referimos?

A 1 prestar servicios con enfoque de género, el(la) proveedor(a) debe hacer énfasis en las destrezas de comunicación interpersonal que posee. Un saludo cálido y cortés permanecerá en la memoria del(la) cliente mucho tiempo después de la consulta.

El siguiente es un ejemplo de saludo: "Buenos días María, tome asiento por favor". Esta simple oración de bienvenida y una cálida y honesta sonrisa, permitirán crear un ambiente de confianza dentro del consultorio.

\section{¿Qué hacemos para cumplir con este estándar?}

(1) Proveer periódicamente refuerzos de capacitación al personal de salud sobre habilidades de comunicación con el fin de crear un ambiente armónico dentro de los consultorios o salas de orientación.

(2) Observar al personal de salud en su interacción con los(as) usuarios(as). 


\section{Estándar II.2: \\ $\mathrm{Al}$ menos 80 por ciento de proveedores(as) portan una insignia de identificación visible}

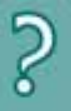

¿A qué nos referimos?

os(as) proveedores(as) de servicios de salud, portan una tarjeta en un lugar - visible, con su nombre y cargo dentro el establecimiento de salud.

Esta tarjeta identifica y distingue al personal que pertenece al establecimiento o institución de salud de personas ajenas o extrañas, por razones de seguridad y para facilitarle al(la) usuario(a) reconocer rápidamente al personal para resolver cualquier situación.

\section{¿Qué hacemos para cumplir con este estándar?}

(1) Observar al personal del establecimiento de salud para verificar el uso de insignias de identificación.

(2) Las insignias de identificación deben contener el nombre del(la) portador(a) y el cargo que desempeña dentro del establecimiento.

(3) Se debe poder leer la información de la insignia a la distancia normal de conversación entre dos personas.

(4) Esta identificación puede estar colgada del cuello o prendida en la ropa en un lugar visible. 


\section{Estándar II.3: \\ $\mathrm{Al}$ menos 80 por ciento de proveedores(as) se refieren a los(as) clientes respetuosamente}

\section{(2)}

¿A qué nos referimos?

El trato respetuoso a las y los usuarios de los establecimientos de salud es parte de la Calidad de la atención y se centra en un trato serio, responsable y amable, tomando en cuenta la condición racial, lenguaje, extracción de clase, edad, sexo, etc.

Por lo tanto, un trato respetuoso debe ser igual para todas las personas que requieran servicios de salud.

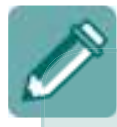

\section{¿Qué hacemos para cumplir con este estándar?}

(1) Todo el personal en un establecimiento de salud que interactúe con las y los usuarios debe ofrecer un trato amable, ser educado, servicial y estar atento a los requerimientos de las y los usuarios, ya sean de salud, de comodidad o de información.

\section{Estándar II.4: \\ $\mathrm{Al}$ menos 80 por ciento de proveedores(as) exploran temas de salud sexual y reproductiva en las consultas/sesiones de orientación}

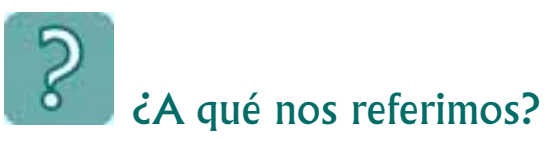

That os(as) proveedores(as) deben orientar a las y los usuarios sobre otros temas de su salud sexual y reproductiva, aparte de la anticoncepción.

Conforme a las recomendaciones del Programa de Acción de la Conferencia Internacional sobre Población y Desarrollo, a los servicios de orientación en anticoncepción deben integrarse otros servicios de salud sexual y reproductiva. 
Además de la anticoncepción, los servicios integrados de orientación deben abordar el VIH/SIDA y otras ITS, infecciones y cánceres del sistema reproductivo, infertilidad, atención ginecológica y de maternidad, atención postaborto, violencia basada en el género y educación sobre la sexualidad y crianza de los hijos.

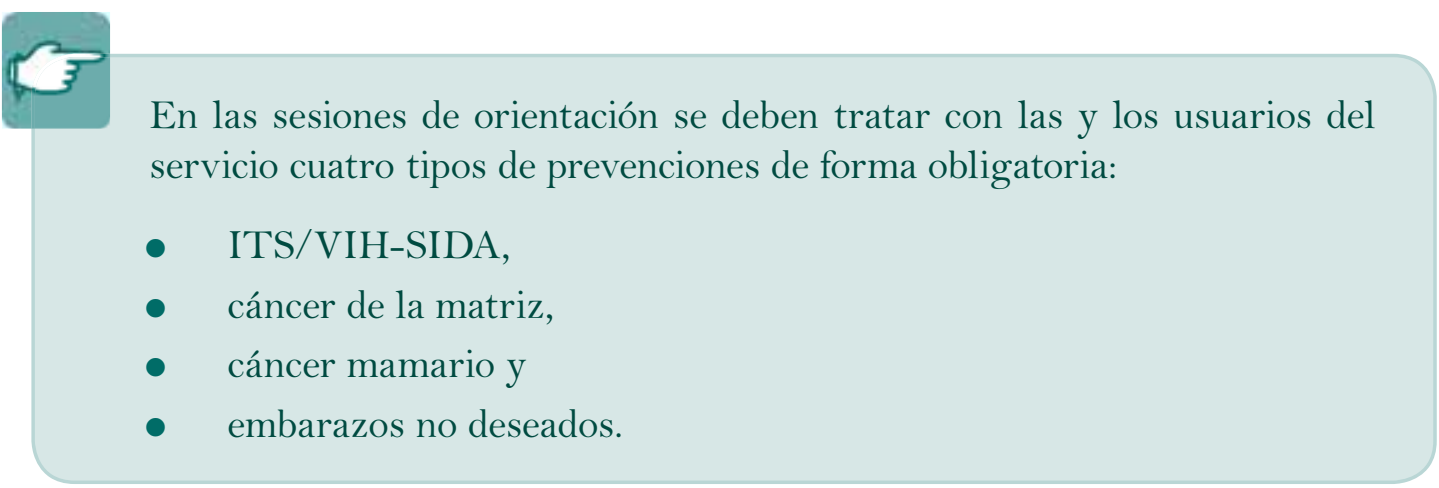

Por ITS se debe entender el grupo de infecciones que se transmiten por contacto sexual. Se contagian de persona a persona a través del contacto de una membrana mucosa afectada con otra membrana mucosa sana o a través de secreciones y una herida en la piel. El riesgo de contraer una de estas infecciones, incluyendo VIH/SIDA, crece en el momento en que se asumen comportamientos de riesgo o no se utiliza un método preventivo como el condón, que es el único anticonceptivo que previene las ITS. El no conocer la historia sexual de la persona con la que se mantiene una relación sexual es otro riesgo que se previene con el uso del preservativo o condón, siempre que haya un contacto vaginal, anal u oral.

El cáncer de la matriz es un tumor maligno de origen viral (Por el virus del papiloma) que se genera en el cuello del útero y que consiste en el desarrollo de abundantes células anormales de crecimiento desordenado. En sus inicios, el cáncer no produce dolor o señal alguna de su presencia. La única forma de descubrir el cáncer cérvico-uterino es a través del examen de Papanicolaou y la biopsia cervical, por lo que es importante hacerlo cada año durante dos años consecutivos y, en caso de dar ambos resultados negativos, se debe hacer cada tres años, preferentemente después de trece días de iniciado el período menstrual.

El cáncer mamario es un tumor maligno que aparece en cualquier parte de la glándula mamaria (pechos, senos) por alteraciones celulares en el tejido. Si el cáncer se detecta antes de que se haya extendido, la posibilidad de curarlo es de 100\%. Este tipo de cáncer se previene a través del autoexamen mamario, aunque con este tipo de examen los tumores son difíciles de detectar en $40 \%$ de quienes tienen senos densos y fibrosos, razón por la cual se debe recurrir a otras técnicas como mamografía digital, ultrasonido e imágenes de resonancia magnética.

Respecto a los embarazos no deseados, se debe tomar en cuenta que la sexualidad y la reproducción son dos cosas distintas. Durante toda la vida se tiene sexualidad (capacidad 
de relacionarse con otras personas y generar placer mutuo basado en el respeto, autonomía y decisión individual), pero sólo se es fértil (se puede tener hijos) durante un período de tiempo (en la mujer aproximadamente desde los 11 hasta los 50 años). La anticoncepción (utilización de métodos anticonceptivos) permite decidir cuantos hijos y en que momento se quieren tener. A pesar de ello, y por falta de información, existen todavía muchos embarazos no deseados. Para reducir estos casos, la anticoncepción y una buena orientación son indispensables.

Si en cada prestación de servicios se trabaja con la difusión de estos conceptos, entonces se crean nuevas oportunidades, tanto para mejorar la calidad de las prestaciones, como para mejorar la calidad de vida de la población usuaria.

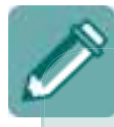

\section{¿Qué hacemos para cumplir con este estándar?}

(1) El(la) proveedor(a) debe abordar en consulta o sesión de orientación temas relacionados con la salud sexual y reproductiva. Estos temas incluyen prevención de ITS/VIH, prevención de cáncer de matriz, prevención de cáncer de senos, prevención de embarazo no deseado, incluyendo las características de los métodos de anticoncepción.

(2) Observar al(la) proveedor(a) de servicios de salud para verificar que ofrece información sobre temas de salud sexual y reproductiva.

\section{Estándar II.5: \\ $\mathrm{Al}$ menos 80 por ciento de proveedores(as) exploran aspectos relacionados con la salud sexual del(la) cliente en las consultas/sesiones de orientación}

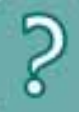

¿A qué nos referimos?

En la década pasada hubo un cambio en el contenido y formato de lo que incluye la L prestación de servicios de salud sexual y reproductiva. Hasta mediados de los años 90, el énfasis de la consulta de orientación se había puesto en proveer información sobre la anticoncepción. 
Posteriormente y hasta la fecha, los currículos se han enfocado cada vez más en las habilidades de comunicación interpersonal en la relación cliente-proveedor para lograr un nivel de confianza que apoye el esfuerzo sistemático para identificar no sólo problemas de anticoncepción sino también problemas en la vida sexual de las y los clientes, todo esto con el fin de mejorar su calidad de vida.

Los problemas relacionados con la salud sexual de las y los clientes tienen que ver, entre otros, con la satisfacción sexual, el abuso o maltrato en las relaciones sexuales, la participación de la pareja para evitar embarazos no deseados y la negociación del uso del condón con la pareja.

Por satisfacción sexual se entiende la acción o modo con que se sosiega y se responde enteramente a las necesidades sexuales en forma voluntaria; la insatisfacción es lo contrario. Cuando este último sentimiento es latente en una usuaria, entonces se está incumpliendo el principio básico de lo que se entiende por salud sexual y reproductiva, es decir, el estado de bienestar físico, mental y social del ser humano, ya que la usuaria no está disfrutando de una vida sexual satisfactoria y placentera. En muchos de los casos, este sentimiento de insatisfacción tiene que ver con el abuso o maltrato en las relaciones sexuales. Esto debe entenderse como la utilización de la mujer (concubina, casada o pareja eventual) como objeto sexual y no sujeto. Generalmente este tipo de trato se da a una persona en condiciones de desventaja en relación con cualquier tipo de poder. El maltrato o abuso en las relaciones sexuales no debe entenderse sólo como la violación -es decir, ejercer sexo impuesto-, sino también los obstáculos, presiones y violencia hacia la utilización de anticoncepción y la poca garantía de tener sexo seguro en cuanto a la posible transmisión de ITS (VIH/SIDA). Estas dos cuestiones son puntos cruciales para el amor propio "machista” y, por eso mismo, vías privilegiadas para ejercer un control violento en las relaciones sexuales.

El evitar los embarazos no deseados es un derecho de la mujer, que ejerce o puede ejercerlo a través de la anticoncepción. Sin embargo, debe entenderse que el acuerdo marital o de convivencia implica goce y reciprocidad sexual, pero de ninguna manera constituye una obligación de conceder sexo o hijos. Por lo tanto, hombre y mujer en pareja deben planificar cuántos hijos tener y cuándo. De esta manera en pareja se participa en evitar los embarazos no deseados.

El diálogo en pareja sobre cuántos y cuándo tener descendencia y evitar ITS utiliza como base el uso de la anticoncepción. Específicamente, si además se desean evitar ITS, se habla del condón. La comunicación usada para tal fin es la negociación del uso del condón en pareja. 


\section{¿Qué hacemos para cumplir con este estándar?}

(1) En toda consulta o sesión de orientación el(la) proveedor(a) debe abordar el tema de la salud sexual del(la) usuario(a). Entre los temas más importantes se encuentran la satisfacción o insatisfacción sexual, el abuso o maltrato en las relaciones sexuales, la anticoncepción para evitar embarazos no deseados, y la negociación del uso de condón en pareja.

(2) Observar al(la) proveedor(a) de servicios de salud para verificar que ofrece al(la) cliente información sobre temas de salud sexual.

\section{Estándar II.6: Menos de 20 por ciento de proveedores(as) sienten que por barreras no se exploran temas de salud sexual y reproductiva}

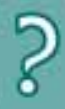

¿A qué nos referimos?

$\mathrm{G}_{\mathrm{s}}$ eneralmente las barreras que se presentan al tratar en profundidad temas de salud sexual y reproductiva tienen que ver con aspectos culturales, sociales y económicos. Por lo tanto, es necesario que el(la) proveedor(a) comprenda al(la) cliente como persona en su integridad. Los(as) proveedores(as) deben plantearse habitualmente que no sólo están tratando con problemas médicos sino también con individuos y que no deben sentirse incómodos(as) discutiendo situaciones personales de los(as) clientes.

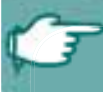

Las teorías para sobrepasar las barreras en la prestación de servicios en salud reproductiva indican que, los(as) proveedores(as) deben aprender a:

- ayudar a los(as) clientes a identificar sus metas reproductivas,

- responder a sus inquietudes y nociones equivocadas e

- indagar sobre temas delicados como las prácticas sexuales y la violencia y hacerlo sin hacer sentir incómodo(a) al(la) cliente. 


\section{¿Qué hacemos para cumplir con este estándar?}

(1) En toda organización prestadora de servicios de salud, los currículos de capacitación deben incluir el desarrollo de habilidades de comunicación que sirvan a los proveedores y proveedoras para averiguar y satisfacer las necesidades de los(as) clientes.

(2) $\mathrm{El}(\mathrm{la})$ proveedor(a) debe comprender de qué forma sus valores influyen en sus prácticas, para contrarrestar sus propios prejuicios, perseverar en interacciones difíciles o embarazosas con clientes y considerar las dificultades o barreras como un desafío más que una limitación.

$3 \mathrm{El}(\mathrm{la})$ proveedor(a) debe explorar sus valores y sentimientos personales, lo cual contribuye a desarrollar su habilidad para conectarse con los(as) clientes y que éstos(as) le confíen rápidamente sus necesidades e inquietudes. Ello requiere tener autoconciencia y empatía, es decir, debe comprender el origen de sus propios sentimientos y, al mismo tiempo, experimentar y apreciar los sentimientos de los clientes.

(4) Observar al(la) proveedor(a) de servicios de salud para verificar que ofrece información a las y los clientes sobre temas de salud sexual y reproductiva sin ninguna barrera.

\section{Estándar II.7: $\mathrm{Al}$ menos 80 por ciento de proveedores(as) usan material didáctico para reforzar sus explicaciones en las consultas/sesiones de orientación}

E ste estándar se refiere al uso de rotafolios, afiches, trípticos, volantes, etc., por parte _de los(as) proveedores(as) como apoyo en su función de proporcionar información durante las consultas o sesiones de orientación. 


\section{¿Qué hacemos para cumplir con este estándar?}

(1) Todo personal proveedor de servicios de salud sexual y reproductiva debe utilizar material de apoyo apropiado para facilitar su explicación durante las sesiones de consulta u orientación.

(2) Observar al(la) proveedor(a) de servicios de salud para verificar que se le ofrece al(la) cliente información con el apoyo de material ilustrativo.

\section{Estándar II.8: \\ $\mathrm{Al}$ menos 80 por ciento de proveedores(as) se comunican con el(la) cliente utilizando un lenguaje sencillo en consultas/sesiones de orientación}

\section{8}

¿A qué nos referimos?

El lenguaje sencillo es aquel modo de comunicarse con otras personas utilizando términos comunes al medio. En las prestaciones de servicios de salud, este tipo de lenguaje es un elemento de éxito.

Muchos organismos o instituciones de salud, económicas, industriales han optado por utilizar un lenguaje sencillo para el logro de sus objetivos; esto quiere decir que utilizan un lenguaje comprensible y sin tecnicismos.

\section{¿Qué hacemos para cumplir con este estándar?}

(1) $\mathrm{El}(\mathrm{la})$ proveedor(a) debe utilizar un lenguaje comprensible y sin tecnicismos médicos.

(2) El(la) proveedor(a) debe conocer y practicar un lenguaje de acuerdo con la extracción de clase del(la) usuario(a), es decir, de acuerdo a la etnia a la que pertenece, a su condición socioeconómica, etc.

(3) Observar al(la) proveedor(a) de servicios de salud para verificar que utiliza un lenguaje fácil de entender al ofrecer información a las y los clientes. 


\section{Estándar II.9: \\ $\mathrm{Al}$ menos 80 por ciento de proveedores(as) explican al(la) cliente los detalles del diagnóstico en las consultas/sesiones de orientación}

\section{(5)}

¿A qué nos referimos?

os(as) proveedores(as) explican detalladamente la naturaleza del problema que aqueja al(la) usuario(a) en un lenguaje sencillo y compresible. De esta manera, el(la) cliente entenderá el origen de su padecimiento, cómo contrajo la enfermedad, y posiblemente podrá determinar cómo evitar contraerla nuevamente en el futuro.

\section{8}

¿Qué hacemos para cumplir con este estándar?

(1) El(la) proveedor(a) debe:

- explicar detalladamente la naturaleza del padecimiento del(la) cliente;

- explicar el origen, cómo se contrae la enfermedad y cómo evitar contraerla, y

- usar un lenguaje sencillo y comprensible, sin tecnicismos médicos.

(2) Observar al(la) proveedor(a) de servicios de salud para verificar que ofrece a los(as) clientes información sobre la naturaleza de sus enfermedades o padecimientos.

\section{Estándar II.10: \\ $\mathrm{Al}$ menos 80 por ciento de proveedores(as) \\ explican al(la) cliente los detalles del tratamiento en las consultas/sesiones de orientación}

¿A qué nos referimos?

E 1 tratamiento es un conjunto de medios que se pueden emplear o se emplean para

Cdar solución, curar o aliviar un problema de salud. 
La explicación detallada del tratamiento en lenguaje sencillo y compresible permitirá que el(la) cliente lleve a cabo los procedimientos necesarios para aliviar su padecimiento exitosamente.

\section{¿Qué hacemos para cumplir con este estándar?}

(1) $\mathrm{El}(\mathrm{la})$ proveedor(a) debe:

- explicar detalladamente el tratamiento a seguir para aliviar o curar el padecimiento del(la) cliente;

- explicar todas las alternativas para completar con el tratamiento exitosamente, $\mathrm{y}$

- usar un lenguaje sencillo y comprensible, sin tecnicismos médicos.

(2) Observar al(la) proveedor(a) de servicios de salud para verificar que ofrece a las y los clientes información detallada sobre los tratamientos.

\section{Estándar II.11: \\ Al menos 80 por ciento de proveedores(as) miran directamente al(la) cliente mientras explican el diagnóstico o el tratamiento en las consultas/ sesiones de orientación}

\section{8}

¿A qué nos referimos?

$\mathrm{M}$

irar directamente a los ojos es un estándar de seguridad, confianza, y respeto. Una persona que mira a los ojos mientras habla demuestra seguridad en lo que dice, pues no necesita ocultar nada. Esto a su vez inspira confianza en el(la) cliente.

Una persona que mira a los ojos mientras escucha demuestra respeto, pues esto comunica que se está prestando atención a lo que se dice y a lo que se hace con los gestos. 


\section{¿Qué hacemos para cumplir con este estándar?}

(1) El(la) proveedor(a) debe mirar directamente a los ojos mientras habla o escucha a las y los clientes.

(2) El(la) proveedor(a) no debe realizar otras actividades mientras habla o escucha a las y los clientes.

(3) Observar al(la) proveedor(a) de servicios de salud para verificar que mira directamente a los ojos las y los clientes mientras habla o escucha.

\section{Estándar II.12: \\ $\mathrm{Al}$ menos 80 por ciento de proveedores(as) preguntan al(la) cliente si tiene preguntas o dudas en las consultas/sesiones de orientación}

\section{?)}

¿A qué nos referimos?

$M$ uchas veces las y los clientes no hacen preguntas por timidez o vergüenza. Esto es peligroso, pues puede resultar en efectos negativos en el tratamiento o el(la) cliente puede tomar decisiones erróneas.

$\mathrm{El}(\mathrm{la})$ proveedor(a) debe indagar si el(la) cliente tiene dudas o preguntas. El objetivo es verificar que el(la) cliente haya comprendido todas las indicaciones y explicaciones realizadas durante la consulta o sesión de orientación.

\section{¿Qué hacemos para cumplir con este estándar?}

(1) $\mathrm{El}(\mathrm{la})$ proveedor(a) debe preguntar al(la) cliente si tiene alguna pregunta o duda.

(2) El(la) proveedor(a) no debe asegurarse que el(la) cliente sale de su consultorio satisfecho(a) por haber conseguido lo que fue a buscar.

(3) Observar al(la) proveedor(a) de servicios de salud para verificar que indaga acerca de posibles dudas o preguntas por parte de las y los clientes. 


\section{Estándar II.13:}

\section{Al menos 80 por ciento de proveedores(as) responden a las preguntas o aclaran dudas del(la) cliente en las consultas/sesiones de orientación}

?

¿A qué nos referimos?

D esponder significa contestar, poner en claro, hacer perceptible, explicar, satisfacer una duda. Por lo tanto, ofrecer servicios de salud con calidad implica responder a todas las preguntas (dudas) que las y los clientes tengan respecto a su salud.

Las respuestas que el(a)la proveedor(a) da las y los clientes deben ser detalladas y con un lenguaje sencillo y compresible. Un(a) cliente que sale de consulta sin dudas, es probablemente un(a) usuario(a) satisfecho(a).

\section{¿Qué hacemos para cumplir con este estándar?}

(1) $\mathrm{El}(\mathrm{la})$ proveedor(a) debe responder todas las preguntas o dudas de los(as) clientes.

(2) Las respuestas deben contener un lenguaje sencillo y comprensible.

3 Observar al(la) proveedor(a) de servicios de salud para verificar que responde a todas las preguntas de las y los clientes.

\section{Estándar II.14: \\ Al menos 80 por ciento de proveedores(as) explican qué es lo que hacen durante la auscultación o el examen pélvico}

\section{()}

¿A qué nos referimos?

Dara determinar el diagnóstico, muchas veces el(la) proveedor(a) debe realizar una auscultación al(la) cliente y esto conlleva tocar al(la) cliente en 
diferentes partes del cuerpo. Estas acciones pueden ser mal interpretadas o rechazadas.

Para evitar el rechazo a la auscultación, el(la) proveedor(a) debe explicar lo que hace paso a paso y por qué realiza determinadas acciones. De esta forma, el(la) cliente sentirá más confianza en las acciones del(la) proveedor(a).

Otro procedimiento físico, e invasor, es el examen pélvico. Este procedimiento consiste en la inspección de los órganos sexuales de la mujer. Por medio de este examen se puede determinar el estado hormonal en una mujer que no está embarazada, el estado de situación del embarazo en una que si lo está, una malformación o tumoración en el útero o anexos, si existe algún componente de riesgo inmediato como un embarazo ectópico, identificar el tipo de hemorragia sanguínea y percibir el olor de los flujos para ver si pertenecen a ciertas patologías.

El examen pélvico es generalmente incómodo y crea susceptibilidad en las mujeres, por lo que el(la) proveedor(a) debe explicar qué está haciendo y por qué, para tranquilizar y dar seguridad a la usuaria.

\section{¿Qué hacemos para cumplir con este estándar?}

(1) El(la) proveedor(a) debe explicar claramente los pasos de todos los procedimiento físicos, como la auscultación y el examen pélvico.

(2) El(la) proveedor(a) no debe esperar a que el(la) cliente pregunte qué le están haciendo. Muchas veces la actitud y los gestos manifiestan incomodidad, dolor e incertidumbre.

(3) Observar al(la) proveedor(a) de servicios de salud para verificar que ofrece al(la) cliente información detallada sobre el procedimiento físico que se está realizando. 


\section{Estándar II.15: \\ Al menos 80 por ciento de proveedores(as) proporcionan al(la) cliente materiales educativos \\ de refuerzo}

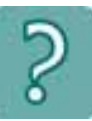

¿A qué nos referimos?

Como material de información se debe entender aquel material generalmente trabajado en papel de cualquier calidad que contiene literatura de información, comunicación, educación y capacitación sobre temas de salud. Su presentación puede ser en forma de folleto, tríptico, díptico, panfleto, etc. Su lectura debe ser fácil de comprender y debe estar en lo posible acompañada de diagramas, dibujos y fotografías.

Este material trabajado didácticamente es una herramienta que utilizan los(as) proveedores(as) de servicios de salud para ampliar sus explicaciones y mejorar la comunicación con el(la) cliente. El(la) cliente puede conservar este material para compartirlo con amigos, vecinos, familiares, etc., o para usarlo como futura referencia.

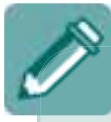

\section{¿Qué hacemos para cumplir con este estándar?}

(1) $\mathrm{El}(\mathrm{la})$ proveedor(a) debe proporcionar material de refuerzo que contenga información que oriente, aporte conocimientos y de respuesta a dudas que tenga el(la) cliente respecto a su salud.

(2) El(la) proveedor(a) no debe esperar a que el(la) cliente pida este material; su entrega debe ser espontánea y, en lo posible, debe estar disponible en lugares visibles del establecimiento de salud y dentro del consultorio o sala de orientación para que el(la) cliente tome un ejemplar libremente.

(3) Observar al(la) proveedor(a) de servicios de salud para verificar que entrega material a los(as) clientes. 


\section{Estándar II.16: \\ Menos de 20 por ciento de proveedores(as) dicen que existe un tiempo de espera de más de media hora entre el tiempo de llegada del personal de salud al establecimiento de salud y el momento en que inicia la atención a clientes}

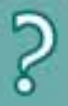

¿A qué nos referimos?

L 1 tiempo de espera es un factor que provoca molestia e incomodidad en los(as) clientes _de los establecimientos de salud. Según las normas nacionales e internacionales, se ha establecido que la prestación de servicios del personal de salud, debe iniciarse inmediatamente al arribo al establecimiento de salud.

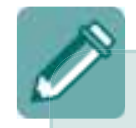

¿Qué hacemos para cumplir con este estándar?

(1) Crear mecanismos para evaluar el cumplimiento de horarios de ingreso del personal prestador de servicios y el inicio de sus actividades.

(2) El(la) proveedor(a) debe iniciar las prestaciones de servicio en el menor tiempo posible después de haber ingresado al establecimiento de salud.

(3) Observar al(la) proveedor(a) de servicios de salud para verificar que atiende a los(as) clientes inmediatamente después de arribar al establecimiento de salud.

\section{Estándar II.17: \\ Menos de 20 por ciento de clientes dicen haber esperado más de media hora para ser atendidos}

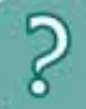

¿A qué nos referimos?

En un concepto integral de calidad de atención con perspectiva de género, el poco

L tiempo de espera para la atención, es sinónimo de satisfacción del(la) cliente. Este es un factor que coadyuva con las coberturas de atención de prestaciones de servicios, pues a menor tiempo de espera mayor asistencia de la población usuaria. 
Según varios estudios relacionados con la satisfacción de los(as) clientes de programas de salud, el tiempo promedio en sala de espera que los(as) clientes pueden asumir con satisfacción es de media hora. Sin embargo, también se ha observado, que el(la) cliente puede esperar más cuando sabe que el(la) proveedor(a) está trabajando eficientemente.

En este mismo sentido, se presentan casos adversos, es decir, cuando el(la) cliente observa que el prestador de servicios está utilizando su tiempo en otras actividades, pierde la paciencia y su disponibilidad se reduce a un menor tiempo, donde 15 minutos se convierten en un tiempo largo y prolongado.

¿Qué hacemos para cumplir con este estándar?

(1) Crear mecanismos para evaluar el cumplimiento de horarios para la prestación de servicios.

(2) El(la) proveedor(a) debe iniciar las prestaciones de servicios en estricto cumplimiento con los horarios establecidos.

(3) Observar al(la) proveedor(a) de servicios de salud para verificar que el tiempo de espera de los(las) clientes es de menos a media hora.

\section{Estándar II.18: \\ Al menos 80 por ciento del personal identifica los servicios de salud sexual y reproductiva que ofrece el establecimiento de salud}

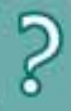

¿A qué nos referimos?

os servicios de salud sexual y reproductiva son aquellos que orientan y proveen atención en anticoncepción, atención prenatal, parto, atención postnatal, amenorrea, lactancia, ITS (VIH/SIDA), infecciones y cánceres del sistema reproductivo, infertilidad, atención ginecológica y de maternidad, atención postaborto; orientación en violencia basada en el género y derechos de la población usuaria; educación sobre la sexualidad y crianza de los hijos, los cuidados sobre el embarazo, parto y postparto y los cuidados del recién nacido. 
¿Cuáles servicios de salud sexual y reproductiva ofrece su establecimiento de salud? Todo el personal debe saberlo.

\section{¿Qué hacemos para cumplir con este estándar?}

(1) Todo el personal de servicios de salud debe conocer los servicios que se prestan en el establecimiento, especialmente los servicios de salud sexual y reproductiva.

(2) Realizar reuniones informativas periódicas con todo el personal del establecimiento de salud para uniformar los conocimientos sobre los servicios de salud sexual y reproductiva que se ofrecen.

\section{Estándar II.19: $\mathrm{Al}$ menos 80 por ciento de proveedores(as) dedican todo su tiempo al(la) cliente sin interrupciones durante las consultas/servicios de orientación}

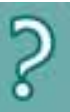

¿A qué nos referimos?

as interrupciones se refieren a interferencias en la prestación del servicio, como —el ingreso de otra persona al consultorio o sala de orientación, sea ésta personal del establecimiento de salud u otra persona ajena al establecimiento, llamadas telefónicas, etc.

¿Qué hacemos para cumplir con este estándar?

(1) El(la) proveedor(a) no debe permitir interrupciones durante las consultas o sesiones de orientación. 
(2) El(la) proveedor(a) debe realizar actividades ajenas a la consulta particular en otros horarios.

(3) Observar al(la) proveedor(a) de servicios de salud para verificar que no existen interrupciones durante las consultas o sesiones de orientación.

4 Crear mecanismos de comunicación para evitar interrupciones. Por ejemplo, poner canastillos en las puertas de los consultorios con el fin de dejar en ellos cualquier mensaje al(la) proveedor(a).

\section{Estándar II.20: \\ $\mathrm{Al}$ menos 80 por ciento del personal conoce $\mathrm{y}$ promueve el uso del método de doble protección}

\section{8)}

¿A qué nos referimos?

El método de doble protección se refiere al uso del condón y de otro método anticonceptivo, asegurando una doble protección: prevenir una infección de transmisión sexual, incluido el VIH/SIDA, y evitar un embarazo no deseado.

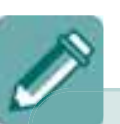

\section{¿Qué hacemos para cumplir con este estándar?}

(1) $\mathrm{El}(\mathrm{la})$ proveedor(a) debe promover el uso del método de doble protección, informando de este modo cómo evitar al mismo tiempo embarazos no deseados e infecciones de transmisión sexual, incluido el VIH/SIDA.

(2) El(la) proveedor(a) debe explicar con un lenguaje sencillo este método y cómo funciona.

(3) Observar al(la) proveedor(a) de servicios de salud para verificar que promueve el método de doble protección. 


\section{Estándar II.21: \\ Al menos 80 por ciento del personal conoce y promueve el examen de Papanicolaou}

子

¿A qué nos referimos?

$\mathrm{T}$

odo personal prestador de servicios de salud debe estar bien capacitado sobre qué es el examen de Papanicolaou, también conocido como la "prueba Pap", examen citológico o citología vaginal, para poder explicar a las y los clientes con naturalidad y en palabras sencillas qué significan todos éstos conceptos.

El examen de Papanicolaou (prueba Pap, examen citológico o citología vaginal) consiste en examinar células recolectadas del cuello uterino y la vagina, para determinar la presencia de infección, inflamación, células anormales o cáncer. Es un examen que el personal de salud realiza para saber si la matriz y el útero de la mujer están sanos.

Todas las mujeres de 25 a 49 años deben hacerse este examen. Primero deben hacerlo consecutivamente dos años y, si salen ambos negativos, pueden hacerse cada tres años (aunque las normas nacionales pueden variar entre países respecto a las edades y frecuencias).

En términos de las recomendaciones del Programa de acción de la Conferencia internacional sobre población y desarrollo (1994), los servicios de orientación integrados deben abordar el tema del cáncer en el sistema reproductivo, es decir, deben promover en la población usuaria -hombres y mujeres- el concepto del cáncer cérvico-uterino y deben motivar la forma de cómo prevenirlo.

\section{¿Qué hacemos para cumplir con este estándar?}

(1) Todo el personal prestador de servicios de salud sexual y reproductiva debe saber qué es el examen de Papanicolaou, para qué sirve, a quienes se les debe practicar, y con qué frecuencia.

(2) Todo el personal prestador de servicios de salud sexual y reproductiva debe promover el examen del Papanicolaou en las consultas o sesiones de orientación.

(3) Los resultados de los exámenes deben ser entregados sin demora a la cliente. 


\section{Estándar II.22: \\ Al menos 80 por ciento del personal conoce $y$ promueve el auto-examen de senos}

\section{(2)}

¿A qué nos referimos?

El auto-examen de senos es la inspección manual del seno o de la mama para notar cualquier cambio de contorno o textura. La inspección manual del seno se realiza con o sin espejo, de pie o recostada, realizando movimientos específicos para buscar protuberancias o engrosamientos inusuales.

Todas las mujeres mayores de 20 años se deben realizar mensualmente un autoexamen de mamas para verificar la presencia de nódulos u otros cambios. Deben hacerlo en lo posible cada mes antes, durante y después del periodo menstrual. Sin embargo, el auto-examen tiene limitantes y no es un sustituto de los exámenes realizados por el médico regularmente ni de las mamografías.

En términos de las recomendaciones del Programa de acción de la Conferencia internacional sobre población y desarrollo (1994), los servicios de orientación integrados deben abordar el tema del cáncer en el sistema reproductivo.

Para lograr este objetivo, el personal prestador de servicios debe estar bien capacitado al respecto; debe saber explicar con naturalidad y en palabras sencillas qué significan todos estos conceptos.

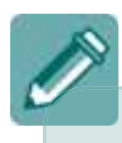

¿Qué hacemos para cumplir con este estándar?

(1) Todo el personal prestador de servicios de salud sexual y reproductiva debe conocer qué es un auto-examen de mama, para qué sirve, cómo se realiza, quién debe hacérselo y con qué frecuencia.

(2) Todo el personal prestador de servicios de salud sexual y reproductiva debe promover el auto-examen de mama.

(3) Observar al(la) proveedor(a) de servicios de salud para verificar que promueve el auto-examen de senos. 



\section{Conocimiento de los(as) proveedores(as)/ personal}

\section{Estándar III.1: \\ $\mathrm{Al}$ menos 80 por ciento del personal conoce la definición de la salud sexual y reproductiva}

\section{?}

¿A qué nos referimos?

a salud sexual y reproductiva es un estado general de bienestar físico, mental y —social y no de mera ausencia de enfermedades o dolencias en todos los aspectos relacionados con el sistema reproductivo, sus funciones y procesos. En un establecimiento de prestación de servicios de salud es elemental que todo el personal conozca esta definición.

La salud reproductiva entraña la capacidad de disfrutar de una vida sexual satisfactoria y sin riesgos y de procrear con la libertad de decidir si hacerlo o no hacerlo, cuándo y con qué frecuencia.

Esta última condición lleva implícito el derecho del hombre y la mujer a:

- obtener información sobre anticoncepción;

- elegir métodos legalmente establecidos;

- tener acceso a métodos seguros, eficaces, asequibles y aceptables, y

- recibir servicios de salud adecuados que permitan embarazos y partos sin riesgos y den a las parejas las máximas posibilidades de tener hijos sanos. 


\section{¿Qué hacemos para cumplir con este estándar?}

(1) Todo el personal proveedor de servicios de orientación y salud sexual y reproductiva debe conocer la definición de salud sexual y reproductiva.

(2) Es establecimiento de salud debe velar porque su personal tenga reflexiones periódicas sobre la terminología sobre salud sexual y reproductiva para mejorar sus competencias y la prestación de servicios.

\section{Estándar III.2: \\ $\mathrm{Al}$ menos 80 por ciento del personal conoce los métodos anticonceptivos disponibles en el establecimiento de salud} odas las mujeres y los hombres deberían tener el control sobre si desean procrear y el número y la frecuencia con que desean tener hijos(as). No es fácil tomar decisiones acerca del control de la natalidad o la contracepción; hay muchas cosas en qué pensar. No existe un método anticonceptivo "mejor." Cada método tiene sus propias ventajas y desventajas. Algunos métodos funcionan mejor que otros para evitar el embarazo. Los investigadores trabajan continuamente para desarrollar o mejorar los métodos anticonceptivos.

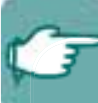

Para elegir un método, se deberá tomar en cuenta:

- la salud general,

- la frecuencia con la que se sostienen relaciones sexuales,

- el número de parejas sexuales,

- el deseo de tener hijos,

- la eficacia de cada método para evitar el embarazo,

- los efectos secundarios y

- la comodidad para usar un método. 
Ningún método anticonceptivo es completamente seguro. Sin embargo, se puede incrementar considerablemente la probabilidad de éxito de un método si se usa siempre correctamente. La mayoría de los anticonceptivos no protegen contra el VIH/SIDA u otras infecciones de transmisión sexual (ITS) como la gonorrea, el herpes y la clamidia. Además de la abstinencia (no tener relaciones sexuales), la mejor protección contra las ITS y el VIH/SIDA es el condón (preservativo) masculino de látex. El condón femenino podría brindar cierta protección contra las ITS. Otros métodos anticonceptivos que utilizan un espermicida (una crema o jalea que mata el esperma) también podrían ofrecer cierta protección contra la clamidia y gonorrea.

A continuación se encuentra una lista de algunos métodos anticonceptivos, incluyendo una evaluación de la eficacia de los mismos y qué tan bien funcionan para evitar el embarazo, si se utilizan correctamente:

Abstinencia. Esto significa no tener relaciones sexuales nunca. Es la
única forma segura de prevenir el embarazo. Este método es $100 \%$ eficaz en
la prevención del embarazo.
menstruales regulares tiene aproximadamente nueve o más días fértiles o
días en los que puede quedar embarazada cada mes. Abstinencia periódica
significa no tener relaciones sexuales en los días en los que la mujer podría
ser fértil. El método de conocimiento del período de fertilidad implica que
durante los días fértiles la mujer/pareja se abstiene de tener relaciones
sexuales o que tiene relaciones sexuales utilizando un método anticonceptivo
de "barrera" para evitar que el esperma llegue al óvulo. Entre los métodos
de barrera se encuentra el condón y el diafragma o capuchón cervical y se
usan junto con espermicidas para matar el esperma. Estos métodos tienen
una eficacia del 75 al 99\% en la prevención del embarazo. Para practicar
este método, se necesita aprender acerca del ciclo menstrual (o la frecuencia
de los periodos.) La mujer debe tomar nota de la fecha de su periodo, de
sus características (flujo abundante o ligero) y de cómo se siente (dolor en
los senos, cólicos). También se puede examinar el moco uterino y tomar la
temperatura elemental corporal diariamente y registrar esta información en
una tabla. De esta forma se aprende a pronosticar, o señalar, cuáles son los
días fértiles o "inseguros".
El condón (preservativo) masculino. Los condones se denominan
métodos anticonceptivos de barrera porque bloquean o ponen una barrera,
lo cual evita que el esperma llegue al óvulo. Se ha comprobado que sólo los


condones de látex o poliuretano (debido a que algunas personas son alérgicas al látex) ayudan a proteger contra las ITS, incluyendo el VIH/SIDA. También están disponibles condones "naturales" o de "corderina" (lambskin). Sin embargo, no se recomiendan los condones de corderina para la prevención de las ITS porque tienen poros muy pequeños y podrían permitir el paso de virus como el VIH, la hepatitis y el herpes. El condón masculino tiene una eficacia del 86 al 98\% en la prevención del embarazo. El condón sólo puede utilizarse una vez. Se pueden comprar en farmacias.

- Anticonceptivos orales. También conocidos como la "píldora", contienen hormonas de estrógeno y progestina. La mujer debe tomar una píldora diariamente para evitar que los ovarios liberen óvulos. También hacen que el flujo del periodo sea más ligero y protegen contra enfermedades pélvicas inflamatorias (EPI), cáncer de ovario y del endometrio. No protegen contra las ITS o el VIH/SIDA. La píldora puede incrementar el riesgo de desarrollar enfermedades cardiacas, incluyendo hipertensión sanguínea, coágulos de sangre y obstrucción de las arterias. En mujeres fumadoras, mayores de 35 años o con antecedentes de coágulos de sangre o cáncer de seno o endometrio, puede no ser recomendable tomar la píldora. Si se usa correctamente, la píldora tiene una eficacia del 95 al 99.9\% en la prevención del embarazo.

- La mini-píldora. A diferencia de la píldora, la mini-píldora sólo contiene una hormona, la progestina. La mujer debe tomarla diariamente. Reduce y adelgaza el moco uterino para evitar que el esperma llegue al óvulo. También evita que el óvulo fertilizado se implante en el útero (matriz.) La mini-píldora también disminuye el flujo del periodo y protege contra la EPI y el cáncer de ovario y del endometrio. Pueden usarla las madres que amamantan porque no afecta el suministro de leche. También es una buena opción para las mujeres que no pueden tomar estrógeno o que tienen un riesgo de desarrollar coágulos de sangre. No protege contra las ITS o el VIH/SIDA. La mini-píldora tiene una eficacia del 95 al $99.9 \%$ en la prevención del embarazo, si se usa correctamente.

- DIU o T de cobre (dispositivo intrauterino). Un DIU es un pequeño dispositivo que tiene la forma de una “T." El médico lo coloca dentro del útero. El DIU libera una pequeña cantidad de hormonas que evitan el embarazo. Las extremidades del DIU contienen cierta cantidad de cobre, el cual detiene la fertilización al evitar que el esperma se abra paso por el útero y llegue a las trompas de Falopio. Si ocurriera la fertilización, el DIU evitaría que el óvulo fertilizado se implante en el revestimiento del útero. El DIU puede permanecer en el útero hasta por 10 años. No protege contra las ITS o el VIH/SIDA. El 
DIU es 99\% eficaz en la prevención del embarazo. Es necesario que un médico lo coloque y se asegure que la mujer no está teniendo problemas.

- El condón femenino. Este método de barrera evita que el esperma se introduzca al cuerpo de la mujer. Está hecho de poliuretano, viene lubricado y puede proteger contra las ITS, incluyendo el VIH/SIDA. Puede insertarse hasta 8 horas antes del contacto sexual. Los condones femeninos tienen una eficacia del 79 al 95\% en la prevención del embarazo. Puede comprarse en farmacias.

- Depo-Provera. Al usar este método las mujeres reciben inyecciones de la hormona progestina en los glúteos o el brazo cada 3 meses. No protege contra las ITS o el VIH/SIDA. Tiene una eficacia del 99.7\% en la prevención del embarazo. Será necesario que un médico se asegure que la mujer no está teniendo problemas.

- Diafragma o capuchón cervical. Estos son métodos anticonceptivos de barrera en los que se bloquea al esperma para evitar que llegue al óvulo. El diafragma tiene la forma de una taza poco profunda y es de látex. El capuchón cervical es una tasa de látex con forma de dedal. Ambos vienen en tamaños diferentes y es necesario que un(a) proveedor(a) de servicios de salud ayude a la usuaria a encontrar el "tamaño" adecuado. se deben colocar en el interior de la vagina para cubrir el cuello del útero (la abertura) antes del contacto sexual y se pueden combinar con un espermicida en gel o espuma. Si el espermicida contiene nonoxinol-9 también ayudará a proteger contra las ITS como la gonorrea y clamidia. Algunas mujeres pueden tener sensibilidad al nonoxynol-9 y necesitarán usar espermicidas que no lo contengan. El diafragma tiene una eficacia del 80 al $94 \%$ en la prevención del embarazo. El capuchón cervical tiene una efectividad del $80 \%$ al 90\% en la prevención del embarazo en mujeres que no han tenido hijos y del $60 \%$ al $80 \%$ en mujeres que sí los han tenido.

- Esterilización quirúrgica (ligadura de trompas o vasectomía). Estos métodos quirúrgicos son para personas que desean un método anticonceptivo permanente. En otras palabras, personas que no desean tener hijos(as) o no quieren tener más hijos(as). La ligadura de trompas o "atado de trompas" se practica en las mujeres para evitar que los óvulos bajen al útero, en donde pueden ser fertilizados. El hombre se somete a la vasectomía para evitar que el esperma llegue al pene; de este modo su eyaculación nunca contendrá esperma. Estos métodos tienen una eficacia del 99 al 99.5\% en la prevención del embarazo. 


\section{¿Qué hacemos para cumplir con este estándar?}

(1) Durante la orientación de métodos anticonceptivos, el(la) proveedor(a) debe tener el conocimiento de las características de todos los métodos anticonceptivos que se ofrecen de acuerdo a la norma interna del establecimiento de salud.

(2) El establecimiento de salud debe ofrecer frecuentes sesiones de actualización de información (reciclaje) al personal sobre los métodos de anticoncepción disponibles en el establecimiento de salud.

\section{Estándar III.3: \\ $\mathrm{Al}$ menos 80 por ciento del personal conoce la definición de género}

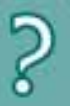

¿A qué nos referimos?

uestra comprensión de lo que significa ser una muchacha o un muchacho, una mujer o un hombre, evoluciona durante el curso de la vida; no hemos nacido sabiendo lo que se espera de nuestro sexo, lo hemos aprendido en nuestra familia y en nuestra comunidad. Por tanto, esos significados variarán de acuerdo con la cultura, la comunidad, la familia y las relaciones, y con cada generación y en el curso del tiempo.

El género en sentido amplio es "lo que significa ser hombre o mujer y cómo define este hecho las oportunidades, los papeles, las responsabilidades y las relaciones de una persona”. Mientras que el sexo es biológico, el género está definido socialmente.

En esta instancia, cuando se habla de SEXO se hace referencia a las diferencias biológicas entre el hombre y la mujer. Estas diferencias son congénitas y universales; esto significa que hombres y mujeres nacen con determinadas características físicas y anatómicas que los distinguen entre sí. Estas diferencias son visibles: las mujeres tienen vagina y los hombres tienen pene. Otras diferencias aparecen cuando niños y niñas 
crecen: las mujeres tienen senos y los hombres desarrollan características anatómicas diferentes, y posteriormente también aparecen otras como el embarazo en las mujeres.

Cuando se habla de GENERO, se hace referencia al modo en que cada sociedad entiende lo que significa "ser mujer" o "ser hombre", señalando cómo debe comportarse cada cual y cuál debe ser la relación entre "hombres y mujeres", entre "mujeres y mujeres" y entre "hombres y hombres". A este tipo de entendimiento se lo denomina construcción social, porque sobre la base de las diferencias sexuales de origen natural entre hombre y mujer, se construyen pautas, valores y normas, que es lo que hace a una cultura. Siempre que se hable de género, debe entenderse que se está hablando de las relaciones entre hombres y mujeres, ya que no se puede entender a unos sin las otras, ni viceversa.

¿Qué hacemos para cumplir con este estándar?

(1) Todo el personal de la institución o establecimiento de salud (directores, gerentes, coordinadores, jefes de área, personal de salud, personal administrativo, personal de mensajería, portería, etc.), debe conocer la definición de género, pues sólo de esta manera podrá además aplicarlo en sus actividades diarias tanto con clientes externos (clientes del establecimiento), como con clientes internos (personal del establecimiento).

(2) El establecimiento de salud debe ofrecer frecuentes sesiones de actualización de información (reciclaje) al personal sobre temas relacionados con género. 



\section{Comodidad del(la) cliente}

\section{Estándar IV.1: \\ Menos del 20 por ciento de los(as) clientes manifiestan dificultades relacionadas al género para acudir al servicio}

?)

\section{¿A qué nos referimos?}

as dificultades relacionadas con el género tienen que ver con aspectos de la vida familiar

o laboral; por tanto, las dificultades relacionadas con el género son aquellas que resultan de las relaciones de poder entre hombres y mujeres (parejas, jefes/empleadas(os), etc.).

Ejemplos de las dificultades que las mujeres atraviesan con mayor frecuencia son no tener con quién dejar a los hijos pequeños mientras van a consulta, el reclamo de la pareja por su ausencia en la casa cuando van a consulta, etc.

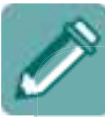

\section{¿Qué hacemos para cumplir con este estándar?}

(1) Todo el personal proveedor de servicios debe tener en cuenta que algunas mujeres para asistir a su prestación de servicio atraviesan problemas relacionados con el género, por lo que su prestación de servicios debe ser respetuosa con estos conflictos y debe tratar de apoyarlas para mejorar su autoestima.

(2) Todo el personal proveedor de servicios de salud sexual y reproductiva debe promover el conocimiento y práctica de los derechos de las mujeres relacionados con su salud:

- derecho a ser apoyadas para que puedan gozar de la mejor salud posible,

- respeto a las diferencias y a la opinión,

- acceso a los servicios y

- trato respetuoso. 


\section{Estándar IV.2: \\ Existen recursos para atender y entretener a los(as) menores que acompañan a los(as) clientes en el servicio de salud}

\section{?}

\section{¿A qué nos referimos?}

E ste estándar se refiere a la existencia de elementos que sean útiles para entretener a Clos hijos e hijas de usuarias(os) de los establecimientos de salud, mientras esperan o reciben un servicio de salud.

Se ha observado que muchos(as) clientes(as) llevan consigo a sus hijos(as) pequeños(as) a los establecimientos de salud por falta de un lugar seguro donde dejarlos(as). Éste es un factor que distrae al(la) cliente durante la consulta y muchas veces impide que realice todas las preguntas que quisiera.

En la ausencia de un espacio dedicado al cuidado de menores dentro del establecimiento de salud, se puede contar con juguetes, libros, juegos, etc., que no necesitan ser sofisticados y que sirvan de entretenimiento al(la) menor durante la espera y durante la consulta.

\section{¿Qué hacemos para cumplir con este estándar?}

(1) El establecimiento de salud debe asegurar la existencia de elementos y recursos para atender y entretener a los(as) niños(as), que acompañan al(la) cliente.

(2) Ejemplos son "rincones infantiles", ubicados en salas de espera, delimitados por barandas y dotados de juguetes seguros, resistentes y económicos. Estos juguetes pueden encontrarse también en los consultorios y salas de orientación. 


\section{Satisfacción del(la) cliente}

\section{Estándar V.1: \\ Existen mecanismos para conocer las opiniones de las(los) clientes sobre el horario y satisfacción del (la) cliente}

\section{(8)}

\section{¿A qué nos referimos?}

E stos mecanismos se refieren a las formas de recolectar información para conocer las

Copiniones de los(as) clientes acerca de los horarios de atención y de su satisfacción con los servicios de salud que reciben. Estos mecanismos se pueden aplicar a través de encuestas de satisfacción de clientes, sondeos o, más informalmente, a través de buzones de sugerencias.

Estos mecanismos de recolección de opiniones generalmente se realizan en salas de espera antes o después de que los(as) clientes reciban el servicio.

\section{¿Qué hacemos para cumplir con este estándar?}

(1) El establecimiento de salud debe realizar encuestas de satisfacción de clientes a la salida de las consultas.

(2) El establecimiento de salud debe realizar sondeos de opinión, con preguntas concretas, tales como:

- ¿Le parecen buenas las horas de atención de este establecimiento de salud?, ¿por qué?

- ¿Recibió un buen trato durante su visita a este establecimiento de salud?

(3) El establecimiento de salud debe colocar buzones de sugerencias, con papel y bolígrafo disponible en un lugar visible de la sala de espera o recepción. 


\section{Estándar V.2: \\ Las condiciones de limpieza y comodidad son satisfactorias}

\section{()}

\section{¿A qué nos referimos?}

as condiciones de limpieza de todos los ambientes del establecimiento (pasillos, sala —de espera, consultorios y baños limpios que cuenten con agua, jabón y papel) y la comodidad que brindan éstos (asientos suficientes para la espera, asientos cómodos, ambiente agradable, buena iluminación, etc.) son aspectos que pueden lograr un nivel importante de satisfacción en el(la) cliente.

En este marco, la satisfacción de las y los clientes tiene que ver con la necesidad de contar con un ambiente limpio y cómodo mientras esperan su turno para ser atendidos(as).

\section{¿Qué hacemos para cumplir con este estándar?}

(1) El establecimiento de salud debe mantener limpios todos los ambientes.

(2) El establecimiento de salud debe ofrecer condiciones cómodas de infraestructura para las y los clientes (asientos cómodos, asientos suficientes en la sala de espera para que ninguna persona espere de pie, buena iluminación, etc.).

3 Se debe establecer una rutina diaria de inspección de todos los ambientes, especialmente los baños, para asegurar que éstos se encuentren limpios.

\section{Estándar V.3: \\ El equipamiento se encuentra disponible y en buen estado}

\section{¿A qué nos referimos?}

Cegún sean sus usuarios y las funciones a desarrollar dentro del local o consultorio, éste deberá contar con el equipamiento adecuado para el(la) menor, la embarazada, el(la) anciano(a) o cualquier otro(a) paciente, según la especialidad médica. 
Existen elementos básicos que deben encontrarse en todo consultorio en funcionamiento y en buen estado:

- escritorio y armario para medicamentos,

- elementos de curación o instrumental,

- sillas para el(la) prestador(a) de servicios y el(la) o los(las) pacientes o grupo familiar,

- balanza, negatoscopio, lavamanos y camilla con luz para examen.

\section{¿Qué hacemos para cumplir con este estándar?}

(1) Se debe verificar la disponibilidad del equipamiento necesario en cada consultorio o sala de atención.

(2) Se debe verificar el estado y buen funcionamiento de todo el equipamiento.

\section{Estándar V.4: \\ Existen condiciones para asegurar la confidencialidad y la privacidad del(la) cliente}

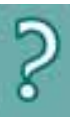

\section{¿A qué nos referimos?}

C uando se analiza el concepto sobre la existencia de condiciones para asegurar la confidencialidad y la privacidad de la(el) cliente en consulta, se refiere a que la infraestructura del establecimiento de salud debe cumplir con ciertos requisitos para que una consulta se desarrolle en forma privada. Este factor de privacidad contribuye a crear un ambiente de confidencialidad entre cliente y proveedor(a).

Para salvaguardar la privacidad del(la) cliente, los establecimientos de salud deben contar con consultorios o salas separadas de la sala de espera, las cuales deben tener puertas que se cierren y ventanas con vidrios y cortinas. Un ambiente privado procura la práctica de la confidencialidad, ésta es esencial en una consulta porque crea un ambiente de confianza y garantiza la seguridad. 
Crear un ambiente de confidencialidad también es prestar servicios sin la presencia de personas no autorizadas por el(la) cliente, como prestadores(as) de servicios que no estén directamente relacionados con el motivo de la consulta, personal administrativo, personas ajenas al establecimiento de salud, etc.

\section{¿Qué hacemos para cumplir con este estándar?}

(1) La infraestructura debe contar con consultorios separados de la sala de espera.

2 Estos consultorios deben tener puerta que se cierre y, de tener ventanas, éstas deben tener vidrios y cortinas.

3 No permitir el ingreso al consultorio o sala, de personas que no estén directamente relacionadas con el motivo de la consulta del(la) cliente.

(4) Asegurarse que no se puede escuchar o ver al(la) cliente desde fuera del consultorio o sala de orientación.

\section{Estándar V.5: Existen asientos suficientes disponibles para los(as) clientes en el área de espera}

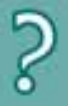

\section{¿A qué nos referimos?}

$\bigcup_{\mathrm{e}}^{\mathrm{n}}$ n motivo por el que los(as) clientes deciden no esperar su turno para ser atendidos es la falta de condiciones cómodas dentro del establecimiento de salud. La falta de asientos cómodos disponibles para las personas en la sala de espera es un aspecto determinante en la calidad de la atención del establecimiento.

Muchas personas deben usar varios tipos de medios de transporte para asistir a los centros de salud. El más común en las áreas rurales es la caminata. Al llegar al centro de salud, el(la) cliente espera poder encontrar un lugar lo suficientemente cómodo para descansar de la larga caminata. 


\section{¿Qué hacemos para cumplir con este estándar?}

(1) De acuerdo a estadísticas normales de flujo de usuarios(as), el establecimiento de salud debe equipar las salas de espera con un número suficiente de asientos, bancas o sillas.

(2) Los asientos deben ser lo suficientemente cómodos para preferirlos sobre la opción de permanecer parados.

3 De ser posible, contar con sillas plegables auxiliares para momentos eventuales de alto flujo de usuarios(as).

\section{Estándar V.6: \\ $\mathrm{Al}$ menos 80 por ciento de los(as) clientes se sienten cómodos(as) hablando con la persona que los(as) atendió en consulta}

?)

¿A qué nos referimos?

a comodidad tiene que ver con el carácter cultural y el clima en el que se desenvuelve la atención. Aspectos como la privacidad, confiabilidad, buena comunicación, lenguaje simple y buen trato, conforman en su conjunto el concepto construido de comodidad.

Un(a) cliente se siente cómodo(a) con el(la) proveedor(a), cuando se crea un ambiente que contiene todos los aspectos arriba mencionados.

\section{¿Qué hacemos para cumplir con este estándar?}

(1) Realizar sesiones frecuentes de actualización (reciclaje) con todo el personal del establecimiento de salud (incluyendo personal administrativo y de apoyo), sobre calidad de atención en el trato de los(as) clientes.

(2) Observar a los(as) proveedores(as) y personal del establecimiento en general, para verificar el buen trato ofrecido a los(as) clientes. 


\section{Estándar V.7: \\ $\mathrm{Al}$ menos 80 por ciento de los(as) clientes se sienten cómodos(as) para hacer preguntas y aclarar sus dudas con los(as) proveedores(as)}

\section{8}

¿A qué nos referimos?

a comodidad del(la) cliente tiene que ver con sentirse a gusto en la consulta. Una ¿de las quejas más comunes de los(as) clientes es la falta de tiempo para realizar más preguntas al(la) proveedor(a) de servicios de salud.

Lo que se pretende es que todo(a) cliente que sea atendido(a) pueda realizar durante la consulta todas las preguntas que desee sobre salud, sin temor a que no se le proporcione el tiempo necesario, o que se le responda de mala manera.

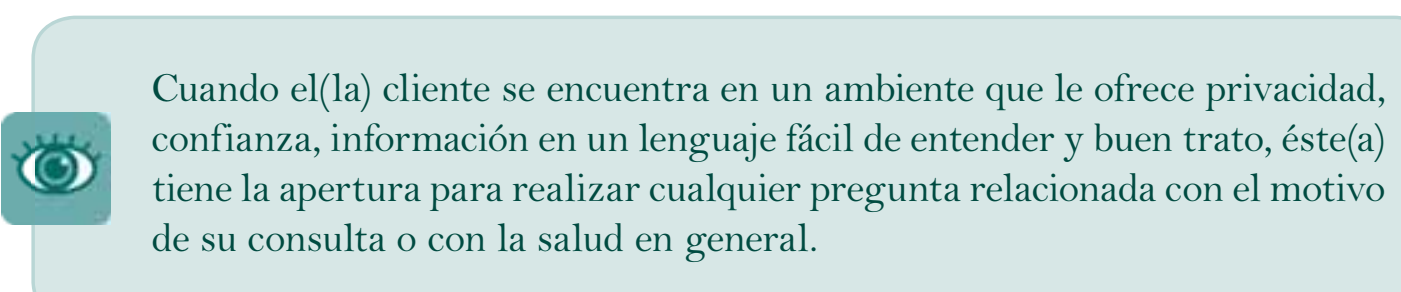

¿Qué hacemos para cumplir con este estándar?

(1) Realizar sesiones frecuentes de actualización (reciclaje) con el personal de salud del establecimiento de salud, sobre calidad de atención en el trato de clientes.

(2) Observar al(la) proveedor(a) de servicios de salud para verificar que proporciona al(la) cliente todo el tiempo necesario para aclarar sus dudas y preguntas. 


\section{Estándar V.8: \\ Al menos 80 por ciento de los(as) clientes consideran que el tiempo en consulta es suficiente}

\section{(8)}

¿A qué nos referimos?

El tiempo en una consulta de salud es un espacio de interacción entre cliente y proveedor(a), con el objetivo de indagar sobre los problemas de salud del(la) usuario(a) y de solucionarlos.

El tiempo determinado para realizar una consulta de salud sexual y reproductiva sugerido por la OPS/OMS es de 15 minutos por cliente. Sin embargo, este lapso de tiempo debe ser flexible para cumplir con las necesidades del(la) cliente.

\section{¿Qué hacemos para cumplir con este estándar?}

(1) Realizar sesiones frecuentes de actualización (reciclaje) con el personal de salud del establecimiento de salud, sobre calidad de atención en el manejo del contenido de la consulta u orientación.

(2) Observar al(la) proveedor(a) de servicios de salud para verificar que proporciona al(la) cliente toda la información necesaria y que el(la) cliente comprende todas las instrucciones.

(3) Observar al(la) proveedor(a) para verificar que proporciona al(la) cliente todo el tiempo necesario para aclarar sus dudas y preguntas.

\section{Estándar V.9: \\ $\mathrm{Al}$ menos 80 por ciento de los(as) clientes dicen haber recibido un buen trato del personal del establecimiento de salud}

\section{(2)}

¿A qué nos referimos?

El servicio al cliente constituye un medio poderoso que ayuda a gerentes y adminis- tradores(as) a identificar y centrar su atención en los servicios que las y los clientes desean y necesitan. Los servicios de salud, al igual que los negocios de tipo comercial, 
han descubierto que al ofrecer a sus clientes un trato cortés y servicios eficientes y de alta calidad, así como la oferta de servicios que los clientes desean, no solamente es beneficioso para los clientes sino también para los servicios de salud.

El buen servicio al cliente constituye un elemento crucial en los centros de salud. El concepto de servicio al cliente sostiene que al comprender y cubrir las necesidades de los(as) clientes y de los(as) clientes potenciales, un área de salud puede mejorar la calidad de sus servicios, aumentar la demanda de los mismos y mejorar su reputación.

El servicio al cliente es una filosofía que va más allá de la "capacidad de respuesta a las necesidades del(la) cliente" y el "enfoque del cliente”. El enfoque del cliente a menudo se incorpora solamente a los servicios de consejería y de tipo clínico. El servicio al cliente amplía dicho enfoque del cliente para que se incluya dentro de la clínica y en los alrededores de la misma, desde la forma en que el personal saluda, hasta el ambiente reinante en la sala de espera y la forma en la que se manejan las quejas de los(as) clientes. Se utiliza para ayudar a cada persona a beneficiarse, no solamente de los servicios inmediatos que vino a buscar, sino a nivel de toda la gama de servicios que ofrece el establecimiento de salud. Incluso puede llevar a la introducción de nuevos servicios para cubrir las necesidades expresadas por los(as) clientes.

El servicio al cliente significa proporcionar asistencia de tal forma que esto redunde en un mayor grado de satisfacción con la atención brindada. Se basa en la preocupación constante por las preferencias de los(as) clientes, tanto en el ámbito de la interacción con el personal como del diseño de servicios. Sostiene que el personal es responsable ante los(as) clientes por las decisiones que toma y que los(as) clientes tienen derechos que se deben respetar.

\section{¿Qué hacemos para cumplir con este estándar?}

(1) Se debe crear un ambiente acogedor para los(as) clientes.

(2) Se debe mantener un flujo continuo de clientes.

(3) Se deben proveer servicios personalizados.

(4) El personal del establecimiento de salud se debe comunicar con los clientes en forma efectiva y cortés.

(5) Se deben manejar las quejas de los(as) clientes en forma satisfactoria para $\operatorname{los}$ (as) mismos(as).

6 Se debe recopilar información sobre las preferencias de los(as) clientes con el fin de encarar sus preocupaciones. 


\section{Estándar V.10: \\ Al menos 80 por ciento de los(as) clientes fueron atendidos(as) por una persona del sexo de su preferencia}

\section{(8)}

\section{¿A qué nos referimos?}

xisten clientes que prefieren ser atendidos por proveedores hombres o por provee-

doras mujeres. En algunos casos esto depende del tipo de servicio que los(as) clientes requieren.

En el caso de servicios de salud sexual y reproductiva, como ginecología, obstetricia, planificación familiar, etc., las mujeres prefieren en muchos casos ser atendidas por proveedoras de salud mujeres. Los hombres probablemente preferirán ser atendidos por proveedores hombres. Esto sucede porque generalmente este tipo de servicios requiere de procedimientos físicos un tanto invasores como el examen pélvico, o requieren de entablar una conversación que toca temas muy íntimos o personales.

Existe otro tipo de servicios, como pediatría, odontología, ecografía, etc., en el que probablemente los(as) clientes no tienen ninguna preferencia respecto al sexo del(la) proveedor(a) que atenderá, pues en estos casos no es necesario entablar conversaciones sobre temas personales o no es necesario realizar procedimientos físicos.

Lo que se pretende es dar al(la) cliente una alternativa de elección del tipo de proveedor(a) que desea que lo(la) atienda. Si el(la) cliente prefiere una mujer, es deseable que existan especialistas mujeres; lo mismo en el caso de que exista una preferencia por proveedores hombres.

\section{¿Qué hacemos para cumplir con este estándar?}

(1) Se debe hacer una lista en la pizarra de recepción (o cartel de información), con los nombres de los(as) especialistas que atienden. De esta manera, los(as) clientes sabrán quiénes están disponibles para ofrecer el servicio.

(2) En recepción preguntar al(la) cliente quién le gustaría que lo(a) atienda.

3 De ser posible, procurar que el establecimiento de salud ofrezca servicios que tanto un proveedor hombre como una proveedora mujer puedan ofrecer. 


\section{Estándar V.11: \\ Al menos 80 por ciento de los(as) clientes consideran que el horario de atención se adapta a sus necesidades (relacionadas con género)}

\section{?}

¿A qué nos referimos?

U n horario de atención con base en necesidades de género se refiere a la prestación de servicios que ofrece un establecimiento de salud en horarios que no coincidan con los horarios de trabajo o de quehaceres del hogar del(la) cliente.

Es posible que para llegar al establecimiento de salud, el(la) cliente necesite dejar sus obligaciones en el trabajo o en el hogar, creando de esta forma potenciales conflictos con jefes o parejas.

Un horario de atención con base en necesidades de género supone una oferta de servicios de salud en horarios extendidos incluyendo horas al mediodía, a partir de las siete de la noche, fines de semana y feriados.

\section{¿Qué hacemos para cumplir con este estándar?}

(1) El establecimiento de salud debe ofrecer servicios, tanto especializados como de consulta general, en horarios que no coincidan con horarios de trabajo u horarios del quehacer doméstico. Lo ideal sería que el establecimiento de salud ofreciera servicio las 24 horas al día, 365 días del año.

(2) Se debe realizar un sondeo de opinión entre los(as) clientes para conocer mejor sus ocupaciones y de esta manera adecuar los horarios del establecimiento de salud a estas rutinas. 


\section{Uso del lenguaje de género}

\section{Estándar VI.1: \\ Se usa lenguaje no discriminatorio}

\section{?)}

\section{¿A qué nos referimos?}

E ste estándar se refiere a los estereotipos basados en el género. Ejemplos de lenguaje discriminatorio son las referencias a mujeres como dóciles, débiles o sin fuerza. Otras imágenes incluyen a los hombres como violentos, irresponsables, controladores o tomadores de las decisiones.

Por el contrario, el lenguaje no discriminatorio podría incluir referencias a las mujeres con control sobre sus decisiones; mujeres en posiciones de liderazgo; imágenes de doctoras mujeres; hombres que comparten los quehaceres del hogar, tales como alimentar a los niños, cambiar pañales, cocinar, etc.

\section{¿Qué hacemos para cumplir con este estándar?}

(1) Promover dentro del establecimiento la utilización el lenguaje no discriminatorio, que debe ser utilizado y practicado cotidianamente por todo el personal de la institución o establecimiento de salud.

(2) El lenguaje no discriminatorio además debe ser incluido en los materiales de IEC y capacitación, documentos internos, etc. 


\section{Estándar VI.2: \\ Se usa lenguaje inclusivo}

\section{?)}

¿A qué nos referimos?

E ste estándar incluye el uso de los(as), el símbolo@, u otras formas para asegurar _que el lenguaje masculino no sea utilizado para representar tanto a hombres como a mujeres. También se refiere al uso de mensajes que incluyan un lenguaje dirigido tanto a hombres como a mujeres.

Un documento que incluya síntomas de ITS tanto para los hombres como para las mujeres sería un ejemplo de lenguaje inclusivo. Más ilustrativamente, la siguiente frase: "Compañeros estudiantes vamos a realizar un viaje de estudios a...", puede convertirse al lenguaje inclusivo de la siguiente manera: "Compañeras y compañeros estudiantes, vamos a realizar un viaje de estudios a..."

\section{¿Qué hacemos para cumplir con este estándar?}

(1) Se debe promover dentro del establecimiento la utilización del lenguaje inclusivo, que debe ser utilizado y practicado cotidianamente por todo el personal de la institución o establecimiento de salud.

(2) El lenguaje inclusivo además debe ser incluido en los materiales de IEC y capacitación, documentos internos, etc. 


\section{Información, educación, comunicación y capacitación}

\section{Estándar VII.1: \\ Existen materiales de IEC y capacitación con información sobre derechos sexuales y reproductivos, derechos de los(as) clientes y derechos de la mujer}

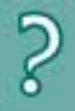

¿A qué nos referimos?

Dor materiales IEC (de información, educación y comunicación) y capacitación, se debe entender un conjunto de documentos que tienen el objetivo de proporcionar al(la) lector(a) conocimientos y orientación. Estos documentos se difunden a través de sistemas de información, educación, comunicación y capacitación. La forma en que se presenta este material es variada: cartillas, afiches, videos, almanaques, etc. Este material puede ser usado como apoyo en talleres de capacitación.

En el campo de las prestaciones de servicios de salud con enfoque de género, los materiales de IEC y las capacitaciones al personal de salud y la comunidad deben contemplar los temas de los derechos sexuales y reproductivos, derechos de los(las) clientes y derechos de la mujer.

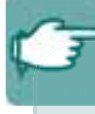

Estos derechos se entienden así:

- Derechos sexuales: parten del absoluto respeto a la integridad de la persona y la distribución de las responsabilidades sobre el comportamiento sexual y sus consecuencias. Comprenden el derecho al más elevado estado de salud sexual; el derecho a la información necesaria y a los servicios con pleno 
respeto de la confidencialidad y el derecho a tomar decisiones relacionadas con la sexualidad segura y placentera, libre de de discriminación, coacción o violencia.

- Derechos reproductivos: son derechos inalienables e imprescriptibles de mujeres y hombres desde el nacimiento hasta la muerte, en todos los sistemas políticos, económicos y culturales. Éstos incluyen el derecho de las parejas e individuos a decidir libre y responsablemente sobre el número y el espaciamiento de los(as) hijos(as) deseados(as), así como el derecho a tener la información y los medios para lograrlo; el derecho a alcanzar el nivel más elevado de salud sexual y reproductiva; el derecho a adoptar decisiones relativas a la reproducción sin sufrir discriminación, coerciones ni violencia y el derecho de ser beneficiario(a) de los avances tecnológicos de la ciencia en anticoncepción.

- Derechos de los(as) clientes: Los(as) clientes tienen derecho a un trato humanizado, a sentirse cómodos(as) en las infraestructuras, con tiempos de espera razonables, así como el acceso a referencias o seguimientos oportunos. Los diez derechos de los(as) clientes son: Elección, Seguridad, Opinión, Privacidad, Información, Dignidad, Acceso, Confidencialidad, Comodidad, Continuidad (ESO PIDA CCC).

- Derechos de la mujer: Son parte inalienable, integral e indivisible de todos los derechos humanos y libertades fundamentales. Implican el reconocimiento del derecho de todas las mujeres a controlar todos los aspectos de su salud, así como el derecho al control de la propia sexualidad sin coerción, violencia, ni abuso de poder.

\section{¿Qué hacemos para cumplir con este estándar?}

(1) Los materiales de IEC y capacitación que se utilicen y/o distribuyan dentro y fuera de la institución o establecimiento de salud deben contener ideas sobre los derechos sexuales y reproductivos, derechos de los(as) clientes y derechos de la mujer. 
Estándar VII.2:

Existen materiales de IEC y capacitación con información sobre aspectos de salud sexual y reproductiva

\section{?}

\section{¿A qué nos referimos?}

Dor materiales IEC (de información, educación y comunicación) y capacitación, se debe entender un conjunto de documentos que tienen el objetivo de proporcionar al(la) lector(a) conocimientos y orientación. Estos documentos se difunden a través de sistemas de información, educación, comunicación y capacitación. La forma en que se presenta este material es variada: cartillas, afiches, videos, almanaques, etc. Este material puede ser usado como apoyo en talleres de capacitación.

La salud sexual y reproductiva es un estado general de bienestar físico, mental y social y no de mera ausencia de enfermedades o dolencias en todos los aspectos relacionados con el sistema reproductivo, sus funciones y procesos.

En consecuencia, la salud reproductiva entraña la capacidad de disfrutar de una vida sexual satisfactoria y sin riesgos; de procrear con la libertad de decidir si hacerlo o no hacerlo, cuándo y con qué frecuencia. Esta última condición lleva implícito el derecho del hombre y la mujer a:

- obtener información sobre anticoncepción;

- elegir métodos legalmente establecidos;

- tener acceso a métodos seguros, eficaces, asequibles y aceptables, y

- recibir servicios adecuados de salud que permitan embarazos y partos sin riesgos y den a las parejas las máximas posibilidades de tener hijos sanos.

\section{¿Qué hacemos para cumplir con este estándar?}

(1) Los materiales de IEC y capacitación que se utilicen y/o distribuyan dentro y fuera de la institución o establecimiento de salud deben contener ideas sobre la salud sexual y reproductiva. 


\section{Estándar VII.3: \\ Al Existe información visual y accesible sobre el establecimiento de salud (servicios que se ofrecen, horarios y lista de precios)}

a existencia de información visual y accesible en los establecimientos de salud, se refiere a aquel material o documento que difunde y promociona los servicios en forma pública dentro y fuera de la institución. Puede consistir en una pizarra o un cartel situado en el área de recepción del establecimiento de salud.

Esta documentación tiene el objetivo de garantizar a la población usuaria, la oferta de los servicios. Debe proporcionar información suficiente sobre los servicios que son prestados y sobre el precio de los mismos. Se debe incluir una clasificación de los servicios, dotando de normas específicas para garantizar la correcta ubicación de los mismos dentro de la institución.

\section{¿Qué hacemos para cumplir con este estándar?}

(1) Situar en el área de recepción de clientes un cartel, pizarra o cuadro que indique:

- los servicios que se prestan,

- los precios por consulta y especialidad,

- horarios de atención por tipo de servicio y

- nombres de los especialistas que atienden.

(2) Actualizar esta información de manera inmediata cuando haya cambios. 


\section{Estándar VII.4: \\ Se desarrollan actividades educativas para los(las) clientes en el área de espera}

(5)

¿A qué nos referimos?

El desarrollo de actividades educativas para los(as) clientes en el área de espera tiene Lque ver con la difusión de conceptos, ideas y conocimientos relacionados con los temas de salud.

El objetivo de estas actividades es orientar, instruir y educar a los(as) clientes del establecimiento, mientras esperan su turno para recibir un servicio. Ésta es una manera efectiva de mantener a un público cautivo interesado e informado en temas de salud.

Las actividades en salas de espera generalmente son realizadas por el personal de enfermería u orientación y utilizan materiales de IEC como rotafolios, cuadros, videos, etc.

\section{¿Qué hacemos para cumplir con este estándar?}

(1) Se debe reorganizar el tiempo de algún personal de enfermería u orientación para realizar actividades educativas en las salas de espera en horarios de mayor flujo de clientes.

(2) Si no se cuenta con un televisor y equipo de video para reproducir cintas educativas, contar con rotafolios, afiches, o algún material de IEC que contenga gráficos para realizar las explicaciones a los(as) clientes que se encuentran en la sala de espera.

(3) El televisor y el equipo de video se deben utilizar para reproducir cintas educativas. Muchas veces los televisores están en sintonía de programas sin contenido educativo. El objetivo no es sólo entretener, sino además educar. 



\section{Monitoreo y evaluación}

\section{Estándar VIII.1: \\ Existe un mecanismo para establecer cambios programáticos con base en sugerencias de clientes}

\section{?)}

\section{¿A qué nos referimos?}

Dara conocer la percepción que tienen los(as) clientes de los servicios, se pueden diseñar encuestas a realizarse fuera del establecimiento de salud, entrevistado a mujeres y hombres de la comunidad o se pueden diseñar entrevistas de salida que se realizan cuando el(la) cliente sale de consulta. También existen opciones como grupos focales, evaluaciones rápidas, sondeos, buzones de sugerencias o investigaciones operativas.

Después de recolectar la información sobre las percepciones de los(as) clientes, se necesita un plan operacional para que los datos lleguen a los miembros indicados del personal en la forma que les sea útil.

El sistema de información necesita emplear métodos para:
- resumir los datos recolectados en los registros, archivos y
formularios,
- analizar los informes para transformarlos en información útil,
transmitir los datos a otros mediante escritos que puedan entenderse
claramente,
sacar conclusiones y tomar decisiones basándose en la información
obtenida.




\section{¿Qué hacemos para cumplir con este estándar?}

(1) Sedebediseñar un procedimiento para recolectar datos sobrelas percepciones de los(as) clientes sobre los servicios que ofrece el establecimiento de salud. Este procedimiento puede consistir en grupos focales, entrevistas de salida, evaluaciones rápidas, sondeos, buzones de sugerencias o investigaciones operativas.

2 Se debe designar a un miembro del personal de apoyo de administración para recoger los formularios con información de los(as) clientes.

(3) La persona designada debe tabular, acumular los datos, desagregar la información en unidades comunes y finalmente elaborar un informe en el cual se presenten las predicciones del programa y si la situación permanece sin variaciones o varía de acuerdo a las sugerencias de los(as) clientes.

(4) El proceso de recolección de información sobre las percepciones de los(as) clientes puede hacerse dos veces al año o de acuerdo a las necesidades de la dirección y gerencias. 


\section{Bibliografía}

Balogh S.A. y Cole L.P. "Contraceptive services for the postpartum and postabortion woman". En Droegemueller W. y Sciarra J.J. (eds.) Gynecology and Obstetrics. Philadelphia: J.B. Lippincott. 1994: $1-11$.

Barrera, D. y Massolo, A. (comps.). El municipio. Un reto para la igualdad entre hombres y mujeres. México: Grupo Intedisciplinario sobre Mujer, Trabajo y Pobreza (Gimtrap) e Instituto Nacional de las Mujeres, julio de 2003.

Burns A.A., Lovich R., Maxwell J. y Shapiro K. Donde no hay doctor para mujeres: Un manual para la salud de la mujer. La Fundación Hesperian. Octubre, 1999.

Caro, D., Schueller, J., Ramsey, M. y Voet, W. Manual de integración de género en programas de salud reproductiva y VIH: del compromiso a la acción. Grupo de Trabajo Interinstitucional de Género de USAID (IGWG/USAID). Marzo, 2005. Disponible en: http://www.prb.org/pdfo5/ManualIntegrGendr Sp.pdf

Díaz Williams, E. Requisitos básicos de planta física para consultorios médicos. Buenos Aires: Instituto Panamericano de Gestión de la Salud, julio, 2003. Disponible en:

http://www.gerenciasalud.com/art171.htm

Distance education at a glance. Strategies for learning at a distance. Guide 8, October 1995. University of Idaho. Engineering Outreach. Disponible en: www.uidaho.edu/eo/dist8.html

Ezeh, A. "Reproductive preferences and behaviour: how men and women compare". Planned Parenthood Challenges. (2):5-19. 1996.

Fondo de Desarrollo de las Naciones Unidas para la Mujer (UNIFEM).Guía de Recursos para Grupos Temáticos de Género. Enero, 2005. Disponible en: http://www.undp.org/women/docs/ ResourceGuideGenderThemeGroups spa.pdf

Frutos, I. y Rodríguez, P. Guía para un uso no discriminatorio del lenguaje (en el entorno de la discapacidad). FUNDABEM (Fundación Abulense para el Empleo). 2001.

Galdós, S. Mujer y desarrollo. Movimiento Manuela Ramos. 2003.

GENSALUD. Violencia de género jes el personal de salud parte del problema? Domestic Violence Project, INC. OPS/OMS. 2002.

Hatcher, R.A., Rinehart, W., Blackburn, R., Geller, J.S., y Shelton, J.D. Lo esencial de la tecnología anticonceptiva. Manual para el personal clínico. Baltimore: Facultad de Salud Pública Bloomberg de Johns Hopkins, Programa de Información en Población. 1999.

Huntington D, Nawar L, Abdel Hady D. An Exploratory Study of the Psycho-social Stress Associated with Abortions in Egypt: Final Report. Cairo: The Population Council. 1995.

Huntington, D., Dervipodlu, A.A., Pile, J.M., Bumin, C. y Mensch, B. "The quality of abortion services in Turkey”. Int J Gynaecol Obstet. 53(1): abril 1996. 41-9. 
INTERCAMBIO MAC. Comunicación centrada en el cliente: El cliente, el proveedor y la comunidad. Doc. II, 2003. Disponible en: http://www.maqweb.org/spanish/present/cpi.pdf

IPPF/RHO, PROCOSI. Manual para evaluar la calidad de servicios de salud, programas y proyectos desde una perspectiva de género.

Manual guía salud de la mujer, calidad de la atención y género. Santiago de Chile: Ed. Colectivo Mujer, Salud y Medicina Social, 1997.

Manual para Evaluar la Calidad de Atención desde una Perspectiva de Género. Federación Internacional de Planificación de la Familia, Región del Hemisferio Occidental, Inc. Nueva York: IPPF/WHR, enero 2000.

Moreno, S. La salud tiene género. 2004.

Mujer Palabra. Lenguaje inclusivo. Página crítica al lenguaje de la exclusión y la opresión. 2004. Disponible en: http://www.mujerpalabra.net/pensamiento/lenguaje/lenguaje inclusivo.htm

Oodit, G. "Withdrawal: a time-honoured but risky method?” Planned Parenthood Challenges 2:25. 1996.

Pile, J.M., Bumin, C., Ciloglu, A. y Akin, A. "Involving men as partners in reproductive health: lessons learned from Turkey”. AVSC Working Paper No. 12. Nueva York: AVSC International, junio 1999.

PROCOSI. Efectos y costos de la incorporación de un enfoque de género en la prestación de servicios en salud reproductiva. 2004.

PROCOSI. Institucionalización de la perspectiva de género en servicios de salud sexual y reproductiva de la red PROCOSI. 2003.

Real Academia Española. Diccionario de la lengua española. http://www.rae.es/

Rinehart, W., Rudy, S. y Drennan M. “Guía de orientación ACCEDA”. Population Reports, Serie J. No. 48. Baltimore: Johns Hopkins University School of Public Health, Population Information Program, diciembre, 1998.

Rivera, R., Kennedy, K. y Balogh, S. Postpartum Contraception: Contraceptive Technology Update Series. Research. Triangle Park, NC: Family Health International, 1994.

Salud reproductiva y la atención de la salud reproductiva. Disponible en: http://www.minsa.gob.pe/dpspf/pe-001.htm

Sempol, D. Sexo, política y mujeres. Marzo 2004.

The National Women's Health Information Center. Preguntas frecuentes acerca de los métodos anticonceptivos. Noviembre de 2002. Disponible en: http://www.womenshealth.gov/espanol/preguntas/birthcont.htm

Time, Tide, and Tonics: The Patent Medicine Almanac in America. Patent Medicine Almanacs. History of Medicine Division. Nacional Library of Medicine. Disponible en: www.nlm.nih.gov/hmd/ almanac/almanacs.html

Wolff, J.A. y Suttenfield, L.J. (eds.) Manual del Administrador de Planificación Familiar: Técnicas para Mejorar la Gestión de Programas. Newton, MA: Management Sciences for Health y Watertown, MA: Pathfinder International. 1994.

Zeledon, B.X. y Watson, E.G. "Estudio de satisfacción del cliente externo: Área de Salud Puriscal - Turrubares”. Rev. cienc. adm. financ. segur. soc. 7(2):23-44. San José: julio, 1999. Disponible en: http://www.scielo.sa.cr/scielo.php?pid=S1409-12591999000200003\&script=sci arttext\&tlng=es 


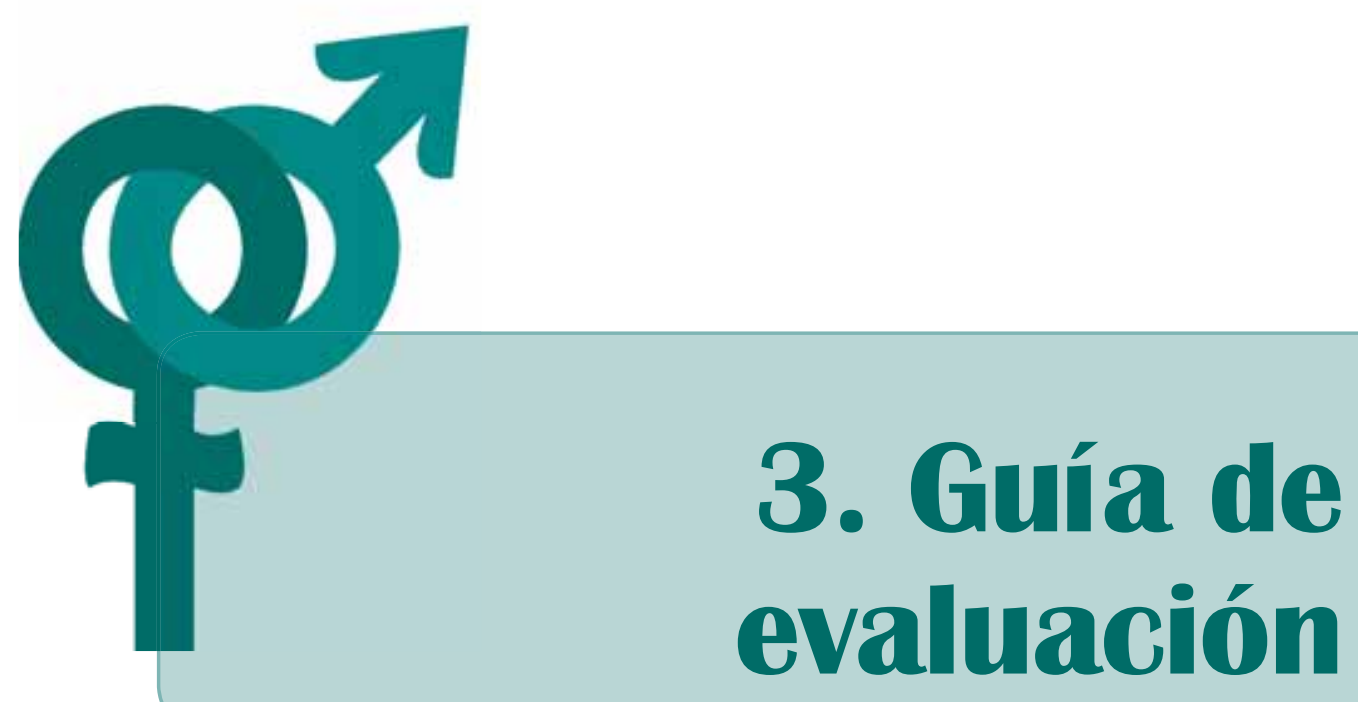

Para instituciones y establecimientos

de salud que buscan acreditar la calidad y enfoque de género de sus servicios

La Paz • Bolivia • septiembre 2007 



\section{Contenido}

I. Introducción

II. Evaluación interna y externa 123

II.1 Estándares de calidad con una perspectiva de género 124

II.2 Instrumentos de evaluación 129

$\begin{array}{lll}\text { II.3 Equipos de evaluación } & 134\end{array}$

evaluación interna

evaluación externa

II.4 Sondeos y muestreos

evaluación interna

evaluación externa

III Captura y análisis de datos 139

IV. Informe de evaluación y acreditación 145

$\begin{array}{ll}\text { V. Reacreditación } & 147\end{array}$ 



\section{Introducción}

E sta Guía de evaluación contiene toda la información necesaria para que los(as)

Cevaluadores(as) internos(as) y externos(as) designados(as) puedan determinar el grado en que los establecimientos o instituciones de salud participantes cumplen con los estándares de calidad con una perspectiva de género.

El proceso de acreditación incluye la revisión formal de varios aspectos del establecimiento o institución de salud para certificar la incorporación de la transversal de género en todos sus procedimientos, ya sean administrativos o clínicos. Cuando esto ocurre, la institución o establecimiento de salud es reconocida públicamente por ofrecer servicios de salud de calidad con un enfoque de género.

Este documento se complementa con otras tres guías: 1) la Guía de procedimientos, dirigida a coordinadores(as) y directores(as) de instituciones y establecimientos de salud y que contiene los lineamientos generales de esta estrategia; 2) la Guía de autocapacitación, la cual contiene conceptos y sugerencias de actividades para alcanzar cada uno de los estándares de género, y 3) la Guía de costos, que incluye instrucciones detalladas para la recolección de información de los costos incurridos durante el proceso de incorporación del enfoque de género en los servicios de salud. 



\section{Evaluación interna y externa}

E n este y los otros documentos nos referimos a evaluaciones internas y evaluaciones externas. Las evaluaciones internas son las que llevan a cabo los miembros de un equipo de trabajo en una misma unidad administrativa o de servicios para ver el grado en que cumplen con los estándares de calidad y género. Esta evaluación comúnmente se lleva a cabo al inicio del proyecto para identificar oportunidades de mejoramiento y, posteriormente, para ver si las acciones de mejoramiento emprendidas tuvieron éxito en modificar las condiciones y, por lo tanto, el grado de cumplimiento con los estándares de calidad.

Las evaluaciones externas son aquellas que realizan miembros externos o ajenos al equipo de trabajo de una unidad administrativa o de prestación de servicios. Esta evaluación se lleva a cabo a solicitud de los equipos de trabajo de las unidades una vez que éstos están seguros de haber alcanzado los estándares mínimos de calidad. El objetivo de la evaluación externa es verificar que la unidad en cuestión cumple con los estándares mínimos exigidos y, si es el caso, poder proceder al reconocimiento formal público de ser un establecimiento que presta servicios de calidad con un enfoque de género. El comité que realiza la evaluación externa puede estar conformado por miembros de las oficinas centrales de una organización; por personal de otras clínicas de la misma institución, diferentes a la que está siendo evaluada, o por profesionales debidamente capacitados(as) de otras instituciones, ya sea de sus áreas administrativas o de las áreas de prestación de servicios, según los aspectos a ser evaluados.

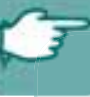

En el caso de la evaluación de clínicas y otros establecimientos que prestan servicios de salud, tanto la evaluación interna como externa se realizan aplicando cinco instrumentos de recolección de datos:

- la guía para la revisión de documentos,

- la guía de observación de aspectos generales,

- la guía de observación de la consulta,

- el cuestionario de entrevistas de salida a clientes y

- el cuestionario de entrevistas al personal. 
Para el caso de la evaluación de las oficinas administrativas y gerenciales se utilizan solamente tres instrumentos: la guía para revisar documentos, la guía de observación de aspectos generales y el cuestionario para entrevistas al personal. El Anexo 4 contiene estos formularios.

Las evaluaciones se realizan normalmente en dos días, pero pueden terminarse en un solo día. Para la evaluación interna puede usarse un número reducido de observaciones y entrevistas. La evaluación externa, sin embargo, necesitará el cálculo de una muestra para las entrevistas a clientes y un número mínimo de observaciones de consultas y entrevistas al personal para obtener datos representativos en la determinación del resultado y para mantener procedimientos estandarizados que no impliquen ventajas en la evaluación de algunas unidades sobre otras.

\section{II.1: Estándares de calidad con una perspectiva de género}

a evaluación que se lleva a cabo consiste en determinar si la institución o clínica en cuestión cumple con un mínimo de una lista de estándares de calidad desde una perspectiva de género. Para cada estándar indicado, la evaluación debe responder con un simple "sí” o "no", siguiendo procedimientos específicos.

La meta de las instituciones es que cuando menos en 80 por ciento de los casos se responda a la pregunta con un "sí".

En este manual utilizamos una versión modificada por PROCOSI de los 68 estándares originalmente propuestos en Bolivia por la IPPF/RHO en su Manual para evaluar la calidad de atención desde una perspectiva de género. Estos 68 estándares miden diferentes aspectos de las políticas y prácticas institucionales, las prácticas de los(as) proveedores(as), la comodidad del(la) cliente, la satisfacción del(la) cliente, el uso del lenguaje de género y, finalmente, de las actividades de información, educación, comunicación (IEC) y capacitación ${ }^{1}$ que llevan a cabo las instituciones. El Anexo 12 contiene la lista de los estándares propuestos por el IPPF.

Con base en una revisión sobre el grado en que podían ser cumplidos los estándares, PROCOSI seleccionó 59 estándares de calidad con enfoque de género que debían cumplir las clínicas y 17 estándares que debían cumplir las áreas administrativas y

1 International Planned Parenthood Federation/WHR (Federación Internacional de Planificación de la Familia, Región del Hemisferio Occidental). 2000. Manual para evaluar la calidad de atención desde una perspectiva de género. New York, NY, IPPF. 
gerenciales de las organizaciones. Estos 17 indicadores solamente evalúan las políticas y procedimientos, el uso del lenguaje de género y los aspectos de IEC y capacitación.

Las instituciones que deseen implementar una estrategia de acreditación pueden llevar a cabo la pertinencia y funcionalidad de los estándares en la realidad en la que se desempeñan, eliminando algunos, agregando otros y modificando otros más.

Los estándares de calidad con una perspectiva de género son los siguientes:

\section{Estándares para instituciones}

I Políticas y prácticas institucionales

I.1 Existe una declaración que promueve el empoderamiento de la mujer

I.2 Existe una declaración que prohíbe la discriminación con base en el género

I.3 Existe una declaración que prohíbe la discriminación con base en el género en términos de promoción del personal

I.4 Existe una declaración que prohíbe el abuso del poder en la institución

I.5 Al menos 80 por ciento del personal siente que la dirección o gerencia de la institución es receptiva a sus opiniones y sugerencias

I.6 Al menos 80 por ciento del personal siente que se ponen en práctica sus recomendaciones o sugerencias

I.7 Al menos 80 por ciento del personal se siente motivado(a) para dar opiniones y sugerencias

I.8 Al menos 80 por ciento del personal siente que la institución tiene un ambiente de trabajo colectivo y de equipo

I.9 Al menos 80 por ciento del personal siente que la institución es receptiva a explicaciones para dejar el trabajo cuando se requiere por razones familiares

I.10 Menos del 20 por ciento del personal siente que en su institución se le da un trato preferencial a un sexo en particular

\section{Conocimiento del personal}

III.1 Al menos 80 por ciento del personal conoce la definición de salud sexual y reproductiva

III.3 Al menos 80 por ciento del personal conoce la definición de género

V Satisfacción del personal

V.2 Las condiciones de limpieza y comodidad son satisfactorias

VI Uso de lenguaje de género

VI.1 Se usa lenguaje no discriminatorio

VI.2 Se usa lenguaje inclusivo 


\section{Información, educación, comunicación y capacitación}

VII.1 Existen materiales de IEC y capacitación con información sobre derechos sexuales y reproductivos, derechos de los(as) clientes, derechos de la mujer

VII.2 Existen materiales de IEC y capacitación con información sobre aspectos de salud sexual y reproductiva

\section{Estándares para establecimientos de salud}

\section{Políticas y prácticas institucionales}

I.1 Existe una declaración que promueve el empoderamiento de la mujer

I.2 Existe una declaración que prohíbe la discriminación con base en el género

I.3 Existe una declaración que prohíbe la discriminación con base en el género en términos de promoción del personal

I.4 Existe una declaración que prohíbe el abuso del poder en el establecimiento de salud

I.5 Al menos 80 por ciento del personal siente que la dirección o gerencia del establecimiento de salud es receptiva a sus opiniones y sugerencias

I.6 Al menos 80 por ciento del personal siente que se ponen en práctica sus recomendaciones o sugerencias

I.7 Al menos 80 por ciento del personal se siente motivado(a) para dar opiniones y sugerencias

I.8 Al menos 80 por ciento del personal siente que el establecimiento de salud tiene un ambiente de trabajo colectivo y de equipo

I.9 Al menos 80 por ciento del personal siente que el establecimiento de salud es receptivo a explicaciones para dejar el trabajo cuando se requiere por razones familiares

I.10 Menos del 20 por ciento del personal siente que en el establecimiento de salud se le da un trato preferencial a un sexo en particular

I.11 Al menos 50 por ciento de las consultas de salud sexual y reproductiva se ofrecen a parejas

I.12 Existe una declaración que establece como procedimiento rutinario ofrecer servicios de orientación

I.13 No existen servicios para los que se requiera el consentimiento de la pareja

I.14 Existe una gama de métodos de anticoncepción disponibles de acuerdo a las normas establecidas por el establecimiento de salud

\section{Prácticas de los(as) proveedores(as)}

II. 1 Al menos 80 por ciento de proveedores(as) saludan a los(as) clientes

II.2 Al menos 80 por ciento de proveedores(as) portan una insignia de identificación visible 
II.3 Al menos 80 por ciento de proveedores(as) se refieren a $\operatorname{los}(\mathrm{as})$ clientes respetuosamente

II.4 Al menos 80 por ciento de proveedores(as) exploran temas de salud sexual y reproductiva en las consultas/sesiones de orientación

II.5 Al menos 80 por ciento de proveedores(as) exploran aspectos relacionados con la salud sexual del(la) cliente en las consultas/sesiones de orientación

II.6 Menos del 20 por ciento de proveedores(as) sienten que por barreras no se exploran temas de SSR

II.7 Al menos 80 por ciento de proveedores(as) usan material didáctico (dibujos, trípticos, rotafolios u otro material) para reforzar sus explicaciones en las consultas/sesiones de orientación

II.8 Al menos 80 por ciento de proveedores(as) se comunican con el/la cliente utilizando un lenguaje sencillo en las consultas/sesiones de orientación

II.9 Al menos 80 por ciento de proveedores(as) explican al/la cliente los detalles del diagnóstico en las consultas/sesiones de orientación

II.10 Al menos 80 por ciento de proveedores(as) explican al/la cliente los detalles del tratamiento en las consultas/sesiones de orientación

II.11 Al menos 80 por ciento de proveedores(as) miran directamente al/la cliente mientras explican el diagnóstico o el tratamiento en las consultas/sesiones de orientación

II.12 Al menos 80 por ciento de proveedores(as) preguntan al(la) cliente si tiene preguntas o dudas en las consultas/sesiones de orientación

II.13 Al menos 80 por ciento de proveedores(as) responden a las preguntas o aclaran dudas de la/el cliente en las consultas/sesiones de orientación

II.14 Al menos 80 por ciento de proveedores(as) explican qué es lo que hacen durante la auscultación o el examen pélvico

II.15 Al menos 80 por ciento de proveedores(as) proporcionan al(la) cliente materiales educativos de refuerzo

II.16 Menos del 20 por ciento de proveedores(as) dicen que existe un tiempo de espera de más de media hora entre el tiempo de llegada del personal de salud al establecimiento de salud y el momento en que inicia la atención a clientes

II.17 Menos del 20 por ciento de clientes dicen haber esperado más de media hora para ser atendidos

II.18 Al menos 80 por ciento del personal identifica los servicios de salud sexual y reproductiva que ofrece el establecimiento de salud

II.19 Al menos 80 por ciento de proveedores(as) dedican todo su tiempo al(la) cliente sin interrupciones durante las consultas/servicios de orientación

II.20 Al menos 80 por ciento del personal conoce y promueve el uso del método de doble protección

II.21 Al menos 80 por ciento del personal conoce y promueve el examen de Papanicolaou 
II.22 Al menos 80 por ciento del personal conoce y promueve el auto-examen de senos

\section{Conocimiento de los(as) proveedores(as)}

III.1 Al menos 80 por ciento del personal conoce la definición de salud sexual y reproductiva

III.2 Al menos 80 por ciento del personal conoce los métodos anticonceptivos disponibles en el establecimiento de salud

III.3 Al menos 80 por ciento del personal conoce la definición de género

IV Comodidad del(la) cliente

IV.1 Menos del 20 por ciento de clientes manifiestan dificultades relacionadas al género para acudir al servicio

IV.2 Existen recursos para atender y entretener a los(as) menores que acompañan a los(as) clientes en el servicio de salud

\section{Satisfacción del(la) cliente}

V.1 Existen mecanismos para conocer las opiniones de los(as) clientes sobre el horario y satisfacción del(la) cliente

V.2 Las condiciones de limpieza y comodidad son satisfactorias

V.3 El equipamiento se encuentra disponible y en buen estado

V.4 Existen condiciones para asegurar la confidencialidad y la privacidad del(la) cliente

V.5 Existen asientos suficientes disponibles para $\operatorname{los}(\mathrm{as})$ clientes en el área de espera

V.6 Al menos 80 por ciento de clientes se sienten cómodos(as) hablando con la persona que los(as) atendió en consulta

V.7 Al menos 80 por ciento de clientes se sienten cómodos(as) para hacer preguntas y aclarar sus dudas con los(as) proveedores(as)

V.8 Al menos 80 por ciento de clientes consideran que el tiempo en consulta es suficiente

V.9 Al menos 80 por ciento de clientes dicen haber recibido un buen trato del personal del establecimiento de salud

V.10 Al menos 80 por ciento de clientes fueron atendidos(as) por una persona del sexo de su preferencia

V.11 Al menos 80 por ciento de clientes consideran que el horario de atención se adapta a sus necesidades (relacionadas con género)

VI. Uso de lenguaje de género

VI.1 Se usa lenguaje no discriminatorio

VI.2 Se usa lenguaje inclusivo 


\section{Información, educación, comunicación y capacitación}

VII.1 Existen materiales de IEC y capacitación con información sobre derechos sexuales y reproductivos, derechos de los(as) clientes, derechos de la mujer

VII.2 Existen materiales de IEC y capacitación con información sobre aspectos de salud sexual y reproductiva

VII.3 Existe información visual y accesible sobre el establecimiento de salud (servicios que se ofrecen, horarios y lista de precios)

VII.4 Se desarrollan actividades educativas para los(as) clientes en el área de espera VIII. Monitoreo y evaluación

VIII.1 Existe un mecanismo para establecer cambios programáticos con base en sugerencias de clientes

La información para determinar si el estándar se cumple o no se recopila a través de los instrumentos de evaluación mencionados anteriormente. El Anexo 5 presenta una tabla que lista los estándares con los ítems o preguntas que permiten evaluar cada estándar. La Guía de auto-capacitación contiene conceptos y sugerencias de actividades a realizar para el cumplimiento de cada estándar.

\section{II.2: Instrumentos de evaluación}

$\mathrm{T}$ anto en la evaluación interna como en la externa de las clínicas y unidades que prestan servicios de salud se usarán los cinco formularios que se presentan en el Anexo 4 (guía para la revisión de documentos, guía para la observación de aspectos generales, guía para la observación de la consulta y orientación, cuestionario para entrevistas de salida a clientes y cuestionario para las entrevistas al personal). Para evaluar las áreas administrativas y gerenciales se utilizarán los tres formularios correspondientes (guía para la revisión de documentos, guía para la observación de aspectos generales, y cuestionario para las entrevistas al personal). A continuación se explican los contenidos y el uso de cada uno de estos formularios:

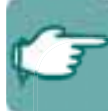

\section{- Guía para la revisión de documentos}

Este formulario mide el nivel de integración de un enfoque de género en las políticas y en la estructura del establecimiento de salud o institución. La guía permite revisar documentos institucionales, protocolos y procedimientos, para determinar el grado en que la institución o establecimiento ha incorporado elementos para eliminar la desigualdad de género en la organización. El formulario contiene cinco secciones: información general, documentos oficiales, material de IEC y capacitación, abastecimiento de métodos 
anticonceptivos, y participación de parejas en consultas. El formulario para establecimientos de salud contiene la lista completa de estándares; el formulario para instituciones contiene sólo los estándares relevantes.

\section{- Observación de aspectos generales}

Este formulario mide las condiciones de infraestructura y la existencia de materiales desplegados en la institución o unidad prestadora de servicios. La observación consiste en un recorrido por los diferentes ambientes de la institución o establecimiento, sin necesidad de ingresar a consultorios o salas privadas. Contiene cinco secciones: información general, condiciones generales de los ambientes y equipamiento, privacidad y confidencialidad, entretenimiento para menores, e IEC. El formulario para establecimientos de salud contiene la lista completa de estándares; el formulario para instituciones contiene sólo los estándares relevantes.

\section{- Observación de la consulta y orientación}

A través de la observación de dos o tres consultas, este formulario mide la calidad de atención que el personal del establecimiento brinda a los(as) clientes. Parte de este estudio es la observación de las consultas médicas y las sesiones de orientación en salud sexual y reproductiva. Contiene cuatro secciones: información general, atención general, diagnóstico y tratamientos, e información proporcionada al(la) cliente sobre salud sexual y reproductiva. Este formulario solo se usa para las evaluaciones a establecimientos de salud.

\section{- Entrevistas de salida a clientes}

A través de un sondeo de las declaraciones de los(as) clientes, este formulario mide la calidad de atención que brinda el establecimiento de salud. Mide el comportamiento y el trato del(la) proveedor(a) de salud en la atención brindada. Contiene cinco secciones: información general, comodidad del(la) cliente y tiempo de espera, relaciones interpersonales/trato, ambientes del establecimiento y desarrollo de la consulta o sesión de orientación. Este formulario solo se usa para las evaluaciones a establecimientos de salud.

\section{- Entrevistas al personal}

Por medio de un sondeo con el personal, este formulario mide la calidad de atención que se brinda en los servicios de salud sexual y reproductiva desde una perspectiva de género y revisa las políticas y prácticas de la institución relacionadas a la equidad de género. Contiene cuatro secciones: información general, procedimientos y prácticas, conceptos generales y contenido de la consulta o sesión de orientación. El formulario para establecimientos de salud contiene la lista completa de estándares; el formulario para instituciones contiene sólo los estándares relevantes. 


\section{Estructura de los formularios}

\section{Información general}

Todos los formularios cuentan con una sección de información general. Esta sección requiere el llenado de los datos generales de la institución o establecimiento de salud y de la persona entrevistada o consulta observada. Los datos requeridos son:

Revisor(es/as)/Observador(a)/Entrevistador(a). Se anotará el o los nombres completos de la o las personas que estén realizando la evaluación (revisor(es/as), observador(a) o entrevistador(a).

Coordinador(a) de acreditación. Se anotará el nombre de la persona que coordina dentro de la institución o establecimiento de salud todas las actividades relacionadas con la acreditación.

Cargo en la institución. Se anotará el cargo que ejerce el(la) coordinador(a) de la acreditación mencionado(a) arriba.

Institución: Se anotará el nombre de la institución que busca la acreditación.

Establecimiento de salud. Si se está evaluando a un establecimiento de salud, se anotará el nombre completo del establecimiento de salud.

Nivel de atención. Se marcará con una cruz la casilla que identifique el nivel de atención del establecimiento de salud (primer, segundo, tercero o cuarto).

Municipio. Se anotará el nombre del municipio donde se encuentra la institución o establecimiento de salud que está siendo evaluado.

Departamento. Se anotará el departamento donde se encuentra el municipio señalado.

Sexo del(la) entrevistado(a). En el formulario de entrevista al personal se anotará el sexo de la persona entrevistada con una marca en la casilla correspondiente.

Cargo. En el formulario de entrevista al personal, se anotará el cargo de la persona entrevistada con una marca en la casilla correspondiente.

Antigüedad en el cargo. En el formulario de entrevista al personal se anotará la antigüedad en años en el cargo de la persona entrevistada. Sólo se debe entrevistar a personal que haya cumplido por lo menos un año de antigüedad en la institución o establecimiento de salud.

Fecha. Se anotará la fecha de la entrevista con el formato día/mes/año. 


\section{Consentimiento informado}

Para el formulario de entrevista a clientes, luego de anotar toda la información arriba mencionada, el(la) entrevistador(a) debe leer textualmente el párrafo de consentimiento informado al(la) cliente. Si el(la) cliente no acepta ser entrevistado(a), se debe terminar con el cuestionario inmediatamente, agradeciendo al(la) cliente cortésmente por el tiempo prestado.

Si el(la) cliente acepta ser entrevistado(a), se realiza la pregunta \#10: ¿Cuál fue el motivo principal de su visita?, y se anota una cruz en la casilla apropiada. Si el motivo principal de la visita no corresponde a un servicio de salud sexual y reproductiva o de orientación, se termina con el cuestionario inmediatamente, agradeciendo al(la) entrevistado(a) cortésmente por el tiempo prestado.

\section{Preguntas específicas}

Todos los formularios cuentan con el mismo formato para las preguntas específicas. El formato consta de cinco columnas: NÚMERO, PREGUNTA, RESPUESTA, PASE y ESTÁNDAR.

\begin{tabular}{|c|l|l|l|l|l|}
\hline$N^{0}$ & \multicolumn{1}{|c|}{ Pregunta } & Respuesta & Pase & Est \\
\cline { 1 - 2 } 16 & $\begin{array}{l}\text { En general, ¿cree que la direccion o gerencia de su establecimiento es } \\
\text { receptiva a las opiniones y sugerencias del personal? }\end{array}$ & Si & No & & 15 \\
\hline
\end{tabular}

La pregunta debe leerse textualmente (en el caso de las entrevistas).

Si la pregunta se encuentra sombreada, significa que NO debe preguntarse ni llenarse inmediatamente, sino que debe completarse al final, puesto que su contenido depende de otra información. Siga las instrucciones de la pregunta sombreada.

En el caso del formulario de entrevista al personal para establecimientos de salud, después de la pregunta \#28, sólo se continúa con la entrevista si la persona entrevistada ofrece servicios de salud sexual y reproductiva, incluyendo orientación. 


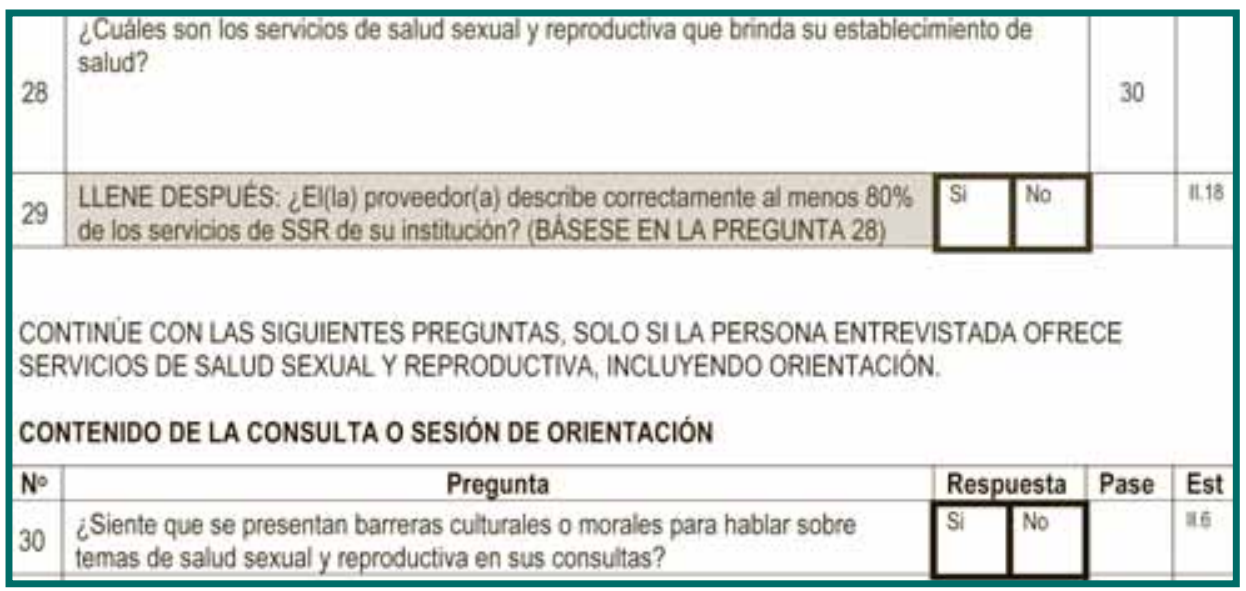

La columna de RESPUESTA puede contener un espacio para marcar SÍ o NO; HOMBRE, MUJER o LE DA IGUAL, o incluir un porcentaje (\%). Para los espacios donde solamente se requiere marcar (en vez de incluir un porcentaje), se deberá trazar una cruz.

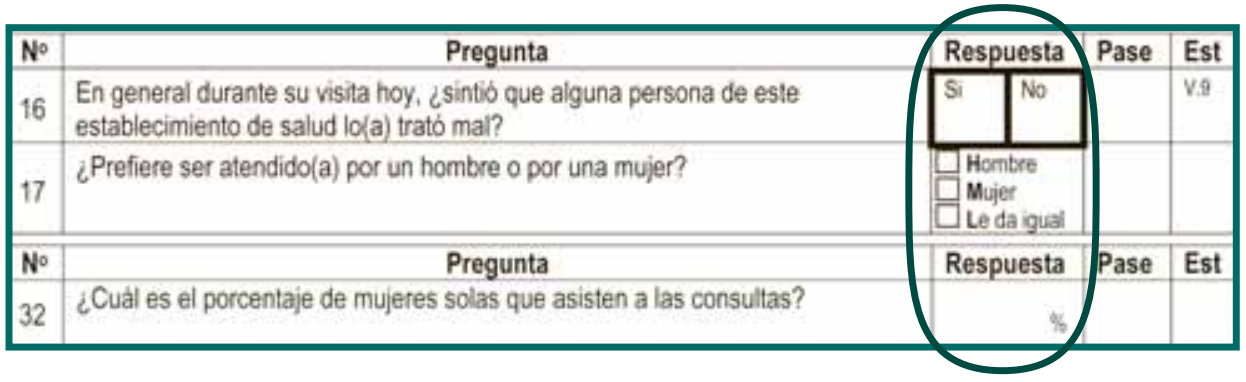

La columna de PASE indica el número de pregunta a la que se debe saltar después de realizar una pregunta y anotar su respuesta. En algunos casos el pase incluye la palabra NO y una flecha indicando el número de la pregunta a la que se debe saltar en caso de que la respuesta sea NO. Si la respuesta fuera SÍ, entonces no es necesario saltar ninguna pregunta y se debe continuar secuencialmente con la siguiente pregunta del formulario.

\begin{tabular}{|c|c|c|c|c|}
\hline \multicolumn{5}{|c|}{ guientes preguntas se refieren a procedimientos y prácticas institucionales: } \\
\hline 13 & $\begin{array}{l}\text { En el último año, ¿hizo alguna sugerencia o recomendación a gerentes o } \\
\text { directores de su institución? }\end{array}$ & $\mathrm{Si}$ & No & 16 \\
\hline 14 & ¿Utilizó conductos escritos o verbales regulares para hacer su sugerencia? & Si & No & \\
\hline 15 & ¿Esta sugerencia o recomendación ha sido puesta en práctica? & Si & No & \\
\hline
\end{tabular}


Finalmente, la columna de ESTÁNDAR incluye el estándar con el cual se relaciona la pregunta. Aquellas preguntas que no tienen ningún dato en la columna de estándar son preguntas auxiliares que permiten recolectar información para responder otra pregunta.

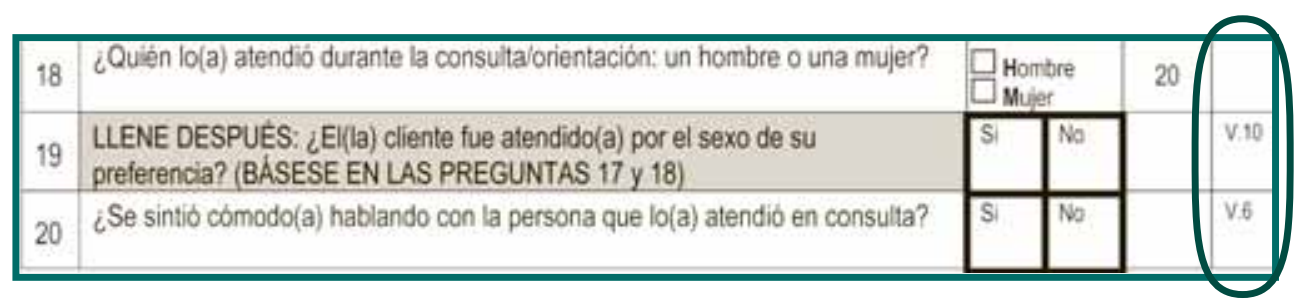

Al finalizar el llenado de cada formulario, se debe revisar nuevamente cada una de las preguntas cuya casilla de respuesta se encuentre resaltada. Con base en la información de las preguntas auxiliares, todas las casillas resaltadas deben contener una cruz en Sí o en NO.

\section{II.3: Equipos de evaluación}

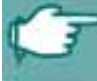

\section{Evaluación interna}

Para la evaluación interna, se recomienda la participación de todo el personal de la institución o establecimiento de salud. Sin embargo, son tres las personas que se encargan primordialmente de realizar la evaluación al interior del establecimiento de salud. Uno(a) de los(as) tres evaluadores(as) para establecimientos de salud, asumirá el papel de coordinador(a). Las responsabilidades del(la) evaluador(a) coordinador(a), son:

- coordinar todas las actividades del proceso de evaluación;

- elaborar el informe de evaluación;

- realizar la revisión de los documentos;

- realizar la observación de aspectos generales;

- realizar las entrevistas al personal;

- recoger información sobre estadísticas de servicio (promedio de consultas de orientación y de SSR por día), y

- apoyar a los(as) otros(as) dos evaluadores(as), si fuera necesario, en las entrevistas de salida y observaciones.

Los(as) evaluadores(as) 2 y 3 tendrán como función principal realizar las entrevistas de salida y las observaciones de las consultas y sesiones de orientación. 
Para el caso de la evaluación de una institución, sólo se necesitarán dos evaluadores(as). Un(a) evaluador(a) se encargará de realizar la revisión de documentos y de la observación de aspectos generales, mientras que el(la) otro(a) evaluador(a) se encargará de realizar las entrevistas al personal.

\section{Evaluación externa}

Para la evaluación externa, el equipo de evaluación también debe incluir a un grupo multidisciplinario de tres o dos personas que puedan realizar el proceso de la manera más objetiva posible.

Para el caso de una evaluación a un establecimiento de salud, el equipo podría estar conformado por un(a) médico(a), un(a) enfermero(a) y un(a) trabajador(a) social. Estas personas pueden pertenecer a una institución o establecimiento de salud miembro de la misma red de salud, pero no de la misma unidad de salud que busca la acreditación.

Debido a que en la evaluación a instituciones no se realizan entrevistas a clientes, ni se observan consultas, la carga de trabajo es mucho menor que en la evaluación a establecimientos de salud. Por esta razón, solo se necesita la presencia de dos personas para la evaluación. Un(a) evaluador(a) puede ser médico(a) y el(la) otro(a) puede ser un(a) trabajador(a) social. El Anexo 6 contiene ejemplos de cronogramas de evaluación.

\section{II.4: Sondeos y muestreos}

D ebido a que esta estrategia está diseñada para poder replicarse sin mayores costos, con recursos y tiempo mínimos, se proponen sondeos y muestreos muy pequeños que permitan cierto nivel de representatividad y validez de los datos. Para las evaluaciones internas se proponen sondeos, y para las evaluaciones externas se propone una mezcla de sondeo con muestreo.

Puesto que se trabajan con pocos casos, no es recomendable realizar análisis estratificado (sexo, o preferencia sexual, por ejemplo). Para obtener resultados sobre grupos específicos, se debe aumentar el número de casos (entrevistas y observaciones). A continuación el detalle para cada tipo de evaluación:

\section{Evaluación interna}

Para la evaluación interna, se llenarán por completo los primeros dos formularios (revisión de documentos y observación de aspectos generales). 
Para las observaciones de la consulta, se realizarán mínimamente dos observaciones de consultas de orientación, y dos consultas de SSR, si las circunstancias lo permiten; es decir, algunas clínicas cuentan con menos de cuatro proveedores(as) que pueden ser observados(as). En ese caso, se observarán a todos(as) los(as) proveedores(as) disponibles en la clínica. Si existieran más de cuatro proveedores(as), se seleccionarán aquellos(as) proveedores(as) que ofrecen servicios de SSR.

Para las entrevistas de salida a clientes, se realizarán mínimamente cuatro entrevistas a clientes que salgan de sesiones de orientación y cuatro entrevistas a clientes que salgan de consultas de SSR. La mayoría de las clínicas no ofrecen orientación como un servicio separado del resto, sino que ofrecen orientación dentro de los consultorios de ginecología y medicina general. En este caso, igual se completarán las ocho entrevistas de salida al azar entre los consultorios de SSR.

Para las entrevistas al personal se realizará un sondeo, de acuerdo al tiempo disponible, con un mínimo de dos entrevistas de personal seleccionado al azar. Un ejemplo de selección al azar es enumerar la lista del personal y pedir a cualquier persona presente que escoja dos números. Sin embargo, entre más entrevistas hagan a clientes y al personal, más seguridad existirá de la validez de los resultados

Para la evaluación interna a establecimientos, todos los formularios pueden ser completados en un día, máximo dos. Para instituciones, los formularios se completan en una mañana o tarde.

El Anexo 6 contiene ejemplos de cronogramas de actividades para las evaluaciones a instituciones y establecimientos de salud. El Anexo 7 contiene las planillas que serán llenadas por el(la) evaluador(a) coordinador(a) para realizar el seguimiento a las actividades durante la evaluación.

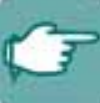

\section{Evaluación externa}

Para la evaluación externa a establecimientos de salud se realizarán las siguientes acciones:

- llenado completo de los primeros dos formularios (revisión de documentos y observación de aspectos generales).

- cuatro observaciones de consulta,

- dos observaciones de sesiones de orientación (si existen dos proveedores que ofrecen este servicio),

- $\quad$ siete entrevistas a miembros del personal y

- entrevistas de salida a una muestra representativa de clientes. 
Se deberán revisar especialmente los estándares que hayan quedado pendientes durante la evaluación interna.

\section{Entrevistas al personal}

La selección de individuos debe ser aleatoria, es decir, por sorteo, colocando papeles con todos los nombres y sacando el número indicado de papeles con los nombres de las personas que serán entrevistadas. Se utilizará el siguiente criterio:

- para instituciones de salud se entrevistará al(la) director(a), y a dos personas para cada área de trabajo (gerencia, coordinación, personal administrativo).

- para establecimientos de salud, se entrevistará al(la) orientador(a) (generalmente solo una persona se encarga de este trabajo), dos médicos, dos enfermeros(as), y dos personas de administración.

\section{Entrevistas de salida a clientes}

Se realizará el siguiente cálculo para obtener una muestra representativa de acuerdo al tamaño y cobertura del establecimiento de salud:

Tamaño de la muestra $=\frac{24.35}{1+(24.35 / p r o n e d i o d i a r i o ~ d e s e s .0 ~}$

Tamaño de la muestra $=\overline{1+(24.35 / \text { promedio diario de sesiones de orientación o consultas de SSR })}$

Ejemplo del cálculo para un establecimiento de salud con un promedio de 15 consultas diarias en los servicios de SSR:

Tamaño de la muestra $=\frac{24.35}{1+(24.35 / 15)}=9$ entrevistas de salida a clientes de SSR

La muestra resultante será representativa con un 90\% de confianza, esperando un 90\% de prevalencia de casos deseados, con un error permitido de $10 \% .^{1}$ A continuación se encuentra una tabla que resume los cálculos, con las cifras resultantes de muestra para las entrevistas de salida:

Si el flujo diario de clientes de SSR o de orientación en un establecimiento de salud es mayor a 36, se entrevistarán 15 clientes a la salida de la consulta o sesión.

$1 \quad$ Kish L. Survey sampling. Nueva York: John Wiley \& Sons; 1965 


\begin{tabular}{|c|c|}
\hline $\begin{array}{c}\text { Universo } \\
\text { (promedio diario de consultas de } \\
\text { SSR/sesiones de orientación) }\end{array}$ & $\begin{array}{c}\text { Muestra } \\
\text { (número de } \\
\text { entrevistas de salida) }\end{array}$ \\
\hline 2 & 2 \\
\hline $3-4$ & 3 \\
\hline 5 & 4 \\
\hline $6-7$ & 5 \\
\hline 8 & 6 \\
\hline $9-10$ & 7 \\
\hline $11-13$ & 8 \\
\hline $14-15$ & 9 \\
\hline $16-18$ & 10 \\
\hline $19-21$ & 11 \\
\hline $22-25$ & 12 \\
\hline $26-30$ & 13 \\
\hline $31-35$ & 14 \\
\hline $36+$ & 15 \\
\hline
\end{tabular}

El cálculo de la muestra se realizará en oficinas centrales, después de haber recibido la conformidad de resultados de la evaluación interna y los datos necesarios.

Se estima que la evaluación externa se realice en dos días, máximo tres, en caso de algún percance. Las entrevistas a clientes se realizarán al azar, y los(as) evaluadores(as) repartirán las entrevistas entre los dos días, mañanas y tardes para evitar cualquier sesgo.

Para la evaluación externa a establecimientos, todos los formularios deben estar completados en un día o máximo dos, si existiera algún impedimento para completar todos el primer día. Para instituciones, los formularios se completan en una mañana o tarde. El Anexo 6 contiene ejemplos de cronogramas de actividades para las evaluaciones a instituciones y establecimientos de salud.

El Anexo 7 contiene las planillas que serán llenadas por el(la) evaluador(a) coordinador(a) para realizar el seguimiento a las actividades durante la evaluación. 


\section{Captura y análisis de datos}

D espués de haber realizado el proceso de recolección de datos y llenado de formularios en campo, toda la información debe ser capturada o transcrita a un sistema de información, ya sea manual (planillas) o automático (planillas electrónicas). La ventaja de utilizar un sistema automático sobre uno manual es la rapidez de la obtención de resultados, libre de errores de cálculos intermedios o de transcripción.

Existe un sistema de información para datos recolectados de evaluaciones a establecimientos de salud y otro sistema de información para datos recolectados de evaluaciones a instituciones. Las planillas contenidas en cada sistema son las siguientes:

\section{Sistema de información para establecimientos (8 planillas):}

- planilla de información general,

- planilla para el formulario de revisión de documentos,

- planilla para el formulario de observación de aspectos generales,

- planilla para el formulario de observación de la consulta y orientación,

- planilla para el formulario de entrevista de salida a clientes,

- planilla para el formulario de entrevista al personal,

- planilla de resultados automáticos, y

- planilla de cálculos manuales

Sistema de información para instituciones (6 planillas):

- planilla de información general,

- planilla para el formulario de revisión de documentos,

- planilla para el formulario de observación de aspectos generales,

- planilla para el formulario de entrevista al personal,

- planilla de resultados automáticos, y

- planilla de cálculos manuales

Para el procedimiento manual, es necesario transcribir información de los formularios de recolección de datos a las planillas del sistema impresas, para luego realizar los cálculos correspondientes en la planilla de cálculos manuales. 
Para el sistema automático, sólo se transcriben los datos de los formularios de recolección de datos a las planillas electrónicas. Los resultados son calculados automáticamente. El sistema automático tiene todas sus planillas protegidas para que ninguna fórmula o formato se borre accidentalmente.

En caso de ser necesario modificar algún formato o fórmula, la clave de acceso para desproteger las celdas es SIGENERO, pero no se recomienda realizar modificaciones sin asistencia técnica.

El Anexo 8 contiene los formularios del sistema manual, que además corresponden exactamente a las pantallas de captura de datos del sistema computarizado.

\section{Llenado de planillas}

Para resumir la información y agilizar la transcripción de datos, las planillas de los sistemas de información para establecimientos e instituciones contienen sólo las preguntas que responden directamente a los 59 estándares; las preguntas auxiliares que se encuentran en los formularios de recolección de datos no figuran en estas planillas. A continuación proporcionamos instrucciones detalladas para llenar cada una de las planillas, tanto del sistema manual como del automático.

\section{Información General}

Para las unidades prestadoras de servicios:

1. Tipo de evaluación. Se debe anotar "I" si se trata de una evaluación interna, y "E" si se trata de una evaluación externa.

2. Coordinador(a) de evaluación. Llene con el nombre de la persona de la organización evaluada que está a cargo de coordinar todas las actividades de la evaluación.

3. Cargo en el establecimiento de salud. Llene con el cargo que el(la) coordinador(a) ocupa en el establecimiento de salud.

4. Institución. Llene con el nombre de la institución a la que pertenece el establecimiento de salud evaluado. En el sistema automático, es importante que este campo esté lleno para que se calculen los resultados automáticamente.

5. Establecimiento de salud. Llene con el nombre del establecimiento de salud evaluado.

6. Nivel de atención. Llene P si el establecimiento de salud es de primer nivel, S si es de segundo nivel, $\mathrm{T}$ si es de tercer nivel, y $\mathrm{C}$ si es de cuarto nivel.

7. Municipio. Llene con el municipio al que pertenece el establecimiento de salud evaluado. 
8. Departamento. Llene con el departamento al que pertenece el establecimiento de salud evaluado.

9. Fecha de recolección de datos. Llene con la fecha del primer día de recolección de datos.

Para instituciones:

1. Tipo de evaluación. Se debe anotar "I" si se trata de una evaluación interna, y "E" si se trata de una evaluación externa.

2. Coordinador(a) de evaluación. Llene con el nombre de la persona de la organización evaluada que está a cargo de coordinar todas las actividades de la evaluación.

3. Cargo en la institución. Llene con el cargo que el(la) coordinador(a) ocupa en la institución.

4. Institución. Llene con el nombre de la institución evaluada. En el sistema automático, es importante que este campo esté lleno para que se calculen los resultados automáticamente.

5. Municipio. Llene con el municipio al que pertenece la institución evaluada.

6. Departamento. Llene con el departamento al que pertenece la institución evaluada.

7. Fecha de recolección de datos. Llene con la fecha de recolección de datos.

Las planillas requieren datos sólo de las casillas resaltadas de los formularios de recolección de datos; es decir, no es necesario transcribir toda la información de los formularios. Esto es válido tanto para el procedimiento manual como el automático.

\section{Revisión de documentos}

1. Revisores(as). Llene con el nombre o los nombres de las personas que realizaron la revisión de documentos.

Para los establecimientos de salud:

10 - 35. Transcriba las respuestas ("S" o "N") del formulario de recolección de datos. Para las instituciones:

10 - 25. Transcriba las respuestas (“S” o "N") del formulario de recolección de datos.

\section{Observación de aspectos generales}

1. Observadores(as). Llene con el nombre o los nombres de las personas que realizaron la observación de los aspectos generales de la institución o establecimiento de salud. 
10 - 21. Transcriba las respuestas ("S" o "N") del formulario de recolección de datos.

\section{Observación de la consulta y orientación}

Esta planilla se deberá llenar sólo si se evaluó a un establecimiento de salud. A partir de la pregunta 11, esta planilla permite registrar datos de hasta 8 formularios con una columna para cada formulario. Debido a la extensión de este formulario, se deberán llenar dos hojas para completar la información para todos los estándares.

1. Observadores(as). Llene con el nombre o los nombres de las personas que realizaron la observación de las consultas y sesiones de orientación.

10. Motivo principal de visita. Transcriba el código del motivo de visita del formulario (ej. a, b, 1, 2, d, etc.)

11 - 44. Transcriba las respuestas (“S” o "N") del formulario de recolección de datos, una columna para cada formulario.

\section{Entrevista de salida a clientes}

Esta planilla se deberá llenar sólo si se evaluó a un establecimiento de salud. A partir de la pregunta 12, esta planilla permite registrar datos de hasta 15 formularios, una columna para cada formulario.

1. Entrevistadores(as). Llene con el nombre o los nombres de las personas que realizaron las entrevistas de salida a clientes.

10. Motivo principal de visita. Transcriba el código del motivo de visita del formulario (e.g. a, b, 1, 2, d, etc.)

12 - 39. Transcriba las respuestas ("S" o "N") del formulario de recolección de datos, una columna para cada formulario.

\section{Entrevista al personal}

A partir de la pregunta 15, esta planilla permite registrar datos de hasta 7 formularios, una columna para cada formulario.

1. Entrevistadores(as). Llene con el nombre o los nombres de las personas que realizaron las entrevistas al personal.

9. Sexo del(la) entrevistado(a). Llene con una $\mathrm{H}$ si el(la) entrevistado(a) fue hombre, y con una $\mathrm{M}$ si fue mujer.

10. Cargo. Para establecimientos. Llene con una M si el(la) entrevistado(a) es médico(a), E si es enfermera(o), O si es orientador(a) y P si es personal administrativo. Para instituciones. Llene con una D si el(la) entrevistado(a) es director(a), $\mathrm{G}$ si es gerente, $\mathrm{C}$ si es coordinador(a), y $\mathrm{P}$ si es personal administrativo.

11. Antigüedad en el cargo. Llene con el número de años de antigüedad de la persona entrevistada. 
Para los establecimientos de salud:

15 - 46. Transcriba las respuestas ("S" o "N") del formulario de recolección de datos.

Para las instituciones:

15 - 27. Transcriba las respuestas ("S" o "N") del formulario de recolección de datos.

\section{Resultados de evaluación}

Esta planilla se llena automáticamente con los datos de las planillas previas. El sistema calculará los resultados automáticamente, tanto en las planillas para establecimientos como para instituciones. Además, el sistema incluirá el nombre de la institución o establecimiento y el resultado final de la evaluación de acuerdo a los cálculos.

\section{Cálculos manuales}

Esta planilla incluye instrucciones precisas de qué cálculos se deben realizar para obtener el resultado para cada estándar y qué cálculos se deben realizar para determinar si el resultado permite o no la acreditación. Imprima esta planilla y siga las instrucciones de cálculo para cada estándar. El siguiente gráfico muestra las características de esta planilla:

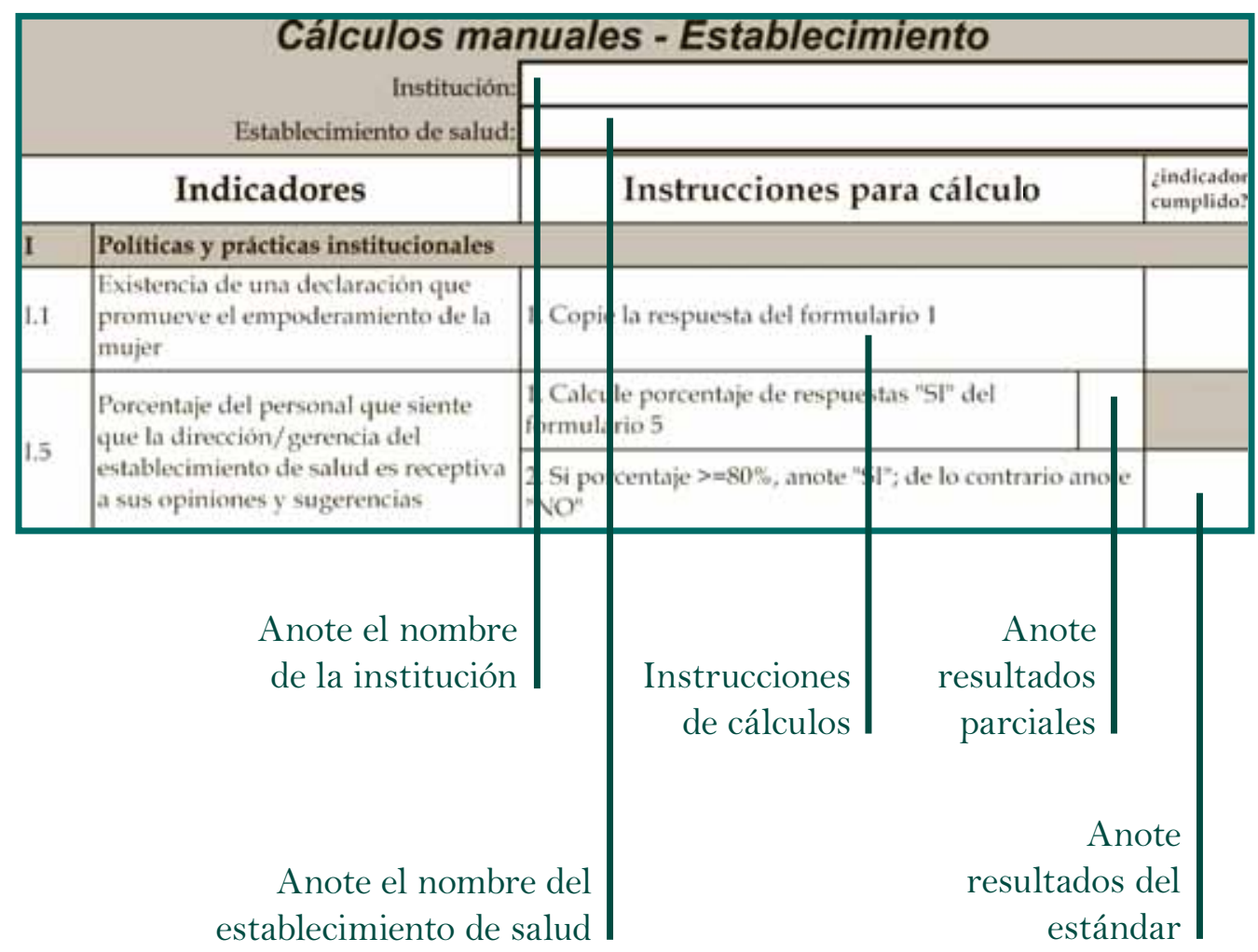


Al final de la planilla también se incluyen instrucciones para el cálculo del resultado final:

\begin{tabular}{|r|}
\hline Cuente el número de indicadores con respuesta "SI" (a) \\
\hline Cuente el número de indicadores en blanco (b) \\
\hline Reste $59-b$ (c): \\
\hline Divida a / c, y redondee a dos puntos decimales (d) \\
\hline Multipliqued $x$ 100 (e): \\
\hline Si e es mayor o igual a $80 \%$, anote "Aprueba"; de lo contrario anote "No aprueba": \\
\hline
\end{tabular}




\section{Informe de evaluación y acreditación}

A una semana de completarse la recolección de datos en campo, se imprimirá una copia original de la planilla de resultados del sistema de información y junto con copias de los formularios de evaluación llenados, los miembros del comité evaluador elaborarán un informe de evaluación. Este informe contendrá la siguiente información:

(1) Resumen del proceso de evaluación y sus resultados.

(2) Miembros del comité de acreditación responsable del proceso y sus responsabilidades.

(3) Comentarios y recomendaciones.

(4) Próximos pasos. Si la institución o establecimiento de salud cumple con un mínimo de 80\% de los estándares de género, se incluye el certificado de acreditación (para el caso de la evaluación externa).

Este informe será firmado por los miembros de la dirección ejecutiva de la red de salud, por el(la) encargado(a) de la supervisión de la acreditación de la red de salud y por los miembros del comité evaluador que visitaron el establecimiento o institución. 



\section{Reacreditación}

a acreditación tiene vigencia de dos años. Se asume que la institución o establecimiento -de salud que obtuvo el reconocimiento mantendrá la calidad y enfoque de género de sus servicios por un lapso mínimo de dos años. Pasado este tiempo, la institución o establecimiento de salud debe volver a realizar el proceso de acreditación: autoevaluación, acciones de mejoramiento, evaluación externa y reconocimiento público.Si el equipo no solicita una evaluación externa oportunamente, la unidad administrativa o de servicios de salud perderá la acreditación. 



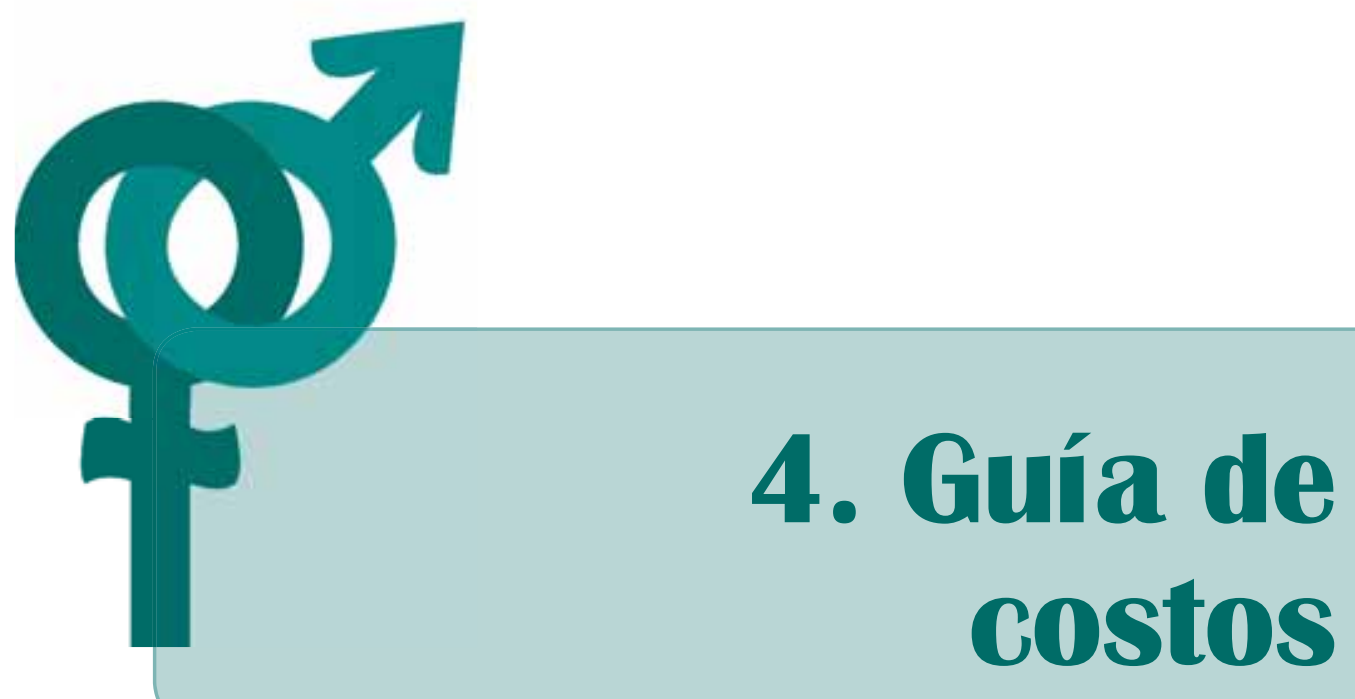

Para instituciones y establecimientos de salud que buscan acreditar la calidad y enfoque de género de sus servicios

La Paz • Bolivia • septiembre 2007 



\section{Contenido}

I. Introducción

II. Recolección de datos

II.1 Estandarización de conceptos 155

II.2 Evaluación interna 155

II.3 Elaboración de un plan de acción 156

II.4 Ejecución del plan de acción 156

III Formularios de recolección de datos de costos 159

Formulario 1 Costos de los cambios en políticas y prácticas institucionales

Formulario 2 Costos de reuniones / talleres

Formulario 3 Costos de las mejoras en infraestructura, equipamiento y mobiliario

Formulario 4 Costos de la elaboración y distribución de material de IEC

Formulario 5 Costos de supervisión 



\section{Introducción}

a finalidad de esta guía es describir los procedimientos para calcular los costos

económicos institucionales incurridos en la incorporación de un enfoque de género en la prestación de servicios de salud sexual y reproductiva.

Los costos económicos miden los costos de todos los recursos utilizados por las instituciones o establecimientos de salud, independientemente de quien los pague.

El análisis económico considera los costos asociados a cuatro actividades principales de la implementación del enfoque de género en los programas de salud:
(1) estandarización de conceptos,
(2) evaluación interna,
(3) elaboración de un plan de acción y
(4) ejecución del plan de acción. 



\section{Recolección de datos}

C han diseñado una serie de formularios que toman datos económicos para medir - los costos de las intervenciones realizadas para incorporar el enfoque de género en instituciones y establecimientos de salud.

Las cuatro actividades principales en las que se requiere recolectar datos de costos son las siguientes:

\section{1: Estandarización de conceptos}

a institución o establecimiento de salud organiza una primera reunión para uniformar conocimientos sobre los estándares y requisitos mínimos para incorporar un enfoque de género en sus programas.

Esta reunión, de un día máximo de duración, permite la socialización del material existente para apoyar las actividades futuras para alcanzar el objetivo de incorporar el enfoque de genero en los programas.

Para conocer la inversión de esta actividad, se deben obtener:

- los costos de personal (tiempo y salarios),

- los costos del evento (alquiler de la sala de reunión, materiales de lectura, material de escritorio, refrigerios) y

- los costos administrativos (pasajes, viáticos, etc.)

\section{II.2: Evaluación interna}

on base en los conocimientos adquiridos en la reunión de estandarización de con la ayuda de los formularios de evaluación. 
El proceso de auto-evaluación consiste en aplicar los formularios de evaluación, para determinar cuáles estándares de calidad y género se cumplen y cuáles no.

Para conocer la inversión de esta actividad, se deben obtener los costos:

- de personal (tiempo y salarios),

- del proceso de elaboración de la auto-evaluación (material de escritorio, refrigerios) y

- administrativos (pasajes, viáticos, etc.)

También se pueden usar datos retrospectivos de contabilidad de gastos similares a los realmente incurridos.

\section{II.3: Elaboración de un plan de acción}

Con información obtenida a partir de la auto-evaluación, la institución o establecimiento de salud elabora un plan de acción con el objetivo de establecer metas específicas para cumplir con los requisitos mínimos para incorporar un enfoque de género en los programas de salud.

Este proceso se puede realizar en una o más sesiones, dependiendo del número de actividades necesarias a ser planteadas para cumplir con los requisitos.

Para conocer la inversión de esta actividad, se deben obtener los costos:

- de personal (tiempo y salarios),

- del proceso de elaboración del plan de acción (material de escritorio, refrigerios) y

- administrativos (pasajes, viáticos, etc.)

\section{II.4: Ejecución del plan de acción}

na vez aprobado el plan de acción, la institución o establecimiento de salud comienza a ejecutar las actividades de acuerdo al cronograma establecido.

Este proceso puede durar entre 2 y 10 meses, dependiendo de la complejidad de las actividades que deben ejecutarse para cumplir con los estándares de calidad requeridos para que la unidad administrativa o de servicios sea acreditada como prestador de servicios de calidad con enfoque de género. 
Para conocer la inversión de todo este proceso, se deben obtener los costos:

- de personal relacionados con las actividades planteadas (tiempo y salarios),

- relacionados con la ejecución de las actividades planteadas (e.g. mejoras en infraestructura, compra de equipamiento o suministros, elaboración de material, honorarios de consultores, material de escritorio, refrigerios) y

- administrativos (pasajes, viáticos, transporte local, etc.). 



\section{Formularios de recolección de datos de costos}

C elaboraron cinco formularios de recolección de costos que permiten registrar toda la información necesaria relativa a las cuatro actividades mencionadas en la anterior sección de este documento. Estos formularios son:

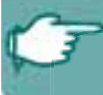

Formulario 1: Costos de los cambios en políticas y prácticas institucionales

Formulario 2: Costos de reuniones / talleres

Formulario 3: Costos de las mejoras en infraestructura, equipamiento y mobiliario

Formulario 4: Costos de la elaboración y distribución de material de IEC

Formulario 5: Costos de supervisión de las intervenciones

Los cinco formularios pueden ser llenados manualmente o a través de planillas electrónicas. La ventaja de éstas últimas, es el cálculo automático de los totales. Las planillas electrónicas están protegidas para evitar modificiones a los formatos. La clave para desproteger las celdas es SICOSTOS. A continuación se describe el detalle del llenado de cada uno de estos formularios. El anexo 9 contiene los cinco formularios.

\section{Formulario 1: Costos de los cambios en políticas y prácticas institucionales}

E ste formulario se debe completar para cada cambio realizado en las políticas y prácticas institucionales. A continuación se presenta el detalle de los campos a llenar.

Institución. Anote el nombre de la institución o establecimiento de salud (si aplica). 
Política o práctica. Anote el nombre de la política o práctica trabajada.

Propósito del cambio. Anote de manera abreviada la justificación para el cambio de la política o práctica.

Período que cubre la actividad. Anote la fecha en la cual se está dando por iniciada la actividad de cambio (después de haberla estudiado, propuesto y aprobado), y la fecha en la cual terminó la ejecución de este cambio.

El resto del formulario requiere datos relacionados con tres actividades que normalmente se llevan a cabo para realizar un cambio en políticas o prácticas:

- revisión documental,

- elaboración de la propuesta y

- reuniones de presentación.

Para cada actividad se deben registrar en cada línea los gastos del personal involucrado y los gastos en materiales o suministros usados.

Para cada actividad se deberá anotar en cada línea las personas involucradas y los materiales usados. Para mantener la confidencialidad de los datos, no se anotará en ningún lugar el nombre ni el cargo de las personas involucradas y sólo se anotará el total de horas trabajadas y el sueldo mensual para realizar el cálculo de costo total por persona involucrada.

Horas trabajadas. Anote el número de horas invertidas por cada persona.

Sueldo mensual. Anote en moneda nacional el sueldo mensual o los honorarios pagados a la o las personas que ejecutaron la actividad.

Costo total. Calcule el costo total de acuerdo a la siguiente fórmula:

$$
\text { Costo total }=\frac{\text { sueldo mensual } / 22 \text { días trabajados al mes }}{8 \text { horas diarias }} \times \text { horas trabajadas }
$$

Ejemplo: una de las personas involucradas en el cambio de una política dedicó 4 días a tiempo completo a este trabajo y gana Bs.3,200 al mes. Las casillas del formulario deben entonces tener la siguiente información:

- horas trabajadas: 32

- sueldo mensual: 3,200

- costo total: 582 
Luego de llenar los datos de todas las personas involucradas, se suman todos los costos totales para obtener el subtotal de personal.

Otros gastos. Anote en cada línea cada tipo de material o suministro usado.

Cantidad usada. Anote la cantidad usada del material o suministro anotado en la anterior columna.

Costo por unidad. Anote el costo del mercado de cada unidad de material o suministro usado. Por ejemplo, si se usaron hojas tamaño carta, se debe anotar el precio calculado por cada hoja y no por el paquete comprado. De esta manera, si el paquete de 100 hojas costó Bs.15, entonces el costo por unidad de hoja cuesta 0.15 centavos de Bs.

Costo total. Calcule el costo total de acuerdo a la siguiente fórmula:

$$
\text { Costo total }=\text { cantidad usada } \quad \mathrm{x} \quad \text { costo por unidad }
$$

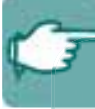

Ejemplo: se necesitó fotocopiar las Normas institucionales para su revisión. El documento tenía 125 páginas, por lo tanto se fotocopiaron 250 hojas para obtener dos copias y la fotocopia por hoja es de 10 centavos. Las casillas del formulario deben entonces tener la siguiente información:

- otros gastos: 2 fotocopias del documento Normas institucionales

- cantidad usada: 250

- costo por unidad: 0.10

- costo total: 25

Luego de llenar los datos de todos los materiales usados, se suman todos los costos totales para obtener el subtotal de otros gastos y finalmente sumar todos los subtotales y obtener el gran total.

\section{Formulario 2: Costos de reuniones/talleres}

E ste formulario se debe completar para cada reunión o taller realizado dentro del - marco de incorporación del enfoque de género en los programas de salud. Aquí se toman en cuenta las reuniones o talleres realizados desde el principio de todo el proceso, incluyendo la reunión de estandarización de conceptos, el diagnóstico, y la elaboración y ejecución del plan de acción. A continuación el detalle de los campos a llenar. 
Nombre del evento. Anote el título del taller o la descripción breve de la reunión. Ejemplo: “taller de sensibilización”, "reunión de coordinación”, “curso de autocapacitación”, “capacitación en temas laborales”, etc.

Persona encargada. Anote el nombre de la persona encargada o responsable de organizar el taller o reunión.

Institución. Anote el nombre de la institución o establecimiento de salud (si aplica).

Facilitador(a) principal. Anote el nombre de la persona que facilita el taller o reunión. SI existe más de una persona facilitadora, sólo anote el nombre de la persona principal.

Período que cubre la actividad. Anote la fecha de inicio y final del evento.

El resto del formulario requiere información de todas las personas que participaron, facilitaron y apoyaron al desarrollo de los talleres o reuniones. Existe una tabla de registro para cada tipo de persona mencionado y una tabla para registrar los materiales usados.

\section{Actividad A. Participantes}

Para llenar la tabla de participantes se requiere la siguiente información:

Horas de asistencia. Anote el número de horas invertidas por cada participante en el taller o reunión.

Sueldo mensual. Anote el sueldo mensual del(la) participante en moneda nacional.

Viáticos. Anote el monto de viáticos gastados por el(la) participante.

Transporte. Anote el monto gastado en transporte (aéreo, terrestre, urbano o rural) por el(la) participante.

Otros gastos. Anote el monto gastado por el(la) participante en cualquier otra actividad relacionada al taller o reunión.

Costo total. Calcule el costo total de acuerdo a la siguiente fórmula:

$$
\begin{gathered}
\text { Costo total }=\frac{\text { sueldo mensual } / 22 \text { días trabajados al mes }}{8 \text { horas diarias }} \times \text { horas de asistencia } \\
+ \text { viáticos }+ \text { transporte }+ \text { otros gastos }
\end{gathered}
$$


Ejemplo: Alfredo López asistió a un taller de 12 horas (dia y medio); gana Bs. 2,000 al mes; gastó Bs.200 en viáticos, Bs.500 en transporte y Bs.10 en fotocopias de un material que compartió con los otros participantes en el taller. Las casillas del formulario deben entonces tener la siguiente información:

- horas de asistencia:12

- sueldo mensual:2,000

- viáticos:200

- transporte: 500

- otros gastos: 10

- costo total: 846

Luego de llenar los datos de los(as) participantes, se suman todos los costos totales para obtener el subtotal de participantes.

\section{Actividad B. Consultores}

Para llenar la tabla de consultores se requiere la siguiente información:

Honorarios. Anote el monto pagado a cada consultor(a) por apoyar en el taller o reunión.

Viáticos. Anote el monto de viáticos gastados por el(la) consultor(a).

Transporte. Anote el monto gastado en transporte (aéreo, terrestre, urbano o rural) por el(la) consultor(a).

Otros gastos. Anote el monto gastado por el(la) consultor(a) en cualquier otra actividad relacionada al taller o reunión.

Costo total. Calcule el costo total de acuerdo a la siguiente fórmula:

Costo total $=$ honorarios + viáticos + transporte + otros gastos

Ejemplo: Luis Jerjes ha sido contratado para asistir a un taller de 3 días. Sus honorarios son Bs.3,000, y tuvo que viajar desde otra ciudad. Sus gastos fueron: viáticos Bs.300, transporte Bs.600. No hubieron otros gastos adicionales. Las casillas del formulario deben entonces tener la siguiente información:

- honorarios:3,000

- viáticos:300

- transporte: 600

- otros gastos: $\mathrm{O}$

- costo total: 3,900 
Luego de llenar los datos de los(as) consultores(as), se suman todos los costos totales para obtener el subtotal de consultores.

\section{Actividad C. Facilitadores}

Para llenar la tabla de facilitadores se requiere la siguiente información:

Horas trabajadas. Anote el número de horas invertidas por cada facilitador en el taller o reunión.

Sueldo mensual. Anote el sueldo mensual del(la) facilitador(a) en moneda nacional.

Viáticos. Anote el monto de viáticos gastados por el(la) facilitador(a).

Transporte. Anote el monto gastado en transporte (aéreo, terrestre, urbano o rural) por el(la) facilitador(a).

Otros gastos. Anote el monto gastado por el(la) facilitador(a) en cualquier otra actividad relacionada al taller o reunión.

Costo total. Calcule el costo total de acuerdo a la siguiente fórmula:

$$
\begin{gathered}
\text { Costo total }=\frac{\text { sueldo mensual } / 22 \text { días trabajados al mes }}{8 \text { horas diarias }} \times \text { horas trabajadas } \\
+ \text { viáticos }+ \text { transporte }+ \text { otros gastos }
\end{gathered}
$$

Ejemplo: Mauricio Lampe ha facilitado un taller de 3 días; gana Bs. 5,000 al mes, no gastó nada en viáticos, pues vive en la misma ciudad, gastó Bs.50 en transporte para llegar al lugar del evento y no gastó nada adicional. Las casillas del formulario deben entonces tener la siguiente información:

- horas trabajadas:24

- sueldo mensual:5,000

- viáticos:0

- transporte: 50

- otros gastos: O

- costo total: 732

Luego de llenar los datos de los(as) facilitadores(as), se suman todos los costos totales para obtener el subtotal de facilitadores(as). 


\section{Actividad D. Apoyo administrativo}

Para llenar la tabla de apoyo administrativo se requiere la siguiente información:

Horas trabajadas. Anote el número de horas trabajadas por cada miembro del personal administrativo para apoyar en el taller o reunión.

Sueldo mensual. Anote el sueldo mensual del personal en moneda nacional.

Costo total. Calcule el costo total de acuerdo a la siguiente fórmula:

$$
\text { Costo total }=\frac{\text { sueldo mensual } / 22 \text { días trabajados al mes }}{8 \text { horas diarias }} \times \text { horas trabajadas }
$$

Ejemplo: la secretaria María Bonilla ayudó a organizar el taller. Trabajó aproximadamente 12 horas en esta labor y su sueldo mensual es de Bs. 3,000. Las casillas del formulario deben entonces tener la siguiente información:

- horas trabajadas:12

- sueldo mensual:3,000

- costo total: 205

Luego de llenar los datos del personal administrativo, se suman todos los costos totales para obtener el subtotal de apoyo administrativo.

\section{Actividad E. Otros gastos}

Finalmente, se deben llenar los datos de los materiales usados para la ejecución del taller o reunión. Los datos a llenar son los siguientes:

Otros gastos. Anote en cada línea cada tipo de material o suministro usado.

Cantidad usada. Anote la cantidad usada del material o suministro anotado en la anterior columna.

Costo por unidad. Anote el costo de mercado de cada unidad de material o suministro usado. Por ejemplo, si se usaron hojas tamaño bond, se debe anotar el precio calculado por cada hoja, y no por el paquete comprado. De esta manera, si el paquete de 100 hojas costó Bs.15, entonces el costo por unidad de hoja cuesta 0.15 centavos de Bs.

Costo total. Calcule el costo total de acuerdo a la siguiente fórmula:

$$
\text { Costo total }=\text { cantidad usada } \quad \mathrm{x} \text { costo por unidad }
$$


Ejemplo: se necesitó fotocopiar las Normas institucionales para su revisión. El documento tenía 125 páginas, por tanto se fotocopiaron 250 hojas para obtener dos copias y la fotocopia por hoja es de 10 centavos. Las casillas del formulario deben entonces tener la siguiente información:

- otros gastos: 2 fotocopias de las Normas institucionales

- cantidad usada: 250

- costo por unidad: 0.10

- costo total: 25

Luego de llenar los datos de todos los materiales usados, se suman todos los costos totales para obtener el subtotal de otros gastos, para finalmente sumar todos los subtotales y obtener el gran total.

\section{Formulario 3: Costos de las mejoras en infraestructura, equipamiento y mobiliario}

E ste formulario se debe completar bimestralmente. En este formulario se registran

Ctodos los gastos relacionados con mejoras en infraestructura, equipamiento, mobiliario, artículos recurrentes, etc., resultantes de la implementación del enfoque de género en los programas. A continuación se presenta el detalle de los campos a llenar.

Institución. Anote el nombre de la institución o establecimiento de salud (si aplica).

Período que cubre la actividad. Anote la fecha de inicio y final de la mejora.

El resto del formulario requiere información del personal de la institución involucrado en las mejoras, costos de los equipos, muebles o material adquirido y los costos de mejoras en infraestructura. Existe una tabla de registro para cada tipo de gasto mencionado.

\section{Actividad A. Personal}

Para llenar la tabla del personal involucrado en las mejoras se requiere la siguiente información:

Horas trabajadas. Anote el número de horas trabajadas por cada persona de la institución involucrada en las mejoras.

Sueldo mensual. Anote el sueldo mensual del personal en moneda nacional.

Costo total. Calcule el costo total de acuerdo a la siguiente fórmula: 
Costo total $=\frac{\text { sueldo mensual } / 22 \text { días trabajados al mes }}{8 \text { horas diarias }} \times$ horas trabajadas

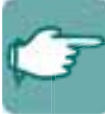

Ejemplo: la coordinadora Juana Uriona realizó todas las negociaciones para comprar equipamiento nuevo. Trabajó aproximadamente dos días a tiempo completo en esta labor y su sueldo mensual es de Bs. 6,500. Las casillas del formulario deben entonces tener la siguiente información:

- horas trabajadas:16

- sueldo mensual:6,500

- costo total: 591

Luego de llenar los datos del personal, se suman todos los costos totales para obtener el subtotal de personal.

\section{Actividad B. Bienes}

La técnica que empleamos para calcular los costos del capital se llama anualización. Calculamos, en esencia, la cantidad del bien que se ha consumido (depreciado) en el tiempo correspondiente al estudio de costos. La depreciación es sólo una parte del costo anual de un bien de capital. La otra parte es una bonificación que representa el interés que se podría haber ahorrado si el programa hubiera invertido los fondos utilizados para comprar el artículo. Este componente suele denominarse como el costo de oportunidad del capital.

Para llenar la tabla de bienes adquiridos, tome en cuenta que sólo se deben registrar aquellos artículos cuyo valor de reposición sea mayor a 100 USD y con una vida útil de más de un año. Estos artículos son llamados bienes de capital.

Si bien esto parece complicado, la mecánica de la anualización se hace relativamente sencilla con tablas estándar, como la que se presenta en el Anexo 10.

Para emplear la tabla de anualización necesitamos calcular para cada bien capital:

- el costo de reposición

- la vida útil

- la tasa de descuento (empleada para las valuaciones económicas de proyectos en el país donde usted esté trabajando). 
La tasa de descuento deberá reflejar la tasa de rendimiento en inversiones que el programa podría haber hecho. Una fuente para esta información podría ser la oficina encargada de planificación económica en el Ministerio de Hacienda. En caso contrario, usted puede ponerse en contacto con representantes locales de organizaciones de desarrollo (como USAID o Banco Mundial) para determinar la tasa de descuento que ellos utilizan en la planificación de proyectos.

\section{Construcciones. Costo de reposición y vida útil}

Para determinar el costo de reposición para una construcción en su situación actual, se necesita determinar el costo del terreno y el costo actual de construcción para un edificio semejante. El costo de construcción original no deberá usarse. Si los costos de construcción actuales no son asequibles, puede utilizarse el costo por metro cuadrado de tipos semejantes de construcción en la zona. Esta información puede encontrarse a veces en contratos gubernamentales recientes para construcciones similares o de agrupaciones del ramo de la construcción.

Si no le es posible conseguir información sobre los costos de construcción, puede servirse del costo de arrendamiento anual como un cálculo del costo capital anual de la construcción. Por definición, la renta abarca tanto los costos de depreciación como el costo de oportunidad del capital, al igual que el valor de arrendamiento del terreno.

Las construcciones tienen una duración diferente, dependiendo de su ubicación física, clima, calidad de la construcción y uso que se les dé. Sin embargo, la mayor parte de los manuales de cálculo de costos concuerdan en que deberían considerarse 20 años para el cálculo de vida útil de una construcción. Debe hacerse una excepción a esta regla si una construcción es claramente una estructura temporal. En este caso, la vida útil puede determinarse preguntando al constructor la duración esperada de esa estructura.

\section{Vehículos. Costo de reposición y vida útil}

Todo vehículo utilizado por el programa deberá registrarse. No debe limitarse el registro a autos y camiones; motocicletas, bicicletas y otros medios de transporte también deberán incluirse.

El costo de reposición es el costo de compra actual de un vehículo semejante, no el precio de compra original. Muchos programas reciben vehículos donados. En esta situación, se deberá emplear el costo actual para el donante o el costo alternativo más bajo. Otras fuentes útiles de información sobre costos vehiculares incluyen la oficina de compras de los ministerios gubernamentales y los negociantes locales.

No es posible utilizar cálculos estándar de la vida útil de los vehículos, ya que las condiciones locales determinan cuánto tiempo dura cada tipo de vehículo. La mejor fuente de esta información es el personal del programa que los usa y los mantiene. Intente obtener varias opiniones de diferentes fuentes y calcule una vida de servicio promedio para cada tipo de vehículo. 


\section{Equipo y mobiliario. Costo de reposición y vida útil}

Todo el equipo y mobiliario utilizados en el programa deben inventariarse. Podemos hacer una distinción entre equipo y mobiliario que se usa específicamente para las actividades del programa (esto es, mesas de auscultación y autoclaves), y el equipo y mobiliario necesarios para apoyar las actividades del programa (es decir, muebles de oficina y máquinas de escribir). Un manual indica que, en vez de registrar y anualizar los costos de todo el mobiliario y equipo, estos costos pueden calcularse aproximadamente multiplicando el costo de la construcción por el ocho por ciento'. Recomendamos que se utilice esta propuesta como un último recurso.

El inventario del equipo y mobiliario deberá organizarse por programa de prestación del servicio (clínico, independiente, de DBC, etc.) y por la zona de la clínica o programa donde el artículo está físicamente ubicado (por ejemplo, en la recepción, en la sala de espera, en la sala de valoración). Hay que estar seguros de incluir también todos los artículos donados en el inventario, junto con el nombre del donante (para permitir a usted averiguar cuánto pagaría el donador para remplazado).

El costo de reposición es el costo actual de compra de un artículo semejante. El precio original de compra no deberá usarse. Muchos programas reciben equipo donado. Utilice el costo corriente para el donador (o el costo alternativo más bajo) en esta situación. Una fuente particularmente útil de los costos de equipo médico es UNIPAC, un banco de liquidación para equipo médico ubicado en Dinamarca. Otras fuentes de información comprenden proveedores locales y oficinas de compras de ministerios gubernamentales.

La vida útil varía dependiendo del tipo de artículo y el modo en que se usa. Algunos cálculos que se utilizan comúnmente y que se encuentran en otros manuales dan de ocho a diez años para el equipo y mobiliario médico y de oficina. Para cualquier fin, un cálculo de diez años de vida útil será suficiente. Al igual que con los vehículos, la mejor fuente para esta información es el personal que usa y mantiene las unidades. Trate de obtener opiniones de varias personas y calcule una vida útil promedio de servicio para cada tipo de artículo.

1 Phillips, M., Shepard, D., et al. "Estimating Costs for Cost-Effectiveness Analysis", Ginebra, WHO Program for Control of Diarrhoeal Diseases, 1988.

El cálculo de un costo anualizado de una entrada de capital es directo. oportunidad promedio de capital y luego los sumamos uno con otro. 
Se puede utilizar una fórmula o, la alternativa más fácil, una tabla de anualización (ver Anexo 10). La tabla proporciona factores de anualización para combinaciones de vida útil y tasas de descuento. Para utilizar la tabla, simplemente encuentre la columna donde está la tasa de descuento aplicable, luego ubique la hilera que corresponde a la vida útil calculada del artículo de capital.

Entonces, para llenar la tabla de bienes adquiridos se requieren los siguientes datos:

Descripción del ítem. Anote una descripción del bien adquirido.

Cantidad. Anote la cantidad de unidades adquiridas.

Precio de compra por unidad. Anote el precio de compra del bien.

Estimado de vida útil. Anote el número de años de vida útil del artículo.

Factor de anualización. De acuerdo al estimado de vida útil y una tasa de descuento (generalmente se usa 5\%), anote el factor de anualización (ver Anexo 10).

Costo total anual. Calcule el costo total de acuerdo a la siguiente fórmula:

$$
\text { Costo total anual }=\frac{\text { precio de compra por unidad } \mathrm{x} \text { cantidad }}{\text { factor de anualización }}
$$

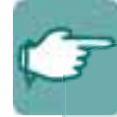

Ejemplo: se compraron dos equipos de diagnóstico, cada uno en Bs.3,500, con vida útil de 5 años. Las casillas del formulario deben entonces tener la siguiente información:

- descripción del ítem: equipos de diagnóstico (densitómetros)

- cantidad: 2

- precio de compra por unidad: 3,500

- estimado de vida útil: 5

- factor de anualización: 4.329

- costo total anual: 1,617

Luego de llenar los datos de los bienes, se suman todos los costos totales anuales para obtener el subtotal de bienes.

\section{Actividad C. Mejoras en infraestructura}

Para llenar la tabla de mejoras en la infraestructura, tome en cuenta que sólo se deben listar aquellos gastos cuyo valor sea mayor a 100 USD, y con una vida útil de más de un año. Se requieren los siguientes datos: 
Descripción de la mejora. Anote una descripción de la mejora realizada.

Costo total. Anote el costo total de la mejora (gastos de albañilería, honorarios a ingenieros, materiales, etc.)

Estimado de vida útil. Anote el número de años de vida útil de la mejora (no de todo el bien).

Factor de anualización. De acuerdo al estimado de vida útil y una tasa de descuento (generalmente se usa 5\%), anote el factor de anualización (ver Anexo 10).

Costo total anual. Calcule el costo total de acuerdo a la siguiente fórmula:

$$
\text { Costo total anual }=\frac{\text { costo total }}{\text { factor de anualización }}
$$

Ejemplo: se pintó toda el área de espera del centro de salud. Para realizar esto, se pagó al pintor Bs.100, y la pintura costó Bs.50. Se estima que la pintura durará un año. Las casillas del formulario deben entonces tener la siguiente información:

- descripción de la mejora: Pintado del área de espera

- costo total: 150

- estimado de vida útil: 1

- factor de anualización: 0.952

- costo total anual: 158

Luego de llenar los datos de las mejoras, se suman todos los costos totales anuales para obtener el subtotal de mejoras en infraestructura.

\section{Actividad D. Gastos recurrentes}

Para llenar la tabla de gastos recurrentes, tome en cuenta que sólo se deben registrar aquellos gastos cuyo valor sea menor a 100 USD y no es necesario anualizar el costo (no vale la pena el esfuerzo). También se incluyen en esta tabla todos los gastos utilizados en servicios de transporte y traslado de muebles de bajo costo. Se requieren los siguientes datos:

Descripción del gasto. Anote en cada línea el gasto incurrido.

Cantidad. Anote la cantidad comprada.

Costo por unidad. Anote el costo de cada unidad comprada. 
Costo total. Calcule el costo total de acuerdo a la siguiente fórmula:

Costo total $=$ cantidad $\mathrm{x}$ costo por unidad

Ejemplo: para elaborar afiches informativos, se compraron dos juegos de marcadores de colores. Cada juego costó Bs.12. Las casillas del formulario deben entonces tener la siguiente información:

- descripción del gasto: marcadores de colores

- cantidad: 2

- costo por unidad: 12

- costo total: 24

Luego de llenar los datos de todos los gastos recurrentes, se suman todos los costos totales para obtener el subtotal de gastos recurrentes, para finalmente sumar todos los subtotales y obtener el gran total.

\section{Formulario 4: Costos de la elaboración y distribución de material de IEC}

E ste formulario se completará para cada material de IEC (Información, Educación

- y Comunicación) que sea elaborado o distribuido. El material de IEC constituye una herramienta valiosa en las actividades de capacitación y sensibilización del personal para varios temas. Los materiales educativos pueden ser de diferentes modalidades:

Videos de capacitación. Recreación de acciones o situaciones cotidianas, que narran en una o varias escenas, una pequeña historia, con personajes ubicados en un determinado tiempo y lugar, dirigido en forma grupal.

Afiche. Medio impreso que busca sintetizar a modo de anuncio publicitario, una determinada idea o conducta, dirigido en forma masiva.

Láminas. Medio impreso que desarrolla ideas claves de un proceso en una secuencia gráfica, dirigido en forma individual.

Letreros. Medio gráfico que sintetiza en isotipos y textos, una idea clave que se busca reforzar en la conducta del público, dirigido en forma masiva.

Señalizadores. Medio gráfico que indica con un mensaje de imagen y texto, una conducta a seguir, dirigido en forma masiva. 
Stickers. Medio promocional recordatorio para una campaña de comunicación, dirigido de forma masiva.

Solapines. Medio promocional que premia o estimula una conducta positiva.

Pizarra. Soporte a modo de periódico mural.

Todo el material de IEC elaborado, adaptado, y distribuido debe ser registrado. También se deben registrar los costos actuales de los materiales antiguos que sean usados en capacitaciones, talleres, etc. A continuación el detalle de los campos a llenar.

Institución. Anote el nombre de la institución o establecimiento de salud (si aplica).

Período que cubre la actividad. Anote la fecha de inicio y final de la actividad relacionada con IEC.

El resto del formulario requiere información sobre el material de IEC elaborado, su distribución y el tiempo del personal involucrado en estas actividades.

\section{Actividad A. Elaboración de material de IEC}

Para llenar la tabla de elaboración de material de IEC se deben tomar en cuenta todas las fases como el diseño, elaboración de prototipo, validación, revisión del material, etc. Esta tabla requiere la siguiente información:

Horas trabajadas. Anote el número de horas trabajadas por cada persona de la institución involucrada en la elaboración de material de IEC.

Sueldo mensual. Anote el sueldo mensual del personal en moneda nacional.

Costo total. Calcule el costo total de acuerdo a la siguiente fórmula:

$$
\text { Costo total }=\frac{\text { sueldo mensual } / 22 \text { días trabajados al mes }}{8 \text { horas diarias }} \times \text { horas trabajadas }
$$

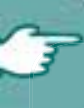

Ejemplo: la coordinadora Juana Uriona trabajó en la elaboración de trípticos informativos. Trabajó aproximadamente una semana a medio tiempo en esta labor y su sueldo mensual es de Bs. 6,500. Las casillas del formulario deben entonces tener la siguiente información:

- horas trabajadas: 20

- sueldo mensual: 6,500

- costo total: 739 
Luego de llenar los datos de la elaboración de material de IEC, se suman todos los costos totales para obtener el sub-total de elabolación de material de IEC.

A continuación se registran los datos de los suministros usados para la elaboración de materiales de IEC. Esta tabla requiere la siguiente información:

Otros gastos. Anote en cada línea cada tipo de material o suministro usado.

Cantidad usada. Anote la cantidad usada del material o suministro anotado en la anterior columna.

Costo por unidad. Anote el costo de mercado de cada unidad de material o suministro usado.

Costo total. Calcule el costo total de acuerdo a la siguiente fórmula:

$$
\text { Costo total }=\text { cantidad usada } \mathrm{x} \text { costo por unidad }
$$

Ejemplo: para imprimir el prototipo del tríptico se usó aproximadamente un cuarto del cartucho de toner de impresora. El cartucho cuesta Bs.220. Las casillas del formulario deben entonces tener la siguiente información:

- otros gastos: Toner de impresora a chorro

- cantidad usada: 0.25

- costo por unidad: 220

- costo total: 55

Luego de llenar los datos de los otros gastos, se suman todos los costos totales para obtener el sub-total de otros gastos.

\section{Actividades B y C. Impresión y distribución de material de IEC}

Las tablas de costos de impresión y distribución de material de IEC (actividades B y $\mathrm{C}$, respectivamente) requieren la siguiente información:

Material. Anote el título o la descripción del material impreso o distribuido.

Cantidad. Anote la cantidad de material impreso o distribuido.

Costo total. Anote el costo total de acuerdo a los registros de contabilidad.

Luego de llenar los datos de impresión y distribución del material de IEC, se suman todos los costos totales para obtener el sub-total de impresión de materiales de IEC y 
el sub-total de distribución de materiales de IEC, para finalmente sumar todos los subtotales y obtener el gran total.

\section{Formulario 5: Costos de supervisión}

Este formulario se completará para cada actividad de supervisión realizada. A Continuación se presenta el detalle de los campos a llenar.

Institución. Anote el nombre de la institución o establecimiento de salud (si aplica).

Período que cubre la actividad. Anote la fecha de inicio y final de la supervisión.

El resto del formulario consiste en una tabla que requiere información sobre el tiempo del personal que realiza la supervisión, más los gastos involucrados en esta actividad.

Horas trabajadas. Anote el número de horas trabajadas por cada supervisor.

Sueldo mensual. Anote el sueldo mensual del personal en moneda nacional.

Costo total. Calcule el costo total de acuerdo a la siguiente fórmula:

$$
\text { Costo total }=\frac{\text { sueldo mensual } / 22 \text { días trabajados al mes }}{8 \text { horas diarias }} \times \text { horas trabajadas }
$$

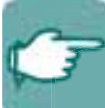

Ejemplo: la gerente de programas visitó el centro de salud para realizar su ronda de supervisión. Esta supervisión le tomó toda una mañana y su sueldo mensual es de 8,500. Las casillas del formulario deben entonces tener la siguiente información:

- horas trabajadas: 4

- sueldo mensual: 8,500

- costo total: 193

Luego de llenar los datos del personal de supervisión, se suman todos los costos totales para obtener el subtotal de personal de supervisión.

A continuación se registran los datos de gastos adicionales y materiales usados para realizar la supervisión.

Otros gastos. Anote en cada línea cada tipo de gasto incurrido.

Cantidad usada. Anote la cantidad usada del material o suministro anotado en la anterior columna o deje en blanco para los gastos relacionados con viáticos, transporte, etc. 
Costo por unidad. Anote el costo de cada unidad de material o suministro usado o el monto del viático/transporte gastado.

Costo total. Calcule el costo total de acuerdo a la siguiente fórmula:

Costo total $=$ cantidad usada $\mathrm{x}$ costo por unidad

Ejemplo: la gerente de programas gastó Bs.100 para transportarse al centro de salud supervisado. Las casillas del formulario deben entonces tener la siguiente información:

- otros gastos: Transporte supervisora

- cantidad usada:

- costo por unidad: 100

- costo total: 100

Luego de llenar los datos de los otros gastos, se suman todos los costos totales para obtener el subtotal de otros gastos, para finalmente sumar todos los subtotales y obtener el gran total.

Para agilizar la recolección de datos también se elaboró una ayuda memoria de actividades (ver anexo 11) que permite a la coordinación de la institución recoger algunos datos importantes de manera rápida, para adelantar las actividades de recolección de datos. Esta ayuda memoria no reemplaza a ninguno de los cinco formularios arriba descritos. 